UC-NRLF

||| || |||||||||||||||||||||||||||||||

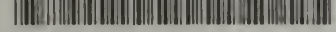

\$8 $805 \quad 734$

ㄷ5ㄴㄷ5ㄷㄷㄷㄷㄴㄷㅡ 


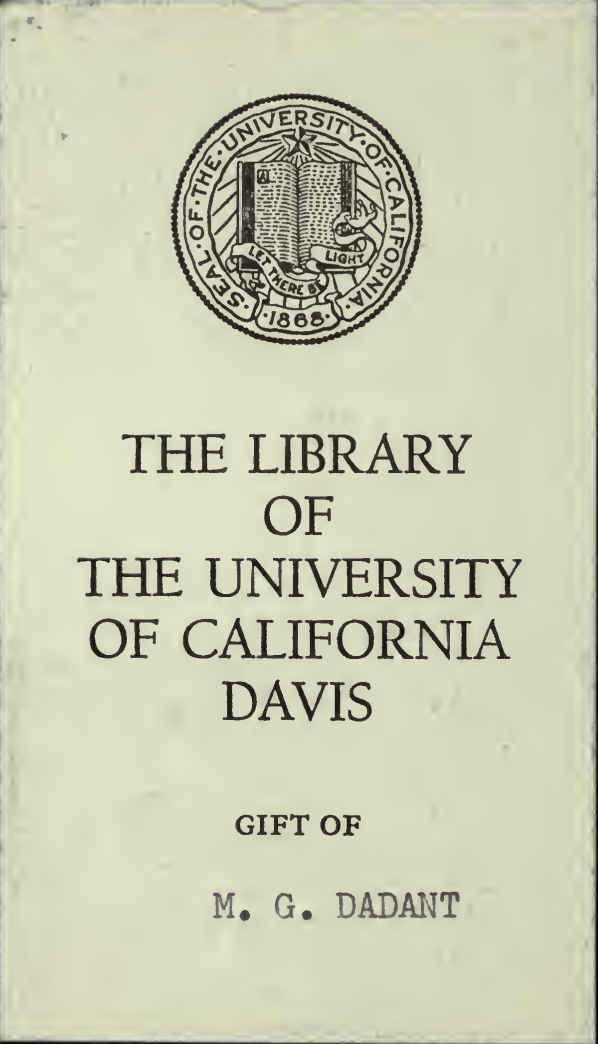



- $3 a z e=$

$2320 \times 0$

- fordint

316 
Honey 33

SCIENTIFIC LECTURES. 
" $\mathrm{s}$

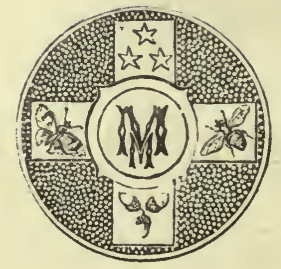


Digitized by the Internet Archive in 2007 with funding from Microsoft Corporation 

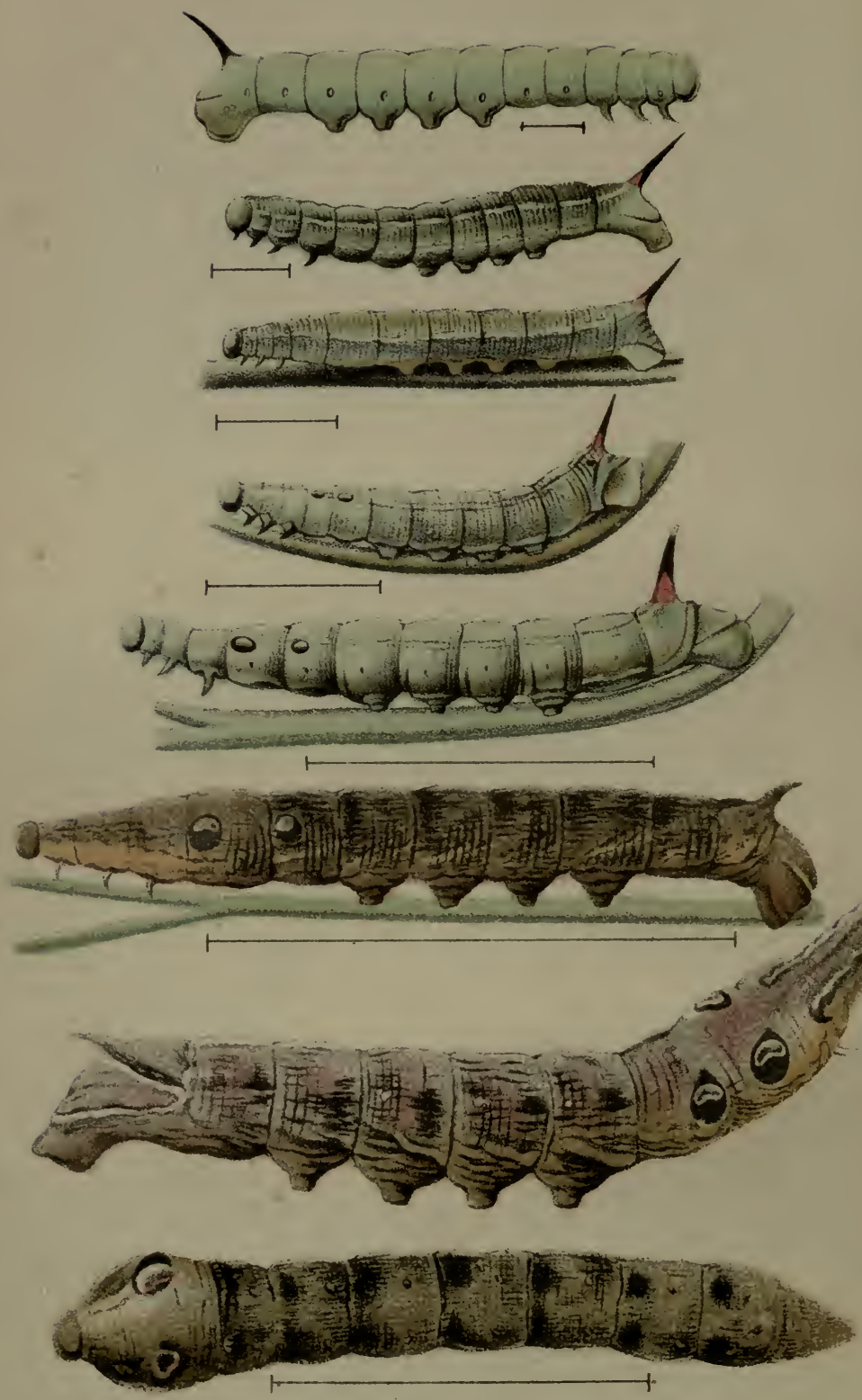


\section{SCIENTIFIC LECTURES.}

BY

\section{SIR JOHN LUBBOCK, BART.,}

$$
\text { M.P., D.C.L., LL.D., }
$$

Vice-Chancellor of the University of London; Vice-President of the Royal Society; President of the Entomological Society; and

Fellow of the Society of Antiquaries; of the Linnean, Geological and various other Learned Societies.

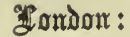 \\ M A C M I L L A N A N D C O. \\ 1879.}

The Right of Translation and Reproduction is Reserved. 
LONDON :

R. CLAY, SONS, AND TAYLOR, BREAD STREET HILL. 


\section{PREFACE.}

Is these days of limited leisure, and continually increasing literary activity, when there is more and more that every intelligent man would wish to read, and apparently less and less time for reading, an apology is required for the publication of a book, however small, which does not profess to contain anything absolutely new. At the same time, the very circumstances above referred to, render it desirable that the observations of specialists should be condensed and epitomised for the general reader, and hence the continually increasing demand for lectures; which need not, because they are popular, be the less truly scientific.

The fact that this little book does not contain anything new to those who have specially studied the parts of science with which it deals, precludes it from constituting any tax on the time of those who have devoted themselves to these subjects. 
On the other hand, I hope it may be found to present the facts in a condensed, and yet interesting form. The demand I have had for separate copies of my lectures may moreover excuse, if not justify, their republication.

High Elms, Down, Kent.

18th March, 1879. 


\section{CON'TENTS.}

\section{ON FLOWERS AND INSECTS.}

LECTURE I.

\section{ON PLAN'IS AND INSECTS.}

LECTURE II. . . . . . . . . . . . . . . . . . 31

ON THE HABITS OF AN'TS.

Lecture III. . . . . . . . . . . . . . . . . 68

ON THE HABITS OF ANTS (continued).

Lecture IV. . . . . . . . . . . . . . . . 97

INTRODUCTION TO THE STUDY OF PREHISTORIC ARCH ÆOLOGY.

I.ECTUKE V. . . . . . . . . . . . . . . . 138

ADDRESS TO THE WILTSHIRE ARCHALOLOGICAL AND NATURAL HISTORY SOCIETY.

LeCTURE VI. . . . . . . . . . . . . . . 168 



\section{LIST OF ILLUSTRATIONS.}

FIG.

1. Lamium album. (After Bentham) . . . . . . . . . . . 1

2. $" \quad$ Flower of . . . . . . . . . . . . . 1

3.,$\quad$ Section of . . . . . . . . . . . 1

4. Drosera rotundifolia. (After Bentham). . . . . . . . . . 4

5. Geranium pratense; young flower. (After Hildebrand) . . . . 7

6. $" \quad$ older flower. $, \quad, \quad$ ) . . . 7

7. Malva sylvestris. (After Sowerby) . . . . . . . . . . . 13

8. Malva rotundifolia. (After Sowerby) . . . . . . . . . . 13

9. Stamens and Stigmas of Malva sylvestris. (After H. Müller). . 13

10. Ditto of Malva rotundifolia ( " , ). . 13

11. Epilobium angustifolium. (After Sowerby) . . . . . . . . 14

12. Epilobium parviflorum. ( , , ). . . . . . . . 14

13. Diagrammatic Section of Arum . . . . . . . . . . 17

14. Salvia officinalis. Section of a young flower. (After Ogle) . . 18

15. " " Visited by a Bee. ( " " ) . 18

16. " " Older Flower. ( " , . . 18

17. Stamens in their natural position. ( $\quad(, \quad)$. 20

18. Stamens when moved by a Bee. ( ", ) . . 20

19. Wild Chervil-Chcerophyllum sylvestre. (After Bentham) . . . 21

20. Floret of Chrysanthemum parthenium, just opened. (After Ogle). 23

21. " " " $"$ somewhat more advanced . 23

22. " " $" \quad$ with stigmas expanded . . 23

23. Lotus corniculatus. (After Bentham) . . . . . . . . . . 24

24. " " $" \quad$ Flower of, seen from the side and in front

(After H. Müller) . . . . . . . . 25

25. " $" \quad$ After removal of the standard . . . . 25

26. " " After removal of the standard and wings . . 25

27. " " After removal of one side of the keel . 
FIG.

28. Terminal portion of Fig. 27 more magnified . . . . . . . . 25

29. Primula (long-styled form) . . . . . . . . . . . . 27

30. " (short-styled form). . . . . . . . . . . . . 27

31. Knautia dipsacifolia. (After Kerner) . . . . . . . . . 37

32. Carlina vulgaris. ( , , ) . . . . . . . 38

33. Linnea borealis, flower of. ( $, \quad, \quad$ ) . . . . . . . . 38

34. Silene nutans. (,$")$. . . . . . . . 39

35. Larva of Arge galathea . . . . . . . . . . . . . . . 46

36. Larva of Smerinthus ocellatus . . . . . . . . . . . . . 47

37. Larva of Chorocampa elpenor. First Stage . . . . . . . . 52

38. " " $"$ Second Stage . . . . . . 53

39. " " " Just before second moult . . . 53

40. " " $"$ " Third Stage . . . . . . 54

41. " " $"$ Fourth Stage . . . . . . 54

42. $" \quad " \quad$ Fifth Stage . . . . . . 55

43. $" \quad " \quad$ Full-grown (natural size) . . . 55

44. " Chorocampa prrcellus . . . . . . . . . . 59

45. Aphis . . . . . . . . . . . . . . . . . . 71

46. Contrivance for testing sagacity of Ants . . . . . . . 115

47. " " $" \quad$. . . . . . . . 124

48. $" \quad " \quad$. . . . . . . . 125

49. $" \quad " \quad$ " . . . . . . . 125

50. " $", \quad$. . . . . . . 126

51. " " " $"$. . . . . . . . . 126

52. Flint Implement from St. Acheul, near Amiens. Natural Size 146

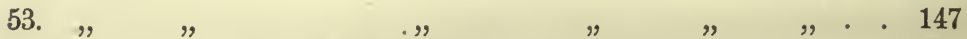

54. Section of Fig. 53, showing discoloration of surface . . . . . 148 


\section{SCIENTIFIC LECTURES.}





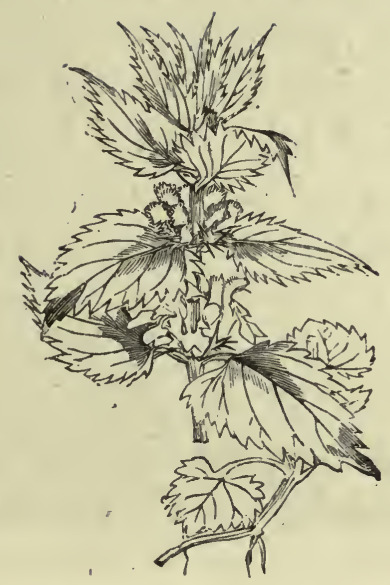

Fig. 1.-Lamium album.

\section{ON FLOWERS AND INSECTS.}

\section{LECTURE I.}

The flower of the Common White Deadnettle (Lamium album, Fig. 1) consists of a narrow tube, somewhat

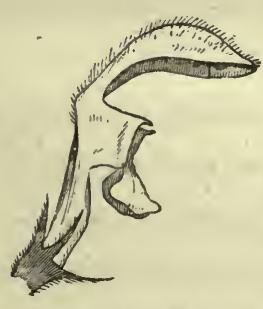

Fig. 2.-Flower of Lamium album.

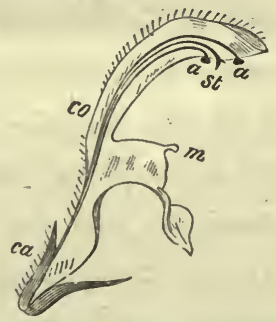

FIG. 3.-Section of ditto.

expanded at the upper end (Fig. 2), where the lower lobe of the corolla forms a platform, on each side of 
which is a small projecting lobe (Fig. $3, m$ ). The upper portion of the corolla is an arched hood (Fig. 3, co), under which lie four anthers $(a a)$, in pairs, while between them, and projecting somewhat downwards, is the pointed pistil (st). At the lower part, the tube contains honey, and above the honey is a row of hairs almost closing the tube. Now, why has the flower this peculiar form? What regulates the length of the tube? What is the use of this arch? What lessons do these lobes teach us? What advantage is the honey to the flower? Of what use is the fringe of hairs'? Why does the stigma project beyond the anthers? Why is the corolla white, while the rest of the plant is green?

Similar questions may of course be asked with reference to other flowers. Let us now see whether we can throw any light upon them.

At the close of the last century, Conrad Sprengel published a valuable work on flowers, in which he pointed out that the forms and colors, the scent, honey, and general structure of flowers, have reference to the visits of insects, which are of importance in transferring the pollen from the stamens to the pistil. This admirable work, however, did not attract the attention it deserved, and remained almost unknown until Mr. Darwin devoted himself to the subject. Our illustrious countryman was the first clearly to perceive that the essential service which insects perform to flowers, consists not only in transferring the pollen from the stamens to the pistil, but in transferring it from the stamens of one flower to the pistil of another. Sprengel had indeed observed in more than one instance that this was the case, but he did not altogether appreciate the importance of the fact. 
Mr. Darwin, however, has not only made it clear from theoretical considerations, but has also proved it, in a variety of cases, by actual experiment. More recently Fritz Müller has even shown that in some cases pollen, if placed on the stigma of the same flower, has no more effect than so much inorganic dust; while, and this is perhaps even more extraordinary, in others the pollen placed on the stigma of the same flower acted on it like a poison. This he observed in several species ; the flowers faded and fell off, the pollen masses themselves, and the stigma in contact with them shrivelled up, turned brown, and decayed; while flowers on the same bunch, which were left unfertilised, retained their freshness.

The importance of this "cross-fertilisation," as it may be called, in contradistinction to "self-fertilisation," was first conclusively proved by Mr. Darwin in his remarkable memoir on Primula (Linnean Journal, 1862), and he has since illustrated the same rule by researches on Orchids, Linum, Lythrum, and a variety of other plants. The new impulse thus given to the study of flowers has been followed up in this country by Hooker, Ogle, Bennett, and other naturalists, and on the Continent by Axell, Delpino, Hildebrand, Kerner, F. Müller, and especially by Dr. H. Müller, who has published an excellent work on the subject, bringing together the observations of others, and adding to them an immense number of his own.

In by far the majority of cases, the relation between flowers and insects is one of mutual advantage. In some plants, however, as for instance in our common Drosera, we find a very different state of things, and 
the plant catches and devours the insects. ${ }^{1}$ The first observation on insect-eating flowers was made about the year 1768 by our countryman Ellis. He observed that in Dionæa, a North American plant, the leaves have a joint in the middle, and thus close over, kill, and actually digest any insect which may alight on them.

In our Common Sundew (Drosera rotundifolia, Fig. 4) the rounded leaves are covered with glutinous glandular hairs or tentacles-on an average

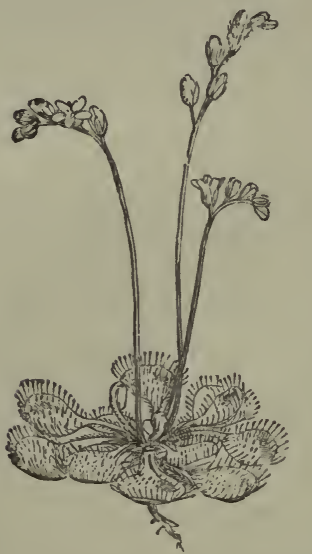

FIG. 4.-Drosera rotundifolia. about 200 on a full-sized leaf. The glands are each surrounded by a drop of an exceedingly viscid solution, which, glittering in the sun, has given rise to the name of the plant. If any object be placed on the leaf, these glandular hairs slowly fold over it, but if it be inorganic they soon unfold again. On the other hand, if any small insect alights on the leaf it becomes entangled in the glutinous secretion, the glands close over it, their secretion is increased, and they literally digest their prey. Mr. Frank Darwin has recently shown that plants supplied with insects grow more vigorously than those not so fed. It is very curious that while the glands are so sensitive that even an cbject weighing only $\frac{1}{\sqrt{874} t}$ th of a grain placed on them is sufficient to cause motion, yet they are "insensible to the weight and repeated blows of drops" of even heavy rain.

Drosera, however, is not our only English insect- 
ivorous plant. In the genus Pinguicula, which frequents moist places, generally on mountains, the leaves are concave with incurved margins, and the upper surfaces are covered with two sets of glandular hairs. In this case the naturally incurved edges curve over still more if a fly or other insect be placed on the leaf.

Another case is that of Utricularia, an aquatic species, which bears a number of utricles or sacs, which have been supposed to act as floats. Branches, however, which bear no bladder float just as well as the others, and there seems no doubt that their real use is to capture small aquatic animals, which they do in considerable numbers. The bladders in fact are on the principle of an eel-trap, having an entrance closed with a flap which permits an easy entrance, but effectually prevents the unfortunate victim from getting out again.

I will only allude to one foreign case, that of the Sarracenia. ${ }^{1}$ In this genus some of the leaves are in the form of a pitcher. They secrete a fluid, and are lined internally with hairs pointing downwards. Up the outside of the pitcher there is a line of honey glands which lure the insects to their destruction. Flies and other insects which fall into this pitcher cannot get out again, and are actually digested by the plant. Bees, however, are said to be scarcely ever caught.

Every one knows how important flowers are to insects; every one knows that bees, butterflies, etc., derive the main part of their nourishment from the honey or pollen of flowers, but comparatively few are aware, on the other hand, how much the flowers themselves are dependent on insects. Yet it has, I think, been clearly

1 See Hooker, British Association Journal, 1874. 
shown that if insects have been in some respects modified and adapted with a view to the acquirement of honey and pollen, flowers, on the other hand, owe their scent and honey, their form and color, to the agency of insects. Thus the lines and bands by which so many flowers are ornamented have reference to the position of the honey; and it may be observed that these honeyguides are absent in night flowers, where they of course would not show, and would therefore be useless, as for instance in Lychnis vespertina or Silene nutans. Night flowers, moreover, are generally pale; for instance, Lychnis vespertina is white, while Lychnis diurna, which flowers by day, is red.

Indeed, it may be laid down as a general rule that those flowers which are not fertilised by insects, as for instance those of the Beech and most other forest trees, are small in size, and do not possess either color, scent, or honey.

Before proceeding further let me briefly mention the terms used in describing the different parts of a flower.

If we examine a common flower, such for instance as a Geranium, we shall find that it consists, firstly, of an outer envelope or calyx, sometimes tubular, sometimes consisting of separate leaves called sepals; secondly, an inner envelope or corolla, which is generally more or less colored, and which, like the calyx, is sometimes tubular, sometimes composed of separate leaves called petals; thirdly, of one or more stamens, consisting of a stalk or filament, and a head or anther, in which the pollen is produced; and fourthly, a pistil, which is situated in the centre of the flower, and consists generally of three principal parts ; one or more compartments at the base, each containing one or more seeds; 
the stalk or style; and the stigma, which in many familiar instances forms a small head at the top of the style or ovary, and to which the pollen must find its way in order to fertilise the flower.

But though the pistil is thus surrounded by a row of stamens there are comparatively few cases in which the pollen of the latter falls directly on the former. On the contrary this transference is in most cases effected in other ways - generally by means of the wind,

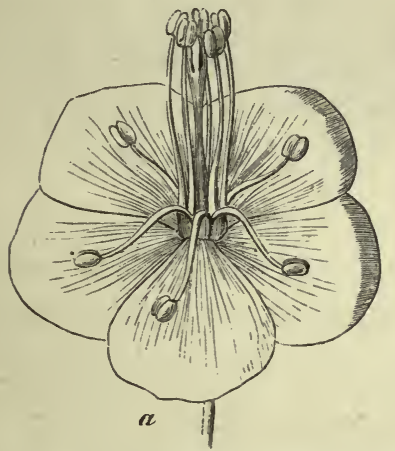

Fig. 5.-Geranium pratense (young flower). Five of the stamens are erect.
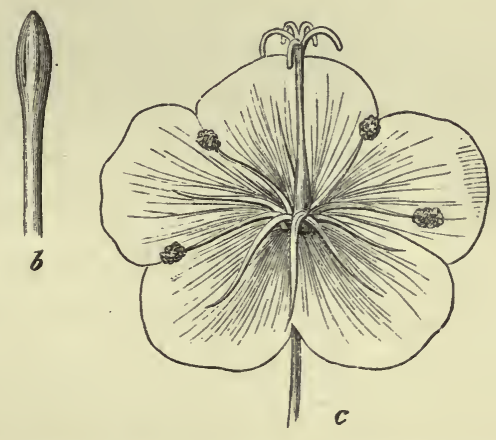

Fig. 6.-Geranium pratense (older flower). The stamens have retired, and the stigmas are expanded.

of insects, or, in some cases, of birds. In the former case, however, by far the greater part of the pollen is wasted; and much more must therefore be produced than in those cases where the transference is effected by insects.

One advantage, of course, is the great economy of pollen. We have not much information on the subject, but it would seem, from the few observations that have been made, that half a dozen pollen grains are sufficient to fertilise a seed. But in plants in which the pollen is carried by the wind, the chances against any given grain 
reaching the pistil of another flower are immense. Consequently by far the greater part of the pollen is lost. Every one for instance must have observed the clouds of pollen produced by the Scotch fir. In such flowers as the Pæony the pollen is carried by insects, and far less therefore is required; yet even here the quantity produced is still large; it has been estimated that each flower produces between $3,000,000$ and $4,000,000$ grains. The Dandelion is more specialised in this respect, and produces far less pollen; according to Mr. Hassall about 240,000 grains to each flower; while in Geum urbanum, according to Gærtner, only ten times more pollen is produced than is actually used in fertilisation.

It might, however, be at first supposed that where stamens and pistil coexist in the same flower, the pollen from the one could easily fall on and fertilise the other. And in fact in some species this does occur; but as we have seen, it is a great advantage to a species that the flower should be fertilised by pollen from a different stock. How then is self-fertilisation prevented?

There are three principal modes.

Firstly, in many plants the stamens and pistil are in separate flowers, sometimes situated on different plants.

Secondly, even when the stamens and pistil are in the same flower, they are in many species not mature at the same time; this was first observed by Sprengel in Epilobium angustifolium as long ago as 1790; in some cases the stigma has matured before the anthers are ripe, while in other and more numerous cases the anthers have ripened and shed all their pollen before the stigma has come to maturity. 
Thirdly, there are many species in which, though the anthers and stigma are contained in the same flower and are mature at the same time, they are so situated that the pollen can hardly reach the stigma of the same flower.

The transference of the pollen from one flower to another is, as already mentioned, effected principally either by the wind or by insects, though in some cases it is due to other agencies, as for instance, by birds, or by water. For instance, in the curious Vallisneria spiralis the female flowers are situated on long stalks which are spirally twisted, and grow very rapidly, so that even if the level of the water alters, provided this be within certain limits, the flowers float on the surface. The male flowers on the contrary are minute and sessile, but when mature they detach themselves from the plant, rise to the surface and float about freely like little boats among the female flowers.

Wind fertilised flowers as a rule have no color, emit no scent, produce no honey, and are regular in form. Colur, scent, and honey are the three characteristics by which insects are attracted to flowers.

Again, as a rule, wind-fertilised flowers produce much more pollen than those which are fertilised by insects. This is necessary, because it is obvious that the chances against any given pollen grain reaching the stigma are much greater in the one case thian in the other. Every one, as already mentioned, has observed the showers of yellow pollen produced by the Scotch fir.

Again, it is an advantage to wind-fertilised plants to flower early in the spring before the leaves are out, because the latter would catch much of the pollen and 
thus interfere with its access to the stigma. Again, in these plants the pollen is less adherent, so that it can easily be blown away by the wind, which would be a disadvantage in most plants which are fertilised by insects.

Again, such flowers generally have the stigma more or less branched or hairy, which evidently must tend to increase their chances of catching the pollen.

Moreover, as Mr. Darwin has observed (Jour. Linn. Soc. vol. viii. p. 176), there does not appear to be a single instance of an irregular flower which is not fertilised by insects or birds.

The evidence derivable from the relations of bees and flowers is probably sufficient to satisfy most minds that bees are capable of distinguishing colors, but the fact had not been proved by any conclusive experiments. I therefore tried the following. If you bring a bee to some honey, she feeds quietly, goes back to the hive, stores away her honey, and returns with or without companions for another supply. Each visit occupies about six minutes, so that there are about ten in an hour, and about a hundred in a day. 'I may add that in this respect the habits of wasps are very similar, and that they appear to be quite as industrious as bees. Perhaps I may give the record of a morning's work of one of my wasps. ${ }^{1}$ She came to the honey at 6.16 A.M., fed and returned to the nest at 6.19 .

Came again at 6.29 , and returned at 6.32

$\begin{array}{llll}" & 6.41 & " & 6.44 \\ " & 6.55 & " & 7 \\ " & 7.11 & " & 7.15 \\ " & 7.23 & " & 7.26\end{array}$

1 In her case the intervals were rather longer than usual. 
Came again at 7.37, and returned at 7.42

$\begin{array}{llll}" & 7.56 & , & 8.3 \\ " & 8.11 & , & 8.14 \\ " & 8.20 & , & 8.24 \\ " & 8.31 & , & 8.34 \\ , & 8.40 & , & 8.42 \\ , & 8.50 & , & 8.52 \\ , & 8.58 & , & 9 \\ " & 9.8 & , & 9.11 \\ " & 9.18 & , & 9.22 \\ " & 9.30 & , & 9.32 \\ , & 9.39 & , & 9.40 \\ , & 9.50 & , & 9.54 \\ , & 10.1 & , & 10.5 \\ , & 10.14 & , & 10.17 \\ , & 10.25 & , & 10.28 \\ , & 10.37 & , & 10.40 \\ , & 10.47 & , & 10.51 \\ " & 11 & , & 11.6 \\ , & 11.17 & , & 11.20 \\ , & 11.34 & , & 11.37 \\ , & 11.50 & , & 11.53 \\ " & 12.5 & , & 12.8\end{array}$

and so on till six in the evening. Thus working twelve hours like a man, and performing more than fifty journeys to and fro. ${ }^{1}$ This, however, was in

$1 \mathrm{Mr}$. Darwin, in his last work, has brought forward some striking evidence how rapidly bees work. They visit, it appears, twenty flowers in a minute, and so carefully do they economise the sunny hours, that in flowers with several nectaries if they find one dry, they do not waste time by examining the others on the same plant. Mr. Darwin watched carefully certain flowers, and satisfied himself that each one was visited by bees at least thirty times in a day. The result is, that even where flowers are very numerousas, for instance, on heathy plains and clover fields-every one is visited during the day. Mr. Darwin has carefully examined a large number of flowers in such cases, and found that every single one had been visited by bees. 
autumn; in summer they make overtime, and work on till late in the evening.

In order then to test the power of bees to appreciate color, I placed some honey on a slip of glass, and put the glass on colored paper. For instance, I put some honey in this manner on a piece of blue paper, and when a bee had made several journeys, and thus become accustomed to the blue color, I placed some more honey in the same manner on orange paper about a foot away. Then during one of the absences of the bee I transposed the two colors, leaving the honey itself in the same place as before. The bee returned as usual to the place where she had been accustomed to find the honey; but though it was still there, she did not alight, but paused for a moment, and then dashed straight away to the blue paper. No one who saw my bee at that moment could have had the slightest doubt of her power of distinguishing blue from orange.

Again, having accustomed a bee to come to honey on blue paper, I ranged in a row other supplies of honey on glass slips placed over paper of other colors, yellow, orange, red, green, black, and white. Then I continually transposed the colored paper, leaving the honey on the same spots; but the bee always flew to the blue paper, wherever it might be. Bees appear fortunately to prefer the same colors as we do. On the contrary, flowers of a livid, yellow, or fleshy color are most attractive to flies; and moreover while bees are attracted by odours which are also agreeable to us, flies, as might naturally be expected from the habits of their larvæ, prefer some which to us seem anything but pleasant. 
Among other obvious evidences that the beauty of flowers is useful in consequence of its attracting insects, we may adduce those cases in which the transference of

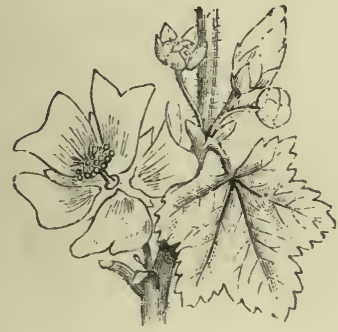

FIG. 7.-Malva sylvestris.

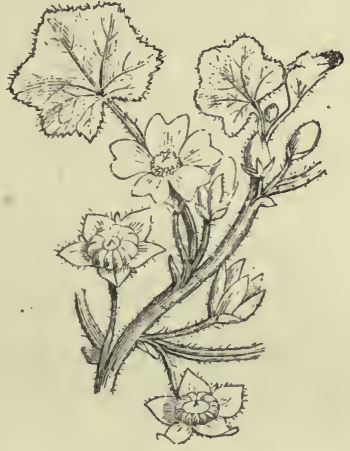

FiG. 8. -Malva rotundifolia.

the pollen is effected in different manners in nearly allied plants, sometimes even in the same genus.

Thus, as Dr. H. Muller has pointed out, Malva sylvestris (Fig. 7) and Malva rotundifolia (Fig. 8) which grow

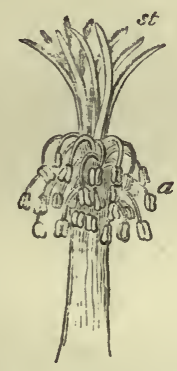

FIG. 9.-Stamens and stigmas of Malva FIG. 10.-Ditto of Malva rotundifolia. sylvestris.

in the same localities, and therefore must come into competition, are nevertheless nearly equally common.

In Malva sylvestris, however (Fig. 9), where the branches of the stigma are so arranged that the plant 
cannot fertilise itself, the petals are large and conspicuous, so that the plant is visited by numerous insects; while in Malva rotundifolia the flowers of which are comparatively small and rarely visited by insects, the branches of the stigma are elongated, and twine themselves (Fig. 10) among the stamens, so that the flower readily fertilises itself.

Another interesting case is afforded by the genus Epilobium. Epilobium angustifolium has large purplish flowers in conspicuous heads (Fig. 11), and is much frequented by insects; while E. parviflorum (Fig. 12)

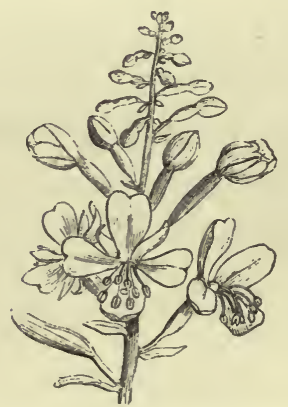

Fig. 11.-Epilobium angustifolium.

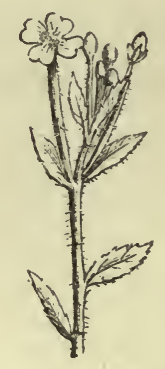

Fig. 12.-Epil,obium parviflorum.

has small solitary flowers and is seldom visited by insects. Now in the former species their visits are necessary, because the stamens ripen and shed their pollen before the pistil, so that the flower is consequently incapable of fertilising itself. In $E$. parviflorum, on the contrary, the stamens and pistil come to maturity at the same time.

Let us take another case-that of certain Geraniums. In $G$. pratense all the stamens open, shed their pollen, and wither away before the pistil comes to maturity. 
The flower cannot therefore fertilise itself, and depends cntirely on the visits of insects for the transference of the pollen. In G. pyrenaicum, where the flower is not quite so large, all the stamens ripen before the stigma, but the interval is shorter, and the stigma is mature before all the anthers have shed their pollen. It is therefore not absolutely dependent on insects. In G. molle, which has a still smaller flower, five of the stamens come to maturity before the stigma, but the last five ripen simultaneously with it. Lastly, in G. pusillum, which is least of all, the stigma ripens even before the stamens. Thus, then, we have a series more or less dependent on insects, from $G$. pratense to which they are necessary, to $G$. pusillum, which is quite independent of them ; while the size of the corolla increases with the dependence on insects.

In those species in which self-fertilisation is prevented by the circumstance that the stamens and pistil do not come to maturity at the same time, the stamens generally ripen first.

The advantage of this is probably connected with the visits of bees. In those flowers which grow in bunches the lower ones generally open first. Consequently in any given spike the flowers are at first all male; subsequently the lower ones, being the older, have arrived at the female stage, while the upper ones are still male. Now it is the habit of bees to begin with the lower flowers of a spike and work upwards. A bee, therefore, which has already dusted herself with pollen from another flower, first comes in contact with the female flowers, and dusts them with pollen, after which she receives a fresh supply from the upper male flowers, with which she flies to another plant. 
There are, however, some few species in which the pistil ripens before the stamens. One is our common Scrophularia nodosa. Now why is this? Mr. Wilson has given us the answer. S. nodosa is one of our few flowers specially visited by wasps; the honey being not pleasing to bees. Wasps, however, unlike bees, generally begin with the upper flowers and pass downwards, and consequently in wasp flowers it is an advantage that the pistil should ripen before the stamens. But though the stamens generally ripen before the pistil, the reverse sometimes occurs. Of this a very interesting case is that of the genus Aristolochia. The flower is a long tube, with a narrow opening closed by stiff hairs which point backwards, so that it much resembles an ordinary eeltrap. Small flies enter the tube in search of honey, but from the direction of the hairs it is impossible for them to return. Thus they are imprisoned in the flower; until the stamens have ripened and shed their pollen, by which the flies get thoroughly dusted. Then the hairs of the tube shrivel up, thus releasing the prisoners, which carry the pollen to another flower.

Again, in our common Arums-the Lords and Ladies of village children-the well-known green leaf incloses a central pillar; near the base of which are arranged a number of stigmas (st in the accompanying Fig.), and above them several rows of anthers $(a)$. It might be supposed therefore that the pollen from the anthers would fall on and fertilise the stigmas. This, however, is not what occurs. In fact the stigmas come to maturity first, and have lost the possibility of fertilisation before the pollen is ripe. The pollen must therefore be brought by insects, and this is effected by small flies, 
which enter the leaf, either for the sake of honey or of shelter, and which, moreover, when they have once entered the tube, are imprisoned by the fringe of hairs (h). When the anthers ripen, the pollen falls on to the flies, which in their efforts to escape get thoroughly dusted with it. Then the fringe of hairs withers, and the flies, thus set free, soon come out, and ere long carry the pollen to another plant.

Now let us return to our White Deadnettle and see how far we can answer the questions which I began by asking.

In the first place, the honey attracts insects. If there were no honey, they would have no object in visiting the flower. The bright color is useful in rendering the flower conspicuous. The platform serves as an alighting stage for bees. The length of the tube has reference to that of their proboscis, and prevents the smaller species from

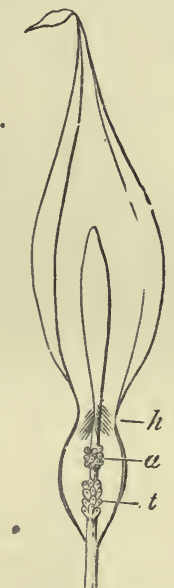

FIG. 13. - Diagram. matic section of Arum. $h$, hairs : $a$, anthers; st, stigmas. obtaining access to the honey, which would be injurious to the flower, as it would remove the source of attraction for the bees, without effecting the object in view. The upper arch of the flower protects the stamens and pistil, and also presses them firmly against the back of the bee. So that, when the bee alights on the stage and pushes its proboscis down to the honey, its back comes into contact with them. The row of small hairs at the bottom of the tube prevents small insects from creeping down the tube and stealing the honey. Lastly, the small processes on each side of the lower lip are 
the rudimentary representatives of parts, formerly more largely developed, but which, having become useless, have almost disappeared.

In the Deadnettle, it would appear that the pistil matures as early as the stamens, and that cross-fertilisation is attained by the relative position of the stigma, which, as will be seen in the figure, hangs down below

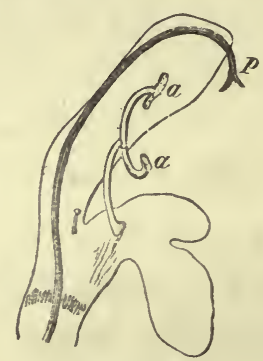

Fig. 14.

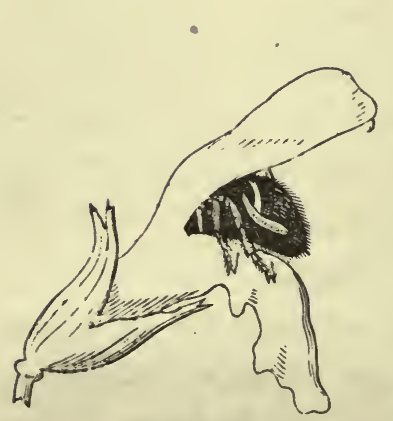

FIG. 15.

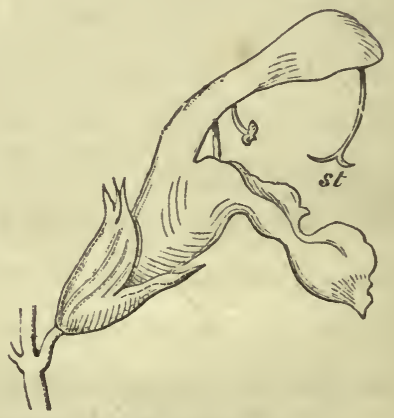

Fig. 16.

FIG. 14.-Salvia officinalis. Section of a young flower. Fis. 15.-Ditto, visited by a Bee.

FIG. 16.-Ditto, older flower.

the stamens; so that a bee, bearing pollen on its back from a previous visit to another flower, would touch the pistil and transfer to it some of the pollen, before coming in contact with the stamens. In other species belonging to the same great group (Labiatæ) as Lamium, 
the same object is secured by the fact that the stamens come to maturity before the pistil; they shed their pollen, and shrivel up before the stigma is mature.

Fig. 14 represents a young flower of Salvia officinalis, in which the stamens $(a a)$ are mature, but not the pistil $(p)$, which, moreover, from its position, is untouched by bees visiting the flower; as shown in Fig. 15. 'The anthers, as they shed their pollen, gradually shrivel up; while, on the other hand, the pistil increases in length and curves downwards, until it assumes the position shown in Fig. 16, st, where, as is evident, it must come in contact with any bee visiting the flower, and would touch just that part of the back on which pollen would be deposited by a younger flower. In this manner cross-fertilisation is effectually secured.

There are, however, several other curious points in which S. officinalis differs greatly from the species last described.

The general form of the flower, indeed, is very similar. We find again that, as generally in the Labiates, the corolla has the lower lip adapted as an alighting board for insects, while the arched upper lip covers and protects the stamens and pistils.

The arrangement and structure of the stamens is, however, very peculiar and interesting. As in Lamium, they are four in number, but one pair is quite rudimentary (Fig. 14). In the other $(a \alpha)$ the two anthers, instead of being attached close together at the summit of the filament, are separated by a long movable rod, or connective (Figs. 17, 18, m), so that they can play freely on the stalk of the stamen. In a natural position, this connective is upright, so that the one anther is situated 
(Fig. 14) in the neck of the tube, the other under the arched hood, The lower anther, moreover, is more or less rudimentary. Now when a bee comes to suck the honey, it pushes the lower anther out of the way with its head ; the result of which is that the connective swings round, and the upper fertile anther comes down on to the back of the bee (Figs. 15 and 18), and dusts it with

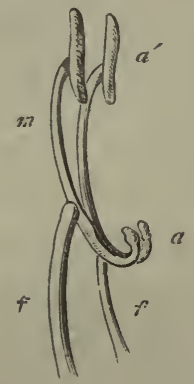

Fig. 17.-Stamens in their natural position.

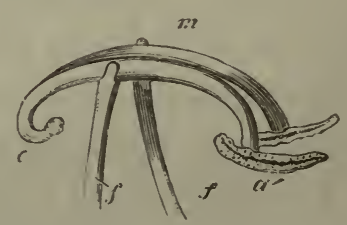

Fig. 18. - Stamens when movel by a Bee.

honey, just at the place where, in an older flower (Fig. 16) it would be touched by the stigma st.

At first sight, it may seem an objection to this view that some species-as, for instance, the Common Antirrhinum, which, according to the above given tests ought to be fertilised by insects, is entirely closed. A little consideration, however, will suggest the reply. The Antirrhinum is especially adapted for fertilisation by humble bees. The stamens and pistil are so arranged that smaller species would not effect the object. It is therefore an advantage that they should be excluded, and in fact they are not strong enough to move the spring. The Antirrhinum is, so to say, a closed box, of which the humble bees alone possess the key.

The Common Heath (Erica tetralix) offers us a very ingenious arrangement. The flower is in the form of an 
inverted bell. 'The pistil represents the clapper, and projects a little beyond the mouth of the bell. The stamens are eight in number, and form a circle round it, the anthers being united by their sides into a continuous ring. Each anther has a lateral hole, but as long as they touch one another, the pollen cannot drop" out. Each also sends out a long process, so that the ring of anthers is surrounded by a row of spokes. Now when a bee comes to suck the honey, it first touches the end of the pistil, on which it could hardly fail to deposit some pollen, had it previously visited another plant. ' It would then press its proboscis up the bell, in doing which it would pass between two of the spokes, and pressing them apart, would dislocate the ring of anthers : a shower of pollen would thus fall from the open cells on to the head of the bee.

In many cases the effect of the coloring and scent is greatly enhanced by the association of several flowers in one bunch, or raceme; as for instance in the wild hyacinth, the lilac, and other familiar species. In the great family of Umbellifera, this arrangement is still further taken advantage of, as in the common Wild Chervil (Chorophyllum sylvestre, Fig. 19).

In this group the honey is

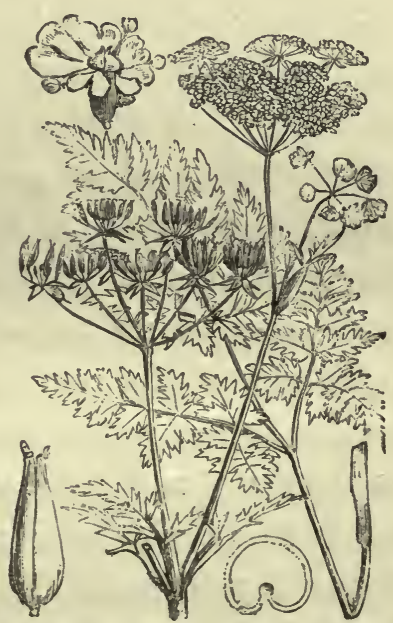

Fig. 19.-Wild Chervil (Charrophyllum sylvestre). not, as in the flowers just described, situated at the bottom of a tube, but lies exposed, and is therefore 
accessible to a great variety of small insects. The union of the florets into a head, moreover, not only renders them more conspicuous, but also enables the insects to visit a greater number of flowers in a given time.

It might at first be supposed that in such small flowers as these self-fertilisation would be almost unavoidable. In most cases, however, the stamens ripen before the stigmas.

The position of the honey on the surface of a more or less flat disc renders it much more accessible than in those cases in which it is situated at the end of a more or less long tube. That of the Deadnettle, for instance, is only accessible to certain humble bees; while $H$. Müller has recorded no less than seventy-three species of insects as visiting the Common Chervil, and some plants are frequented by even a larger number.

In the Composites, to which the Common Daisy and the Dandelion belong, the association of flowers is carried so far, that a whole group of florets is ordinarily spoken of as one flower. Let us take, for instance, the Common Feverfew, or large white Daisy (Chrysanthemum parthenium, Figs. 20-22). Each head consists of an outer row of female florets, in which the tubular corolla terminates on its outer side in a white leaf-ovary, which serves to make the flower more conspicuous, and thus to attract insects. The central florets are tubular, and make up the central yellow part of the flower-head. Each of these florets contains a circle of stamens, the upper portions of which are united at their edges and at the top (Fig. 20), so as to form a tube, within which is the pistil. The anthers open inwards so as to shed the pollen into t?is box, the lower 
part of which is formed by the stigma, or upper part of the pistil. As the latter elongates, it presses the pollen against the upper part of the box, which at length is forced open, and the pollen is pushed out (Fig. 21). Any insect then alighting on the flower would carry off some of the pollen adhering to its under side. The upper part of the pistil terminates in two branches (Fig. 22, st), each of which bears a little brush of hairs. These hairs serve to brush the pollen out of the tube; while in the tube the

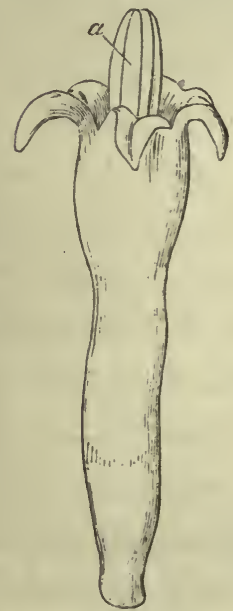

Fig. 20.

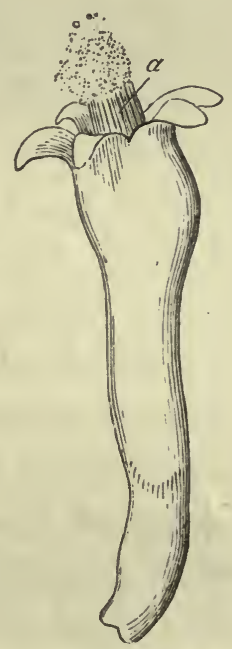

FIG. 21.

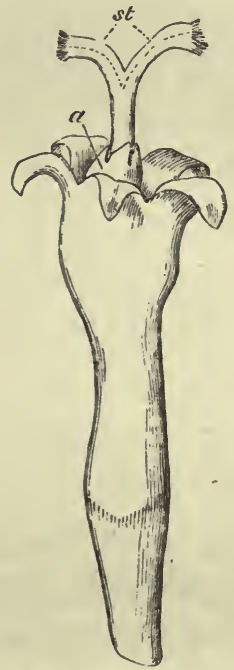

FIG. 22.

FIG. 20.-Floret of Chrysanthemum parthenium, just opened.

FIG. 21.-Ditto, somewhat more advanced.

FIG. 22.-Ditto, with the stigmas expanded.

two branches are pressed close together, but at a later stage they separate, and thus expose the stigmatic surfaces (Fig. 21), on which an insect, coming from a younger flower, could hardly fail to deposit some pollen. The two stigmas in the ray florets of Parthenium have no brush of hairs; and they would be of no use, as these flowers have no stamens. 
The Leguminosæ, or Pea-tribe, present a number of beautiful contrivances. Let us take a common little Isotus corniculatus (Fig. 23). The petals are five in number; the upper one stands upright, and is known as the standard (Fig. 24, std) ; the two lateral ones present a slight resemblance to wings

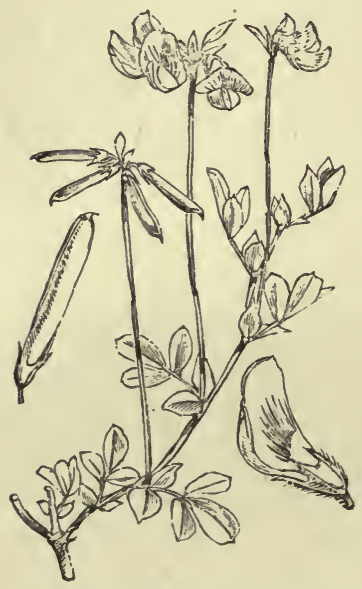

Fis. 23.-Lotus corniculatus. (Figs. 24, 25 w), while the two lower ones are united along their edges, so as to form a sort of boat, whence they are known as the "keel" (Figs. $25,26 k)$. The stamens, with one exception, are united at their bases, thus forming a tube (Figs. 27, $28 t$ ), surrounding the pistil, which projects beyond them into a triangular space at the end of the keel. Into this space the pollen is shed (Fig. 28, $p^{\circ}$ ). It must also be observed that each of the wings has a projection (c) which locks into a corresponding depression of the keel, so that if the wings are depressed they carry the keel with them. Now when an insect alights on the flower, its weight depresses the wings, and as they again carry with them the keel, the latter slips over the column of stamens, thus forcing some of the pollen out at the end of the keel and against the breast of the insect. As soon as the insect leaves the flower, this resumes its natural position, and the pollen is again snugly protected. The arrangement in the Sweet Pea is very similar, and if the wings are seized by the fingers, and pressed 
down, this out-pumping of the pollen may be easily effected, and the mechanism will then be more clearly understood.
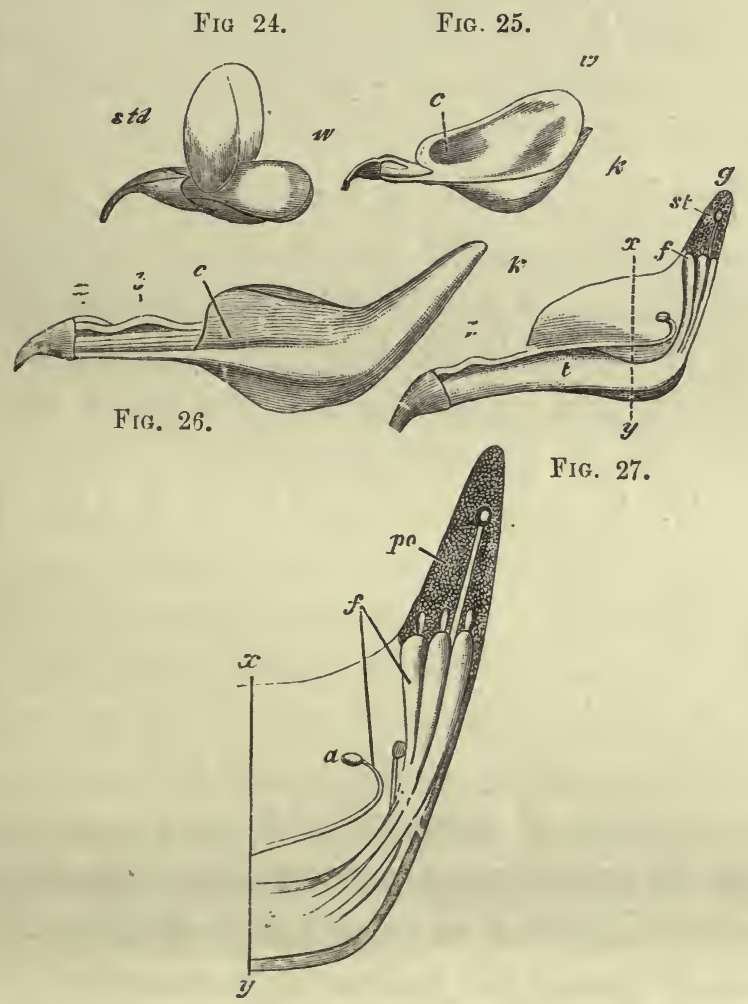

Fig. 27.

FIg. 28.

Fic. 24.-Flower of Lotus corniculatus seen from the side and in front. FIG. 25.--Ditto, after removal of the standard.

Fig. 26.-Ditto, after removal of the standard and wings.

Fig. 27.-Ditto, after removal of one side of the keel.

FIG. 28. - Terminal portion of Fig. 27. more magnified.

$e$, entrance to the honey : $\hat{a}$, the free stamen; $c$, the place where the wings lock with the keel ; $f^{\prime}$, expanded ends of stamens; $f$, filaments of stamens ; $g$, tip of keel; $p o$, pollen ; st, stigma.

It will be observed (Fig. 28) that one stamen is separated from the rest. The advantage of this is that it 
leaves a space through which the proboscis of the bee can reach the honey, which is situated inside the tube formed by the united stamens. In those Leguminosæ which have no honey, the stamens are all united together. Such flowers are, nevertheless, in spite of the absence of honey, visited by insects for the sake of the pollen.

In other Leguminosæ, as for instance in the Furze (Ulex europarus), and the Broom (Sarothamnus scopavius), the flower is in a state of tension, but the different parts are, as it were, locked together. The action of the bee, however, puts an end to this; the flower explodes, and thus dusts the bee with pollen.

It would, however, take too long to refer to the various interesting arrangements by which cross-fertilisation is secured in this great order of plants.

It is impossible not to be struck by the marvellous variety of contrivances found among flowers, and the light thus thrown upon them, by the consideration of their relations to insects; but I must now call your attention to certain very curious cases, in which the same species has two or more kinds of flowers. Probably in all plants the flowers differ somewhat in size, and I have already mentioned (ante, p. 13) some species in which these differences have given rise to two distinct classes of flowers, one large, and much visited by insects, the other small, and comparatively neglected. In other species, as, for instance, some of the violets, these differences are carried much further. The smaller flowers have no smell or honey, the corolla is rudimentary, and, in fact, an ordinary observer would not recognise them as flowers at all. Such "cleistogamic" Howers, as they 
have been termed by Dr. Kuhn, are already known to exist in about fifty genera. Their object probably is to secure, with as little expenditure as possible, the continuance of the species, in cases when, from unfavourable weather or other causes, insects are absent; and under such circumstances, as scent, honey, and color are of no use, it is an advantage to the plant to be spared from the effort of their production.

As the type of another class of cases in which two kinds of flowers are produced by the same species (though not on the same stock) we may take our common Cowslips and Primroses. If you examine a number of them, you will find that they fall into two distinct series. In some of the flowers, the pistil is as long as the tube, and the button-shaped stigma (Fig. 29, st) is situated at the mouth of the flower; the stamens $(a \alpha)$ being half-way down the tube: while in the other set, on the contrary,
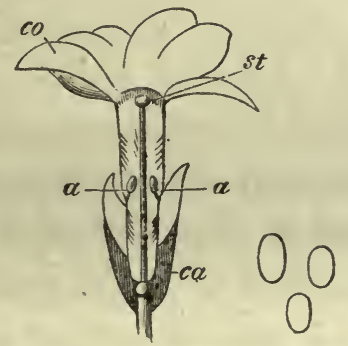

$\times 250$

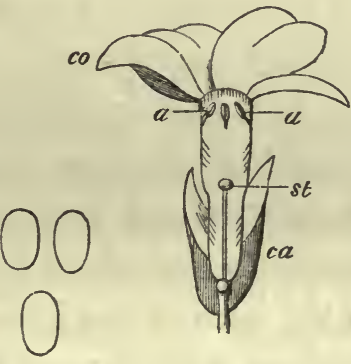

Fig. 29.-Primula (long-styled form).

FIG. 30.-Primula (short styled form).

the anthers are at the mouth of the flower, and the stigma half-way down. The existence of these two kinds of flowers had long been known, but it remained unexplained until Mr. Darwin devoted his attention to the subject. Now that he has furnished us with the clue, the rase is clear enough. 
An insect visiting a plant of the short-styled form would dust its proboscis at a certain distance from the extremity (Fig. 30, a), which, when the insect passed to a long-styled flower, would come just opposite to the pistil (Fig. 29, st). At the same time, the stamens of this second form (Fig. 29 a) would dust the proboscis at a point considerably nearer to the extremity, which in its turn would correspond to the position of the stigma in the first form (Fig. 30, st). The two kinds of flowers never grow together on the same stock, and the two kinds of plants generally grow together in nearly equal proportions. Owing to this arrangement, therefore, insects can hardly fail to fertilise each flower with pollen from a different stock.

The two forms differ also in some other respects. In the long-styled form, the stigma (st) is globular and rough, while that of the short-styled is smoother, and somewhat depressed. These differences, however, are not sufficiently conspicuous to be shown in the figure. Again, the pollen of the long-styled form is considerably smaller than the other, a difference, the importance of which is obvious, for each has to give rise to a tube which penetrates the whole length of the style, from the stigma to the base of the flower; and the one has therefore to produce a tube nearly twice as long as that of the other. The careful experiments made by Mr. Darwin have shown that, to obtain the largest quantity of seed, the flowers must be fertilised by pollen from the other form. Nay, in some cases, the flowers produce more seed, if fertilised by pollen from another species, than by that from the other form of their own.

This curious difference of the Primrose and Cowslip, 
between flowers of the same species which Mr. Darwin has proposed to call Dimorphism, is found in most species of the genus Primula, but not in all.

The Cowslip and Primrose resemble one another in many respects, but the honey they secrete must be very different, for while the Cowslip is habitually visited during the day by humble bees, this is not the case with the Primrose, which, in Mr. Darwin's opinion, is fertilised almost exclusively by moths.

The genus Lythrum affords a still more complex case, for here we have three sets of flowers. The stamens are in two groups; in some plants, the pistil projects beyond them; in the second form it is shorter than any of the stamens, and in the third it is intermediate in length, so that the stigma lies between the two sets of anthers.

Although flowers present us with these beautiful and complex contrivances, whereby the transfer of pollen from flower to flower is provided for, and waste is prevented, yet they appear to be imperfect, or at least not yet perfect in their adaptations. Many small insects obtain access to flowers and rob them of their contents. Malve rotundifolia can be, and often is, sucked by bees from the outside, in which case the flower derives no advantage from the visit of the insect. In Medicago sativa, also, insects can suck the honey without effecting fertilisation, and the same flower continues to secrete honey after fertilisation has taken place, and when, apparently, it can no longer be of any use. Fritz Müller has observed that, though Posoqueria fragrans is exclusively fertilised by night-flying insects, many of the flowers open in the day, and consequently remain sterile. It is of course possible that these cases may be explained 
away; nevertheless, as both insects and flowers are continually altering in their structure, and in their geographical distribution, we should naturally expect to find such instances. Water continually tends to find its own level ; animals and plants as constantly tend to adapt themselves to their conditions. For it is obvious that any blossom which differed from the form and size best adapted to secure the due transference of the pollen would be less likely to be fertilised than others; while on the other hand, those richest in honey, sweetest, and most conspicuous, would most surely attract the attention and secure the visits of insects; and thus, just as our gardeners, by selecting seed from the most beautiful varieties, have done so much to adorn our gardens, so have insects, by fertilising the largest and most brilliant flowers, contributed unconsciously, but not less effectually, to the beauty of our woods and fields. ${ }^{1}$

1 I have treated the subject of this lecture at greater length in a little book on Flowers and Insects, forming one of the "Nature Series." 


\section{ON PLANTS AND INSECTS.}

\section{LECTURE II.}

Is the last lecture I endeavoured to show in a variety of cases how beautifully flowers are constructed, so as to secure their fertilisation by insects. Neither plants nor insects would be what they are, but for the influence which each has exercised on the other. Some plants, indeed, are altogether dependent on insects for their very existence. We know now, for instance, that certain plants produce no seeds at all, unless visited by insects. Thus, in some of our colonies, the common Red Clover sets no seeds, on account of the absence of humble bees; for the proboscis of the hive bee is not long enough to effect the object. According to Mr. Belt, the same is the case, and for the same reason, in Nicaragua, with the scarlet-runner. But even in those instances in which it is not absolutely necessary, it is an advantage that the flowers should be fertilised by pollen brought from a different stock, and with this object in view, insects are tempted to visit flowers for the sake of the honey and pollen; while the colors and scents are useful in making the flowers more easy to find.

Fortunately for us, bees like the same odours as we do; and as the great majority of flowers are adapted for bees, 
they are consequently sweet; but it might have been otherwise, for flies prefer unpleasant smells, such as those of decaying meat, and other animal substances on which they live as larvæ, and some flowers, consequently, which are fertilised by them, are characterised by very evil odours. Colors also are affected in the same manner, for while bee-flowers (if I may coin such an expression) have generally bright, clear colors, flyflowers are usually reddish or yellowish brown.

The real use of honey now seems so obvious that it is curious to see the various theories which were once entertained on the subject. Patrick Blair thought that the honey absorbed the pollen, and then fertilised the ovary. Pontedera thought it kept the ovary in a moist condition. Linnæus confessed his inability to solve the question. Other botanists considered that it was useless material thrown off in the process of growth. Krünitz thought he observed that in meadows much visited by bees the plants were more healthy, but the inference he drew was, that the honey, unless removed, was very injurious, and that the bees were of use in carrying it off.

Kurr observed that the formation of honey in flowers is intimately associated with the maturity of the stamens and pistil. He lays it down, as a general rule, that it very seldom commences before the opening of the anthers, is generally most copious during their maturity, and ceases so soon as the stamens begin to wither and the development of the fruit commences. Rothe's observations also led him to a similar conclusion, and yet neither of these botanists perceived the intimate 
association which exists between the presence of honey and the period at which the visits of insects are of importance to the plant. Sprengel was the first to point out the real office of honey, but his views were far from meeting with general assent, and, even as lately as 1833, were altogether rejected by Kurr, who came to the conclusion that the secretion of honey is the result of developmental energy, which afterwards concentrates itself on the ovary.

No doubt, however, seems any longer to exist that Sprengel's view is right; and that the true function of honey is to attract insects, and thus to secure crossfertilisation. Thus, most of the Rosaceæ are fertilised by insects, and possess nectaries; but, as Delpino has pointed out, the genus Poterium is anemophilous, or wind-fertilised, and possesses no honey. So also the Maples are almost all fertilised by insects, and produce honey; but Acer negundo is anemophilous, and honeyless. Again, among the Polygonaceæ, some species are insect-fertilised and melliferous, while, on the other hand, certain genera, Rumex and Oxyria, have no honey, and are fertilised by the wind. At first sight it might appear an objection to this view,-and one reason perhaps why the earlier botanists missed the true explanation may have been the fact,-that some plants secrete honey on other parts than the flowers. Belt and Delpino have, I think, suggested the true function of these extra floral nectaries. ${ }^{1}$ The former of these excellent observers describes a South American species

1 I by no means, however, wish to suggest that we as yet fully understand the facts. For instance, the use of the nectary at the base of the leaf of the fern is still quite unexplained.

S. E. 
of acacia: this tree, if unprotected, is apt to be stripped of the leaves by a leaf-cutting ant, which uses them, not directly for food, but, according to Mr. Belt, to grow mushrooms on. The acacia, however, bears hollow thorns, while each leaflet produces honey in a craterformed gland at the base, and a small, sweet, pearshaped body at the tip. In consequence, it is inhabited by myriads of a small ant, which nests in the hollow thorns, and thus finds meat, drink, and lodging all provided for it. These ants are continually roaming over the plant, and constitute a most efficient body-guard, not only driving off the leaf-cutting ants, but, in Belt's opinion, rendering the leaves less liable to be eaten by herbivorous mammalia. Delpino mentions that on one occasion he was gathering a flower of Clerodendron fragrans, when he was suddenly attacked by a whole army of small ants.

I am not aware that any of our English plants are protected in this manner from browsing quadrupeds, but not the less do our ants perform for them a very similar function, by keeping down the number of small insects, which would otherwise rob them of their sap and strip them of their leaves.

Forel watched, from this point of view, a nest of Formica pratensis. He found that the ants brought in dead insects, small caterpillars, grasshoppers, cercopis, \&c., at the rate of about twenty-eight a minute, or more than one thousand six hundred in an hour. When it is considered that the ants work not only all day, but in warm weather often all night too, it is easy to see how important a function they fulfil in keeping down the number of small insects. 
Some of the most mischievous insects, indeed-certain species, for instance, of aphis and coccus-have turned the tables on the plants, and converted ants from enemies into friends, by themselves developing nectaries, and secreting honey, which the ants love. We have all seen the little brown garden ant, for instance, assiduously running up the stems of plants, to milk their curious little cattle. In this manner, not only do the aphides and cocci secure immunity from the attacks of the ants, but even turn them from foes into friends. They are subject to the attacks of a species of ichneumon, which lays its eggs in them, and Delpino has seen ants watching over the cocci with truly maternal vigilance, and driving off the ichneumons whenever they attempted to approach.

But though ants are in some respects very useful to plants, they are not wanted in the flowers. The great object is to secure cross-fertilisation; but for this purpose winged insects are almost necessary, because they fly readily from one plant to another, and generally, as already mentioned, confine themselves for a certain time to the same species. Creeping insects, on the other hand, naturally would pass from each floret to the next; and, as Mr. Darwin has shown in his last work, it is of little use to bring pollen from a different flower of the same stock; it must be from a different plant altogether. Moreover, creeping insects, in quitting a plant, would generally go up another close by, without any regard to species. Hence, even to small flowers (such as many cruciferæ, compositæ, saxifrages, \&c.), which, as far as size is concerned, might well be fertilised by ants, the visits of flying insects are much more advantageous. 
Morcover, if larger flowers were visited by ants, not only would these deprive the flowers of their honey, without fulfilling any useful function in return, but they would probably prevent the really useful visits of bees. If you touch an ant with a needle or a bristle, she is almost sure to seize it in her jaws; and if bees, when visiting any particular species, were liable to have the delicate tip of their proboscis seized on by the horny jaws of an ant, we may be sure that such a plant would soon be deserted.

On the other hand, we know how fond ants are of honey, and how zealously and unremittingly they search for food. How is it, then, that they do not anticipate the bees, and secure the honey for themselves? Kerner has recently published a most interesting memoir on this subject, and has pointed out a number of ingenious contrivances by which flowers protect themselves from the unwelcome visits of such intruders. The most frequent are the interposition of chevaux de frise, which ants cannot penetrate, glutinous parts which they cannot traverse, slippery slopes which they cannot climb, or barriers which close the way.

Firstly, then, as regards chevaux de frise. In some respects these are the most effectual protection, since they exclude not only creeping insects, but also other creatures, such as slugs. With this object, it will be observed that the hairs which cover the stalks of so many herbs usually point downwards. A good example of this is afforded, for instance, by a plant, Knautia dipsacifolia (Fig. 31), allied to our common blue scabious. The heads of the common carline (Carlina vulgaris) (Fig. 33), again, present a sort of thicket, which must offer an almost impenetrable barrier to ants. Some 
species of plants are quite smooth, excepting just below. the flowers. The common but beautiful cornflower (Centaurea cyanus) is quite smooth, but the involucres forming the flower-head are bordered with recurved teeth. In this case, neither the stem nor the leaves show a trace of such prickles.

The same consideration throws light on the large number of plants which are more or less glutinous, a

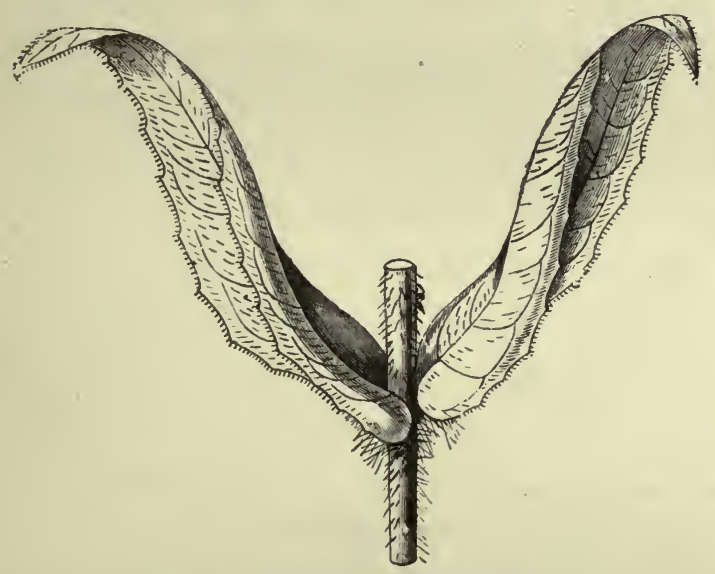

Fig. 31.-Kunautia dipsacifolia.

condition generally produced, as, for instance, in the flowers of the Gooseberry and of Linncea borealis (Fig. 32), by the presence of glandular hairs. Kerner has called attention to a very interesting illustration afforded by Polygonum amphibium. In this species the stigma projects about one-fifth of an inch above the flower, so that if ants could obtain access, they would steal the honey without fertilising the flower; a flying insect, on the contrary, alighting on the flower, could scarcely fail to touch the stigma.

The bcautiful rosy flowers of this species are rich in 
nectar: the stamens are short; the pistil, on the contrary, projects considerably above the corolla. The nectar is not protected by any special arrangement of the flower itself, and is accessible even to very small insects. The stamens ripen before the pistil, and any flying insect, however small, coming from above, would assist in cross-fertilisation. Creeping insects, on the contrary, which in most cases would enter from below, would rob the honey without benefiting the plant. P. amphibium, as its name denotes, grows

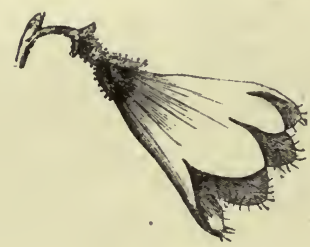

FI(x. 32.-Linroce.

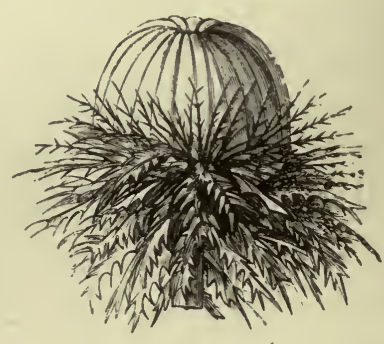

Fis. 33.-Carlina.

sometimes in water, sometimes on land. So long, of course, as it grows in water, it is thoroughly protected, and the stem is smooth; while, on the other hand, those specimens which live on land throw out certain hairs which terminate in sticky glands, and thus prevent small insects from creeping up to the flowers. In this case, therefore, the plant is not-sticky, except just when this condition is useful. All these viscous plants, as far as I know, have upright or horizontal flowers.

On the other hand, where the same object is effected by slippery surfaces, the flowers are often pendulous; creeping creatures being thus kept out of them, just as the pendulous nests of the weaver-bird are a protection 
from snakes and other enemies. As instances of this kind, I may mention the common Snowdrop, and the Cyclamen.

Many flowers close their petals during rain, and this. is obviously an advantage, since it prevents the honey and pollen from being spoilt or washed away. I have elsewhere suggested that the so-called "sleep" of flowers has reference to the habits of insects, on the ground that flowers which are fertilised by night-flying insects would derive no advantage from being open in the day; while, on the other hand, those which are fertilised by bees would gain nothing by being open at night. I confess that I suggested this with much diffidence, but it may now, I think, be regarded as well established.

Silene nutans (Fig. 34), the Nottingham catchfly, is a very instructive species from this point of view, and indeed illustrates a number of interesting points in the relations between plants and insects. Its life history has recently been well described by Kerner. The upper part of the flowering stem is viscid; from which it has derived its English name, the Nottingham

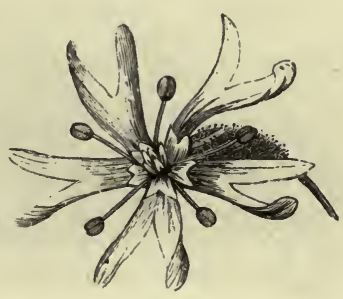

Fig. 34.-Silene nutans. catchfly. 'This prevents the access of ants and other small creeping insects. Each flower lasts three days, or rather three nights. The stamens are ten in number, arranged in two sets, the one set standing in front of the sepals, the other in front of the petals. Like other night Howers, it is white, and opens towards evening, when it also becomes extremely fragrant. The first evening, towards dusk, the 
five stamens in front of the sepals grow very rapidly for about two hours, so that they emerge from the flower; the pollen ripens, and is exposed by the bursting of the anther. So the flower remains through the night, very attractive to, and much visited by, moths. Towards three in the morning the scent ceases, the anthers begin to shrivel up or drop off, the filaments turn themselves outwards, so as to be out of the way, while the petals, on the contrary, begin to roll themselves up, so that by daylight they close the aperture of the flower, and present only their brownish-green undersides to view; which, moreover, are thrown into numerous wrinkles. Thus, by the morning's light, the flower has all the appearance of being faded. It has no smell, and the honey is covered over by the petals. So it remains all day. Towards evening, however, everything is changed. The petals unfold themselves; by eight o'clock the flower is as fragrant as before, the second set of stamens have rapidly grown, their anthers are open, and the pollen again exposer. By morning the flower is again "asleep," the anthers are shrivelled, the scent has ceased, and the petals rolled up as before. The third evening, again the same process occurs, but this time it is the pistil which grows: the long spiral stigmas on the third evening take the position which on the previous two had been occupied by the anthers, and can hardly fail to be dusted by moths with pollen brought from another flower.

An objection to the view that the sleep of flowers is regulated by the visits of insects, might be derived from the cases of those flowers which close early in the day, the well-known Tragopogon pratense, or "John Go-tobed at Noon," for instance; still more, such species as 
Lapsana communis, or Crepis pulchra, which open before six and close again before ten in the morning. Bees, however, are very early risers, while ants come out later, when the dew is off; so that it might be an advantage to a flower which was quite unprotected, to open early for the bees, and close again before the ants were out (see ante p. 35), thus preserving its honey exclusively for bees.

So much for the first part of my subject. I must now pass to the second-the action of plants upon insects. It would here, perhaps, be most natural to discuss the modifications which have been produced in insects by the search after honey and pollen; especially the gradual lengthening of the proboscis in butterflies, moths, and bees, to enable them to suck the honey, and the adaptation of the legs of bees, to enable them to carry off the more or less dry and dusty pollen. Having, however, already said so much about flowers and insects, it will be better for me to take other illustrations, and fortunately there is no lack or difficulty.

Many of the cases in which certain insects escape danger by their similarity to plants are well known; the leaf insect and the walking-stick insect are familiar and most remarkable cases. The larvæ of insects afford, also, many interesting examples, and, in other respects, teach us, indeed, many instructive lessons. It would be a great mistake to regard them. as merely preparatory stages in the development of the perfect insect. They are much more than this, for external circumstances act on the larvæ, as well as on the perfect insect: both, therefore, are liable to adaptation. In fact, the modifications which insect larvæe undergo may be divided into two kindsdevelopmental, or those which tend to approximation 
to the mature form; and adaptational or adaptive; those which tend to suit them to their own mode of life.

It is a remarkable fact, that the forms of larvæ do not depend on that of the mature insect. In many cases, for instance, very similar larvæ produce extremely dissimilar insects. In other cases, similar, or comparatively similar, perfect insects have very dissimilar larvæ. Indeed, a classification of insects founded on larvæ would be quite different from that founded on the perfect insects. The Hymenoptera, for instance, which so far as the perfect insects are concerned, form a very homogeneous group, would be divided into two-or rather one portion of them, namely, the saw-flies, would be united to the butterflies and moths. Now, why do the larvæ of sawflies differ from those of other Hymenoptera, and resemble those of butterflies and moths? It is because their habits differ from those of other Hymenoptera, and they feed on leaves, like ordinary caterpillars.

In some cases the form changes considerably during the larval state. From this point of view, the transformations of the genus Sitaris, which has -been carefully investigated by M. Fabre, are peculiarly interesting.

The genus Sitaris (a small beetle allied to Cantharis, the blister-fly, and to the oil-beetle) is parasitic on a kind of bee (Anthophora) which excavates subterranean galleries, each leading to a cell. The eggs of the sitaris, which are deposited at the entrance of the galleries, are hatched at the end of September or beginning of October, and M. Fabre not unnaturally expected that the young larvæ, which are active little creatures with six serviceable legs, would at once eat their way into the cells of the anthophora. No such thing : till the month 
of April following they remained without leaving their birth-place, and consequently without food; nor did they in this long time change either in form or size. M. Fabre ascertained this, not only by examining the burrow of the anthophoras, but also by direct observations of some young larvæ kept in captivity. In April, however, his captives at last awoke from their long lethargy, and hurried anxiously about their prisons. Naturally inferring that they were in search of food, M. Fabre supposed that this would consist either of the larvæ or pupæ of the anthophora, or of the honey with which it stores its cell. All three were tried without success. The first two were neglected, and the larvæ, when placed on the latter, either hurried away or perished in the attempt, being evidently unable to deal with the sticky substance. M. Fabre was in despair: "Jamais expérience," he says, "n’a éprouvé pareille déconfiture. Larves, nymphes, cellules, miel, je vous ai tous offert; que voulez-vous, donc, bestioles maudites?" The first ray of light came to him from our countryman, Newport, who ascertained that a small parasite found by Léon Dufour on one of the wild bees was, in fact, the larva of the oil-beetle. The larva of sitaris much resembled Dufour's larvæ. Acting. on this hint, M. Fabre examined many specimens of anthophora, and found on them at last the larvæ of his sitaris. The males of anthophora emerge from the pupæ sooner than the females, and M. Fabre ascertained that, as they come out of their galleries, the little sitaris larvæ fasten upon them. Not, however, for long: instinct teaches them that they are not yet in the straight path of development; and, watching their opportunity, they pass from 
the male to the female bee. Guided by these indications, M. Fabre examined several cells of anthophora; in some, the egg of the anthophora floated by itself on the surface of the honey: in others, on the egg, as on a raft, sat the still more minute larva of the sitaris. The mystery was solved. At the moment when the egg is laid, the sitaris larva springs upon it. Even while the poor mother is carefully fastening up her cell, her mortal enemy is beginning to devour her offspring; for the egg of the anthophora serves not only as a raft, but as a repast. The honey, which is enough for either, would be too little for both; and the sitaris, therefore, at its first meal, relieves itself from its only rival. After eight days the egg is consumed, and on the empty shell the sitaris undergoes its first transformation, and makes its appearance in a very different form.

The honey, which was fatal before, is now necessary, the activity, which before was necessary, is now useless; consequently, with the change of skin, the active, slim larva changes into a white, fleshy grub, so organized as to float on the surface of the honey, with the mouth beneath and the spiracles above the surface: "Grâce à l'embonpoint du ventre," says M. Fabre, "la larve est.à l'abri de l'asphyxie." In this state it remains until the honey is consumed ; then the animal contracts, and detaches itself from its skin, within which the further transformations take place. In the next stage, which M. Fabre calls the pseudo-chrysalis, the larva has a solid corneous envelope and an oval shape, and in its color, consistency, and immobility, reminds one of a dipterous pupa. The time passed in this condition varies much. When it has elapsed, the animal moults again, again 
changes its form; after this it becomes a pupa, without any remarkable peculiarities. Finally, after these wonderful changes and adventures, in the month of August the perfect beetle makes its appearance.

In fact, whenever in any group we find differences in form or color, we shall always find them associated with differences in habit. Let us take the case of caterpillars. The prevailing color of caterpillars is green, like that of leaves. The value of this to the young insect, the protection it affords, are obvious. We must all have observed how difficult it is to distinguish small green caterpillars from the leaves on which they feed. When, however, they become somewhat larger, their form betrays them, and it is important that there should be certain marks to divert the eye from the outlines of the body. This is effected, and much protection given, by longitudinal lines (Fig. 35), which accordingly are found on a great many caterpillars. These lines, both in color and thickness, much resemble some of the lines on leaves (especially those, for instance, of grasses), and also the streaks of shadow which occur among foliage. If, however, this be the explanation of them, then they ought to be wanting, as a general rule, in very small caterpillars, and to prevail most among those which feed on or among grasses. Now, similar lines occur on a great number of caterpillars belonging to most different groups of butterflies and moths, as you may see by turning over the illustrations of any monograph of the group. They exist among the hawk-moths, as, for instance, in the humming-bird hawk-moth; they occur in many butterflies, as, in Arge galathea, which feeds on the cat's-tail grass ; and in many moths, as, for instance, 
in Pyrophila tragopoginis, which feeds on the leaves of the "John Go-to-bed at Noon" (Tragopogon). But you will find that the smallest caterpillars rarely possess these white streaks. As regards the second point also, the streaks are generally wanting in caterpillars

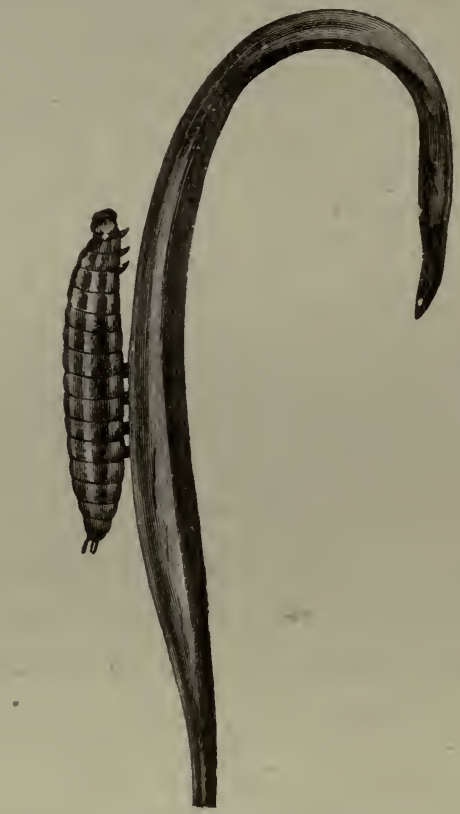

Fig. 35.-Arge galuthea.

which feed on large-leaved plants. The Satyridce, on the contrary, all possess them, and all live on grass. In fact we may say, as a general rule, that these longitudinal streaks only occur on caterpillars which live on or among narrow-leaved plants. As the insect grows, these lines often disappear on certain segments, and are replaced by diagonal lines. These diagonal lines (Fig. 36) occur in a great many caterpillars, belonging to the most distinct families of butterflies 
and moths. They come off just at the same angle as the ribs of leaves, and resemble them very much in general effect. They occur also especially in species which feed on large-leaved plants, and I believe I may say that though a great many species of caterpillars present these lines, they rarely, if ever, occur in species which live on grass; while, on the contrary, they are very frequent in those species which live on large-leaved plants. It might at first be objected to this view that there are many cases, as in the elephant hawk-moth, in which caterpillars have both. A little consideration, however, will explain this. In small caterpillars these oblique lines would be useless, because they must have

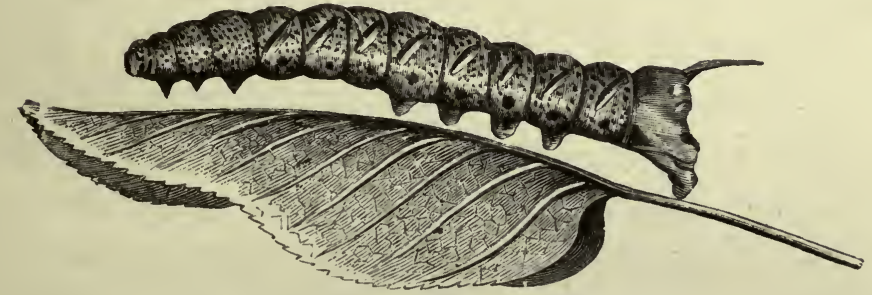

FIG. 36. - Smerinthus ocellatus.

some relation, not only in color, but in their distance apart, to the ribs of the leaves. Hence, while there are a great many species which have longitudinal lines when young, and diagonal ones when they are older and larger, there is not, I believe, a single one which begins with diagonal lines, and then replaces them with longitudinal ones. The disappearance of the longitudinal lines on those segments which have diagonal ones, is striking, where the lines are marked. It is an advantage, because white lines crossing one another at such an angle have 
no relation to anything which occurs in plants, and would make the creature more conspicuous. When, therefore, the diagonal lines are developed, the longitudinal ones often disappear. There is one other point in connection with these diagonal lines to which I must call your attention. In many species they are white, but in some cases, as for instance in the beautiful green caterpillar of the privet hawk-moth, the white streak is accompanied by a colored one-in that case lilac. At first we might think that this would be a disadvantage, as tending to make the caterpillar more conspicuous; and in fact, if we put one in full view, for instance, out on a table, and focus the eye on 'it, the colored lines are very striking. But we must remember that the habit of the insect is to sit on the lower side of the leaf, generally near the midrib, and in the subdued light of such a situation, especially if the eye be not looking exactly at them, the colored lines beautifully simulate a line of soft shadow, such as must always accompany a strong rib; and I need not tell any artist that the shadows of yellowish green must be purplish. Moreover, any one who has ever found one of these large caterpillars will, I am sure, agree with me that it is surprising, when we consider their size and conspicuous coloring, how difficult they are to see.

But though the prevailing color of caterpillars is green, there are numerous exceptions. In one great family of moths (the Geometridce) the prevailing color is brown. These caterpillars, however, escape observation by their great similarity to brown twigs, a resemblance which is heightened by their peculiar attitudes; and in many cases by the existence of warts or protuberances, 
which look like buds. Some, however, even of these caterpillars, when very young, are green. Again, some caterpillars are white. These either feed on and burrow in wood; such are, for instance, the species of Sphecia, Trochilium, and Zeuzera; or on roots, as the ghost-moth (Hepialus humuli). Hipparchia hyperanthus (the ringlet butterfly) also has whitish caterpillars, and this may at first sight appear to contradict the rule, since it feeds on grass. Its habit is, however, to keep at the roots by day, and feed only at night.

In various genera we find black caterpillars, which are of course very conspicuous, and, so far as I know, not distasteful to birds. In such cases, however, it will be found that they are covered with hairs or spines, which protect them from most birds. In these species, the bold dark color may be an advantage, by rendering the hair more conspicuous. As instances of caterpillars which are black and hairy, I may quote, among our English butterflies, Melitac cinxia, $M$. artemis, $M$. athalia, M. selene, M. dia, M. Euphrosyne, Argynnis aglaia, Vanessa polychloros, $V$. io, and $V$. antiope; while among moths, there are Arctia villica, A. caja, and Heraclea dominula. I do not know any large caterpillar which is black and smooth.

Brown caterpillars, also, are frequently protected by hairs or spines in the same way. As instances may be mentioned Cynthia cardui, Argynnis lathonia, Eriogaster lanestris, Odonestis potatoria, Lasiocampa rubi, L. trifolii, and L. roboris. Brown caterpillars, however, unlike black ones, are frequently naked. These fall into two principal categories: firstly, those which, like the Geometrida, put themselves into peculiar and stiff 
attitudes, so that in form, colour, and position they closely resemble bits of dry stick; and, secondly, those which feed on low plants, concealing themselves on the ground by day, and only coming out in the dark.

Yellow and yellowish-green caterpillars are abundant, and their color is a protection. Red and blue, on the contrary, are much less common colors, and are generally present as spots.

Moreover, caterpillars with red lines or spots are generally hairy, and this for the reason given above. Such species, therefore, would be avoided by birds. There are no doubt some apparent exceptions. Papitio machaon, for instance, has red spots and still is smooth; but as it emits a strongly-scented liquid when alarmed, it is probably distasteful to birds. I cannot recall any other case of a British caterpillar which has conspicuous red spots or lines, and yet is smooth.

Blue is among caterpillars even a rarer color than red. Indeed, among our larger larvæ, the only cases I can recall are the species of Gastropacha, which have two conspicuous blue bands, the Death's-head moth, which has broad diagonal bands, and Charoccimpa, which has two bright blue oval patches on the third segment. The species of Gastropacha are protected by being hairy, but why they have the blue bands I have no idea. It is interesting, that the other species both frequent plants which have blue flowers. The peculiar hues of the Death's-head hawk-moth caterpillar, which feeds on the potato, unite so beautifully the brown of the earth, the yellow and green of the leaves, and the blue of the flowers, that, in spite of its size, it can scarcely be perceived unless the eye be focussed exactly upon it. 
Charocampa nerii is also an interesting case. Many of the hawk-moth caterpillars have eye-like spots, to which I shall have to allude again presently. These are generally reddish or yellowish, but in Ch. nerii, which feeds on the periwinkle, they are bright blue, and in form as well as color closely resemble the blue petals of that flower. Ch. celerio also has two smaller blue spots, with reference to which I can make no suggestion. It is a very rare species, and I have never seen it. Possibly, in this case, the blue spots may be an inherited character.

No one who looks at any representations of hawkmoth caterpillars can fail to be struck by the peculiar coloring of those belonging to the genus Anceryx, which differ in style of coloring from all other sphinx larvæ, having longitudinal bands of brown and green. Why is this? Their habitat is different. They feed on the leaves of the pinaster, and their peculiar coloring offers a general similarity to the brown twigs and narrow green leaves of a conifer. There are not many species of Lepidoptera which feed on the pine, but there are a few ; such, for instance, are Achatia spreta and Dendrolimus pini, both of which have a very analogous style of coloring to that of Anceryx, while the latter has also tufts of bluish-green hair which singularly mimic the leaves of the pine. It is still more remarkable that in a different order of insects, that of the Hymenoptera, we again find species, for instance, Lophyrus socia, which live on the pine, and in which the same style of coloring is repeated.

Let us now take a single group, and see how far we can explain its various colors and markings, and what are the lessons which they teach us. For this purpose, I 
think I cannot do better than select the larvæ of the Sphingida, which have just been the subject of a masterly monograph by Dr. Weissmann, from whom most of the following facts are taken.

The caterpillars of this group are very different in color-green, white, yellow, brown, sometimes even gaudy, varied with spots, patches, streaks, and lines. Now, are these differences merely casual and accidental, or have they a meaning and a purpose? In many, perhaps in most cases, the markings serve for the purpose of concealment. When, indeed, we see caterpillars represented on a white sheet of paper, or if we put them on a plain table, and focus the eye on them, the colors and markings would seem, if possible, to render them even more conspicuous; as, for instance, in D. galii; but amongst the intricate lines and varied colors of foliage and flowers, and if the insect be a little out of focus, the effect is very different.

Let us begin with the Chorrocampa elpenor, the elephant hawk-moth. The caterpillars, as represented in most entomological works, are of two varieties, most of them brown (Fig. 43), but some green. Both have

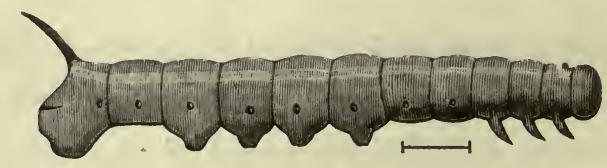

Fig. 37.-Chacrocampa elpenor. First stage.

a white line on the three first segments; two remarkable eye-like spots on the fourth and fifth, and a very faint median line; and are rather more than four inches long. I will direct your attention specially, for the moment, to 
three points:- What do the eye-spots and the faint lateral line mean? and why are some green, and some brown, offering thus such a marked contrast to the leaves of the Epilobium parvum, on which they feed? Other questions will suggest themselves later. I must now call your attention to the fact that, when the caterpillars first quit the egg, and come into the world (Fig. 37), they are

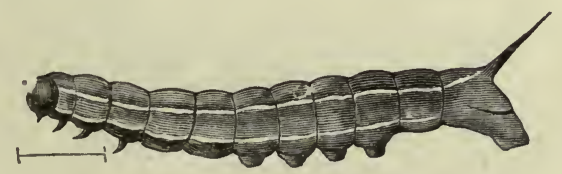

Frg. 38.-Charocampa elpenor. Second stage.

quite different in appearance, being, like so many other small caterpillars, bright green, and almost exactly the color of the leaves on which they feed. That this color is not a necessary or direct consequence of the food, we see from the case of quadrupeds, which, as I need scarcely say, are never green. It is, however, so obviously a protection to small caterpillars, that the explanation of their green color suggests itself to every one. After five or six days, and when they are about a quarter of an inch in length, they go through their first moult. In their second stage (Fig. 38), they have two white lines,

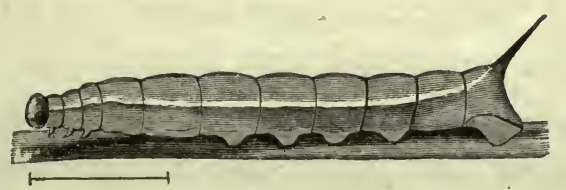

Fig. 39.-Charocampa elpenor. Just before second moult.

stretching along the body from the horn to the head; and after a few days (Fig. 39), but not at first, traces 
of the eye-spots appear on the fourth and fifth segments, shown by a slight wave in the upper line. After another five or six days, and when about half an inch in length, our caterpillars moult again. In their third stage (Fig. 40), the commencement of the eye-

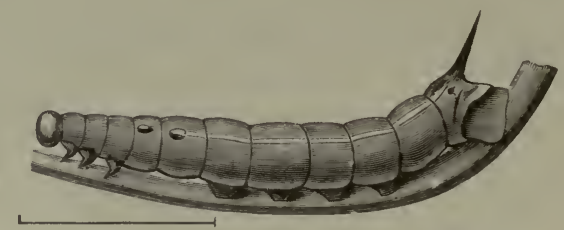

Fig. 40.-Chcerocampa elpenor. Third stage.

spots is more marked, while, on the contrary, the lower longitudinal line has disappeared. After another moult (Fig. 41), the eye-spots are still more distinct, the white gradually becomes surrounded by a black line, while in the next stage (Fig. 42) the centre becomes somewhat

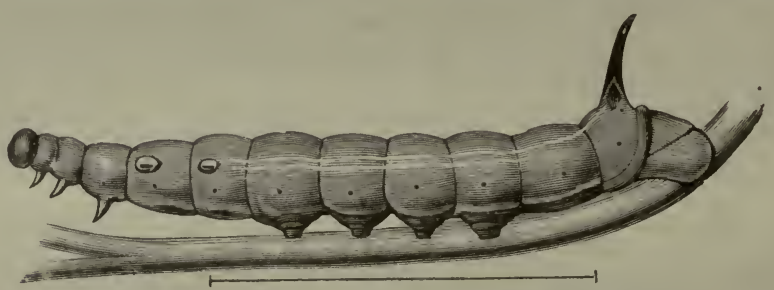

FIG. 41.-Checrocampa elpenor. Fourth stage.

violet. The white lines have almost, or entirely disappeared, and in some specimens, faint diagonal lines make their appearance. Some few assume a brownish tint, but not many. A fourth moult takes place in seven or eight days, and when the caterpillars are about an inch and a half in length. Now, the difference shows itself still more between the two varieties, some remaining green, while the majority become brown. 
The eye-spots are more marked, and the pupil more distinct, the diagonal lines plainer, while the white line is only indicated on the first three, and on the

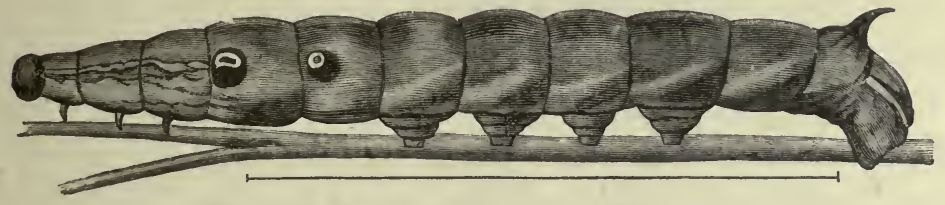

Fig. 42.-Charocampa elpenor. Fifth stage.

eleventh segment. The last stage (Fig. 43) has been already described.

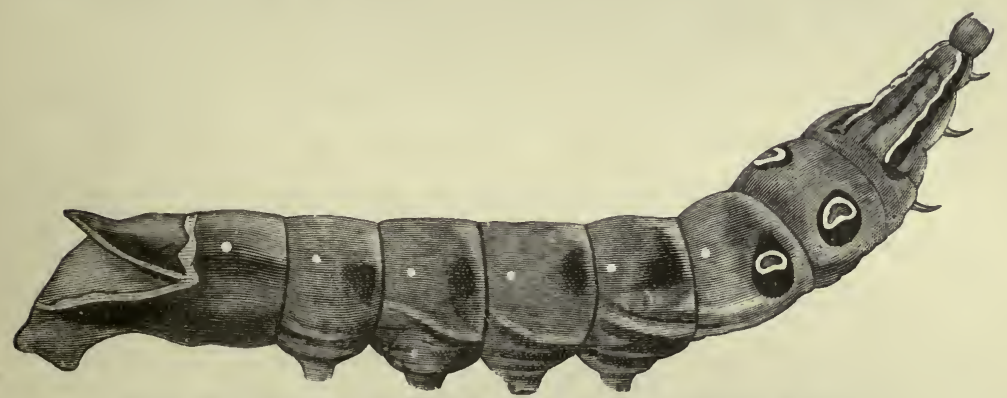

FIG. 43.-Chocrocumpa elpenor. Full grown. (Natural size.)

Now, the principal points to which I desire to draw attention are (1) the green color, (2) the longitudinal lines, (3) the diagonal lines, (4) the brown color, and (5) the eye-spots.

As regards the first three, however, I think I need say no more. The value of the green color to the young larva is obvious; nor is it much less clear that when the insect is somewhat larger, the longitudinal lines are a great advantage, while subsequently diagonal ones become even more important.

The next point is the color of the mature caterpillars. We have seen that some are green, and others 
brown. The green ones are obviously merely those which have retained their original color. Now for the brown color. This probably makes the caterpillar even more conspicuous among the green leaves than would otherwise be the case. Let us see, then, whether the habits of the insect will throw any light upon the riddle. What would you do if you were a big caterpillar? Why, like most other defenceless creatures, you would feed by night, and lie concealed by day. So do these caterpillars. When the morning light comes, they creep down the stem of the food plant, and lie concealed among the thick herbage, and dry sticks and leaves, near the ground, and it is obvious that under such circumstances the brown color really becomes a protection. It might indeed be argued that the caterpillars, having become brown, concealed themselves on the ground; and that we were in fact reversing the state of things. But this is not so; because, while we may say, as a general rule, that (with some exceptions due to obvious causes) large caterpillars feed by night and lie concealed by day, it is by no means always the case that they are brown; some of them still retaining the green color. We may then conclude that the habit of concealing themselves by day came first, and that the brown color is a later adaptation. It is, moreover, interesting to note, that while the caterpillars which live on low plants often go down to the ground, and turn brown, those which feed on large trees or plants remain on the under side of the leaves, and retain their green color.

Thus, in Smerinthus ocellatus, which feeds on the 
willow and sallow; S. populi, which feeds on the poplar; and $S$. tilice, which frequents the lime, the caterpillars all remain green; while in those which frequent low plants, such as the convolvulus hawkmoth, which frequents the convolvulus; Charocampa nerii, which feeds in this country on the periwinkle; Chcerocampa celerio, Ch. elpenor, and Ch. porcellus, which live on galium, most of the caterpillars turn brown. There are, indeed, some caterpillars which are brown, and still do not go down to the ground, as, for instance, those of Aspilatis aspersaria, and indeed of the Geometrida generally. These caterpillars, however, as already mentioned, place themselves in peculiar attitudes, which, combined with their brown color, make them look almost exactly like bits of stick or dead twigs.

The last of the five points to which I called your attention was the eye-spots. In some cases, spots may serve for concealment, by resembling the marks on dead leaves. In Deilephila hippophae, which feeds on the hippophae, or sea buckthorn, a grey-green plant, the caterpillar also is a similar grey-green, and has, when full grown, a single red spot on each side, which, as Weissmann suggests, at first sight much resembles in color and size one of the berries of hippophae. This might, at first, be supposed to constitute a danger, and therefore to be a disadvantage, but the seeds, though present, are not ripe, and consequently are not touched by birds. Again, in Charocampa tersa, there is an eye-spot on each segment, which mimics the flower of the plant on which it feeds (Spermacoce hyssopifolia). White spots, in some cases, 
also resemble the spots of light which penetrate foliage. In other instances, however, and, at any rate, in our elephant hawk-moth, the eye-spots certainly render the insect more conspicuous. Now in some cases, as Wallace has pointed out, this is an advantage, rather than a drawback. Suppose that from the nature of its food or any other cause, as, for instance, from being covered with hair, a small green caterpillar were very bitter, or in any way disagreeable or dangerous as food, still, in the number of small green caterpillars which birds love, it would be continually swallowed by mistake. If, on the other hand, it had a conspicuous and peculiar color, its evil taste would serve to protect it, because the birds would soon recognise and avoid it, as Weir and others have proved experimentally. I have already alluded to a case of this among the hawkmoths in Deilephila euphorbice, which, feeding on euphorbia, with its bitter milky juice, is very distasteful to birds, and is thus actually protected by its bold and striking colors. The spots on our elephant hawk-moth caterpillar do not admit of this explanation, because the insect is quite good to eat-I mean for birds. We must, therefore, if possible account for these spots in some other way. There can, I think, be little doubt that Weissmann is right when he suggests that the eyespots actually protect the caterpillar, by frightening its foes.

Every one must have observed that these large caterpillars, as for instance that of Ch. porcellus (Fig. 44), have a sort of uncanny, poisonous appearance; that they suggest a small thick snake or other evil beast, and the so-called "eyes" do much to increase the deception. 
Moreover, the ring on which they are placed is swollen, and the insect, when in danger, has the habit of retracting its head and front segments, which gives it an additional resemblance to some small reptile. That

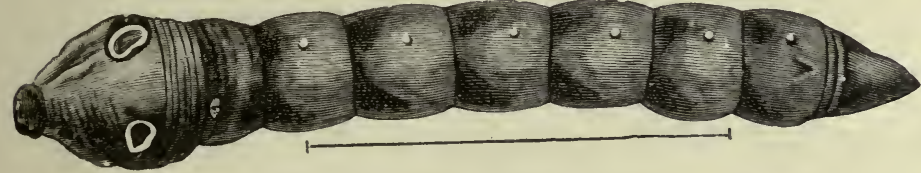

FIG. 44.-Chcerocampa porcellus.

small birds are, as a matter of fact, afraid of these caterpillars (which, however, I need not say, are in reality altogether harmless) Weissmann has proved by actual experiment. He put one of these caterpillars in a tray, in which he was accustomed to place seed for birds. Soon a little flock of sparrows and other small birds assembled to feed as usual. One of them lit on the edge of this tray, and was just going to hop in, when she spied the caterpillar. Immediately she began bobbing her head up and down, but was afraid to go nearer. Another joined her, and then another, until at last there was a little company of ten or twelve birds, all looking on in astonishment, but not one ventured into the tray; while one bird, which lit in it unsuspectingly, beat a hasty retreat in evident alarm as soon as she perceived the caterpillar. After watching for some time, Weissmann removed it, when the birds soon attacked the seeds. Other caterpillars also are probably protected by their curious resemblance to spotted snakes.

Moreover, as Weissmann points out, we may learn another very interesting lesson from these caterpillars. They leave the egg, as we have seen, a plain green, like 
so many other caterpillars, and gradually acquire a succession of markings, the utility of which I have just attempted to explain. The young larva, in fact, represents an old form, and the species, in the lapse of ages, has gone through the stage which each individual now passes through in a few weeks. Thus the caterpillar of Chorocampa porcellus, the small elephant hawkmoth, a species very nearly allied to Ch. elpenor, passes through almost exactly the same stages as that of $C h$. elpenor. But it leaves the egg with a subdorsal line, which the caterpillar of $C h$. elpenor does not acquire until after its first moult. No one can doubt, however, that there was a time when the new-born caterpillars of Ch. porcellus were plain green, like those of $C$ h. elpenor. In this respect, then, $C h$. porcellus is a newer specific form than Ch. elpenor. Again, if we compare the mature caterpillars of Chcerocampa, we shall find there are some forms, such as $C h$. myron and $C h$. chcrilus which never develope eje-spots, but which, even when full grown, correspond to the second stage of Ch. elpenor. Here, then, we seem to have a species still in the stage which $C h$. elpenor must have passed through long ago.

The genus Diilephila, of which we have in England three species-the euphorbia hawk-moth, the galium hawk-moth, and the rayed hawk-moth-is also very instructive. The caterpillar of the euphorbia hawk-moth begins life of a clear green color, without a trace of the subsequent markings. After the first moult, however, it has a number of black patches, a white line, and a series of white dots, and has, therefore, at one bound, acquired characters which in Ch. elpenor, as we 
have seen, were only very gradually assumed. In the third stage, the line has disappeared, leaving the white spots. In the fourth, the caterpillars have become very variable, but are generally much darker than before, and have a number of white dots under the spots. In the fifth stage, there is a second row of white spots under the first. The caterpillars not being good to eat, there is, as has been already pointed out, no need for, or attempt at, concealment. Now if we compare the mature caterpillars of other species of the genus, we shall find that they represent phases in the development of D. euphorbice. D.hippophae, for instance, even when full grown, is a plain green, with only a trace of the line, and corresponds, therefore, with a very early stage of $D$. euphorbice; $D$.zygophylli, of South Russia, has the line, and represents the second stage of $D$. euphorbice; Deilephila livornica has the line and the row of spots, and represents therefore the third stage; lastly, $D$. vespertileo and $D$. galii have progressed further, and lost the longitudinal line, but they never acquire the second row of spots which characterises the last stage of $D$. euphorbice.

Thus, then, the individual life of certain caterpillars gives us a clue to the history of the species in past ages.

For such inquiries as this, the larvæ of Lepidoptera are particularly suitable, because they live an exposed life; because the different species, even of the same genus, often feed on different plants, and are therefore exposed to different conditions; and last, not least, because we know more about the larvæ of the Lepidoptera than about those of any other insects. The larvæ of ants all live in the dark; they are fed by the perfect ants, and being 
therefore all subject to very similar conditions, are all very much alike. It would puzzle even a good naturalist to determine the species of an ant larva, while, as we all know, the caterpillars of butterflies and moths are as easy to distinguish as the perfect insects; they differ from one another as much as, sometimes more than, the butterflies and moths themselves.

There are five principal types of coloring among caterpillars. Those which live inside wood, or leaves, or underground, are generally of a uniform pale hue; the small leaf-eating caterpillars are green, like the leaves on which they feed. The other three types may, to compare small things with great, be likened to the three types of coloring among cats. There are the ground cats, such as the lion or puma, which are brownish or sand color, like the open places they frequent. So also caterpillars which conceal themselves by day at the roots of their food-plant tend, as we have seen, even if originally green, to assume the color of earth. Nor must I omit to mention the Geometridee, to which I have already referred, and which, from their brown color, their peculiar attitudes, and the frequent presence of warts or protuberances, closely mimic bits of dry stick. That the caterpillars of these species were originally green, we may infer from the fact that some of them at least are still of that color when first born. Then there are the spotted or eyed cats, such as the leopard, which live among trees; and their peculiar coloring renders them less conspicuous by simulating spots of light which penetrate through foliage. So also many caterpillars are marked with spots, eyes, or patches of color. Lastly, there are the jungle cats, of which the 
tiger is the typical species, and which have stripes, rendering them very difficult to see among the brown grass which they frequent. It may, perhaps, be said that this comparison fails, because the stripes of tigers are perpendicular, while those of caterpillars are either longitudinal or oblique. This, however, so far from constituting a real difference, confirms the explanation; because in each case the direction of the lines follows that of the foliage. The tiger, walking horizontally on the ground, has transverse bars; the caterpillar, clinging to the grass in a vertical position, has longitudinal lines; while those which live on large-veined leaves have oblique lines, like the oblique ribs of the leaves.

It might, however, be suggested that the cases given above are exceptional. I have, therefore, in a paper read before the Entomological Society, tabulated all our larger British caterpillars, and the result is very interesting. As regards butterflies, we have sixty-six species, out of which eighteen are spiny, and two may fairly be called hairy. I do not speak of mere pubescence, but of true hairs and spines. Now, out of these twenty, ten are black, two greyish, six brown or brownish, one greyish-green, and only one (L. sybilla) green. Thus, while green is so preponderating a color among smoothskinned or ordinarily pubescent caterpillars (thirtyseven out of the sixty-six species of butterflies being of this color), only a single spiny species is thus colored.

Now; let us look at these numbers under a different aspect. Out of sixty-six species, ten are black; and, as we have already seen, all these are spiny or hairy. The larva of Parnassius Apollo-a species reputed to have been taken in this country-is stated to be black, and is 
not hairy or spiny; but, as it has red spots and blue tubercles, and the neck is furnished with a yellow forked appendage, it is probably sufficiently protected. The larva of Papilio machaon is also marked with black, and provided with strongly-scented tentacles, which probably serve as a protection.

Again, there are sixteen brown species, and of these, seven are hairy or spiny.

Red and blue are rare colors among caterpillars. Omitting minute dots, we have six species, more or less marked with red or orange, viz., A. aglaia, $V$. antiopa, $N$. lucina, C. alsus, $P$. cratogi and $P$. machaon. Of these, two are spiny, two hairy, and one protected by scent-emitting tentacles. The orange medio-dorsal line of $C$. alsus is not very conspicuous, and has been omitted in some descriptions. Blue is even rarer than red; in fact, none of our butterfly larvæ can be said to exhibit this color.

Now, let us turn to the moths. Of these caterpillars, the Sphingida, Cocliopida, Procridee, Zyganida, Nolida, Lithosida, Euchelidu, Chelonida, Liparida, Bombycida, Drepanulce and Pseudo-Bombyces are tabulated-these groups comprising nearly all our larger species. The Hepialida, Zeuzerida and Sesidce have been omitted, because these larvæ are all internal or subterranean feeders, and are devoid of any striking color. This leaves 122 species, out of which sixtyeight are hairy or downy; and of these, forty-eight are marked with black or grey; fifteen brown or brownish, two yellowish-green, one bluish-grey, one striped with yellow and black, and one reddish-grey. Of the two yellowish-green hairy species, which might be regarded 
as exceptions, $Z$. lonicerce is marked with black and yellow, and $N$. albulatis is variable in color, some specimens of this caterpillar being orange. This last species is also marked with black, so that neither of these species can be considered of the green color which serves as a protection. Thus, among the moths tabulated, there is not a single hairy species of the usual green color. On the other hand, there are fifty species with black or blackish caterpillars, and of these, fortyeight are hairy or downy.

In ten of our larger moths the caterpillars are more or less marked with red. Of these, three are hairy, one is an internal feeder, four have reddish lines, which probably serve for protection by simulating lines of shadow, and one (D. euphorbice) is inedible. The last, $D$. livornica, is rare, and I have never seen the caterpillar; but, to judge from figures, the reddish line and spots would render it, not more, but less conspicuous amongst the low herbage which it frequents.

Seven species only of our larger moths have any blue; of these four are hairy, the other three are hawk-moths. In one ( $A$. atropos) the violet color of the side stripes certainly renders the insect less conspicuous among the flowers of the potato; on which it feeds. In C. nerii there are two blue patches, which, both in color and form, curiously rësemble the petals of the periwinkle, on which it feeds. In the third species, $C$. porcellus, the bluish spots form the centres of the above-mentioned ocelli.

Among the Geometrida, as already mentioned, the caterpillars are very often brown, and closely resemble S. E. 
bits of stick, the similarity being much increased by the peculiar attitudes they assume. On the other hand, the large brown caterpillars of certain Sphingidce are night feeders, concealing themselves on the ground by day; and it is remarkable that while species, such as $S$. convolvuli, which feed on low plants, turn brown as they increase in age and size; others, like the Smerinthi, which frequent trees, and cannot therefore descend to the ground for concealment, remain green throughout life. Omitting these, we find in the table, among the larger species, seventeen which are brown, of which twelve are hairy, and two have extensile caudal filaments. The others, though not Geometrida, closely resemble bits of stick, and place themselves in peculiar, and stiff attitudes.

And thus, summing up the caterpillars, both of butterflies and moths, out of the eighty-eight spiny and hairy species tabulated, only one is green ( $L$. sybilla), and even this may not be protectively coloured, since it has yellow warts and white lateral lines. On the other hand, a very great majority of the black and brown caterpillars, as well as those more or less marked with blue and red, are either hairy or spiny, or have some special protection.

Here, then, I think, we see reasons, for many at any rate, of the variations of color and markings in caterpillars, which at first sight seem so fantastic and inexplicable. I should, however, produce an impression very different from that which I wish to convey, were I to lead you to suppose that all these varieties have been explained, or are understood. Far from it; they still 
offer a large field for study; nevertheless I venture to think the evidence now brought forward, however imperfectly, is at least sufficient to justify the conclusion that there is not a hair or a line, not a spot or a color, for which there is not a reason,-which has not a purpose or a meaning in the economy of nature. 


\section{ON THE HABITS OF ANTS.}

LECTURE III.

I.

THE Anthropoid apes no doubt approach more nearly to Man in bodily structure than do any other animals; but when we consider the habits of Ants, their social organisation, their large communities, elaborate habitations, their roadways, their possession of domestic animals, and even, in some cases, of slaves, it must be admitted that they have a fair claim to rank next to man in the scale of intelligence. They present, moreover, not only a most interesting but also a very extensive field of study. In this country we have nearly thirty species; but ants become more numerous, in species as well as individuals, in warmer countries, and more than seven hundred kinds are known. Even this large number is certainly far short of those actually in existence.

I have kept in captivity nearly half of our British species of ants, and at the present moment have in my room more than thirty nests, belonging to about twenty species; some of which, however, are not English. No two species are identical in habits; and, on various accounts, their mode of life is far from easy to unravel. In the first place, most of their time is passed underground: all the education of the young, for instance, 
is carried on in the dark. Again, ants are essentially gregarious; it is in some cases difficult to keep a few alive by themselves in captivity, and at any rate their habits under such circumstances are entirely altered. If, on the other hand, a whole community be kept, then the great number introduces a fresh element of difficulty and complexity. Moreover, within the same species, the individuals seem to differ in character, and even the same individual will behave very differently, under different circumstances. Although, then, ants have attracted the attention of many naturalists, as Gould, De Geer, Swammerdam, Latreille, Leuwenhoeck, and Huber, and have recently been the object of interesting observations by Frederick Smith, Belt, Moggridge, Bates, Mayr, Emery, Forel, and others, they still present one of the most promising fields for observation and experiment. The larvæ of ants, like those of bees and wasps, are small, white, legless grubs, somewhat conical in form, narrow towards the head. They are carefully tended and fed, being carried about from chamber to chamber by the workers, probably in order to secure the most suitable amount of warmth and moisture. I have observed also that they are very often sorted according to age. It is sometimes very curious in my nests to see the larvæ arranged in groups according to size, so that they remind one of a school divided into five or six classes. When full grown, they turn into pupæ, sometimes naked, sometimes covered with a silken cocoon, constituting the so-called "ant-eggs." After remaining some days in this state, they emerge as perfect insects. In many cases, however, they would perish in the attempt, if they were not assisted; and it is very pretty to see the older ants helping them to extricate them- 
selves, carefully unfolding their legs and smoothing out their wings, with truly feminine tenderness and delicacy. Under ordinary circumstances, an ants' nest, like a beehive, consists of three kinds of individuals : workers, or imperfect females (which constitute the great majority), males, and perfect females. There are, however, often several Queens in an ants' nest; while, as we all know, there is never more than one in a hive. The ant queens have wings, but after a single flight they tear off their own wings, and do not again quit the nest. In addition to the ordinary workers, there is in some species a second, or rather a third, form of female. In almost any ants' nest, we may see that the workers differ more or less in size. The amount of difference, however, depends upon the species. In Lasius niger, the small brown garden ant, the workers are, for instance, much more uniform than in the little yellow meadow ant, or in Atta barbara, where some of them are more than twice as large as others. But in certain ants there are differences still more remarkable. Thus, in a Mexican species, besides the common workers, which have the form of ordinary neuter ants, there are certain others, in which the abdomen is swollen into an immense subdiaphanous sphere. These individuals are very inactive, and principally occupied in elaborating a kind of honey. ${ }^{1}$ In the genus Pheidole, very common in southern Europe, there are also two distinct forms of workers without any intermediate gradations; one with heads of the usual proportion, and a second with immense heads, provided with very large jaws. These latter are generally supposed to act as soldiers, and the size of the head enables the muscles which move the jaws to be of unusual

1 Westwood, Modern Classification of Insects, vol. ii. p. 225. 
dimensions : the little workers are also very pugnacious. This differentiation of certain individuals, so as to adapt them to special functions, seems to me very remarkable ; for it must be remembered that the difference is not one of age or sex.

The food of ants consists of insects, great numbers of which they destroy; of honey, honeydew, and fruit; indeed, scarcely any animal or sweet substance comes amiss to them. Some species, such, for instance, as the small brown garden ant, ascend bushes in search of aphides. The ant then taps the aphis gently with her antennæ, and the aphis emits a drop of sweet fluid, which the ant drinks.

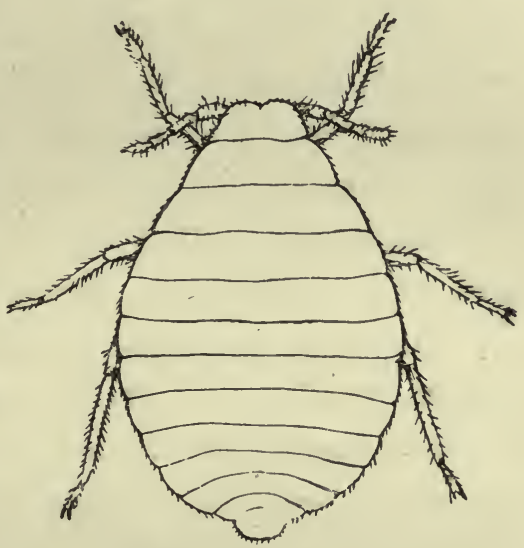

FIG. 45.-Aphis.

Sometimes the ants even build corered ways up to and over the aphides, which, moreover, they protect from the attacks of other insects. Our English ants do not collect provision for the winter; indeed, their food is not of a nature which would admit of this. Some southern species, however, collect grain, occasionally in considerable quantities. Moreover, though our English ants cannot be said exactly to lay up stores, some at least do take steps to provide themselves with food in the future. The small yellow meadow ant (Lasius flavus), for instance, lives principally on the honeydew of certain aphides which suck the roots of grass. The ants collect the aphides in 
the nest, not only watching over them themselves, but, as I have been able to satisfy myself, even over their eggs; an act which one is much tempted to refer to forethought, and which in such a case implies a degree of prudence superior to that of some savages.

Besides these aphides, many other insects live in ants' nests. If they are to be regarded as domestic animals, then ants have more domestic animals than we have. The majority of these ant-guests are beetles. Some of them, as, for instance, the curious little Claviger, are quite blind, and are only found in ants' nests, the ants taking just as much care of them as of their own young. It is evident, therefore, that in some way they are useful or agreeable to the ants. The subject, however, is one as yet but little understood, and very difficult to study. Grimm and Lespés consider that some of these beetles secrete a sweet fluid, as do the aphides, and from analogy this seems probable. Other creatures which habitually live in ants' nests, like the little Beckia albinos, or the blind woodlouse (Platyarthrus), perhaps make themselves useful as scavengers.

Nor are ants without their enemies. In addition to birds and other larger foes, if you disturb a nest of the brown ants at any time during the summer, you will probably see some very small flies hovering over them, and every now and then making a dash at some particular ant. These flies belong to the genus Phora, and to a species hitherto unnamed, which Mr. Verrall has been good enough to describe for me. They lay their eggs on the ants, inside which the larvæ live. Other species of the genus are in the same way parasitic on bees. In one case I observed that one of my ants had a mite attached to the underside of her head. The 
mite, which remained continuously in the same position, was almost as large as the head. The ant could not remove it herself. She did not come out of the nest, so that I could not do it for her, and none of her own companions for three months, during which I watched her, thought of performing this kind office.

In character the different species of ants differ very much from one another. $F$. fusca, the one which is pre-eminently the enslaved ant, is, as might be expected, extremely timid; while the nearly allied $F$. cinerea has, on the contrary, a considerable amount of individual audacity. $F$. rufa, the horse ant, according to M. Forel, is especially characterised by the want of individual initiative, and always moves in troops; he also regards the genus Formica as the most brilliant, though some others excel it in other respects; for instance, in the sharpness of their senses. F. pratensis worries its slain enemies; $F$. sanguinea never does. The slave-making ant (P. rufescens) is, perhaps, the bravest of all. If a single individual finds herself surrounded by enemies, she never attempts to fly, as any other ant would, but transfixes her opponents one after another, springing right and left with great agility, till at length she succumbs, overpowered by numbers. M. scabrinodis is cowardly and thievish; during wars among the larger species, they haunt the battle-fields and devour the dead. Tetramorium is said to be very greedy; Myrmecina very phlegmatic.

In industry, ants are not surpassed even by bees and wasps. They work all day, and in warm weather, if need be, even at night too. I once watched an ant from six in the morning, and she worked without intermission till a quarter to ten at night. I had put her to a saucer 
containing larvæ, and in this time she carried off no less than a hundred and eighty-seven to the nest. I once had another ant, which I employed in my experiments, under observation several days. Before I came up to London in the morning, and when I went to bed at night, I used to put her in a small bottle, but the moment she was let out she began to work again. On one occasion I was away from home for a week. On my return I let her out of the bottle, placing her on a little heap of larvæ, about three feet from the nest. Under these circumstances, I certainly did not expect her to work. However, though she had thus been six days in confinement, the brave little creature immediately picked up a larva, carried it off to the nest, and after half an hour's rest returned for another.

We have hitherto very little information as to the length of life in ants. So far, indeed, as the preparatory stages are concerned, we know that while they take only a few weeks in summer, in some species, as our small yellow meadow ants, the autumn larvæ remain with comparatively little change throughout the winter. It is much more difficult to ascertain the length of life of the perfect insect. It has, however, generally been supposed that they live about a season, and this is perhaps generally the case; but I have still some workers of F. cinerea, which I captured at Castellamare, in November, 1875, and some of $F$. sanguinea and $F$. fusca, since September in that year. I have also some queens of $F$. fusca, which have been with me since December, 1874, and still seem in perfect health. ${ }^{1}$ If they lived

1 These latter must have been born at latest in the spring of 1874, and would now, therefore (March 1879), be five years old, if not more. 
much longer, and could compare their experiences, ants would, from their immense numbers, even in temperate regions, contend with mankind on no such very unequal terms.

The behaviour of ants to one another differs very much, according as they are alone or supported by numerous companions. An ant which would run away in the first case, will fight bravely in the second.

It is hardly necessary to say that, as a general rule, each species lives by itself. There are, however, some interesting exceptions. The little Stenamma Westwoodii is found exclusively in the nests of the much larger $F$. rufa, and the allied $F$. pratensis. We do not know what the relations between the two species are. The Stenammas, however, follow the Formicas when they change their nest, running about among them and between their legs, tapping them inquisitively with their antennæ, and even sometimes climbing on to their backs, as if for a ride, while the large ants seem to take little notice of them. They almost seem to be the dogs, or perhaps rather cats, of the ants. Another small species, Solenopsis fugax, which makes its chambers and galleries in the walls of the nests of larger species, is the bitter enemy of its hosts. The latter cannot get at the foe, being too large to enter the galleries. The little Solenopsis, therefore, are quite safe, and, as it appears, make incursions into the nurseries of the larger ant, and carry off the larvæ as food. It is as if we had small dwarfs, about eighteen inches to two feet long, harbouring in the walls of our houses, and every now and then carrying off some of our children into their horrid dens. 
Most ants, indeed, will carry off the larvæ and pupæ of others if they get a chance; and this explains, or at any rate throws some light upon, that most remarkable phenomenon, the existence of slavery among ants. If you place a number of larvæ or pupæ in front of a nest of the horse ant, for instance, they are soon carried off ; and those which are not immediately required for food remain alive for some days, though I have never been able to satisfy myself whether they are fed by their captors. Both the horse ant and the slave ant ( $F$. fusca) are abundant species, and it must not unfrequently occur that the former, being pressed for food, attack the latter and carry off some of their larvæ and pupæ. Under these circumstances, it occasionally happens that the pupæ come to maturity in the nests of the horse ant; and nests are sometimes, though rarely, found, in which, with the legitimate owners, there are a few $F$. fuscas. With the horse ant this is, however, a very rare and exceptional phenomenon; but with an allied species, $F$. sanguinea, a species which exists in our southern counties and throughout Europe, it has become an established habit. The $F$. sanguineas make periodical expeditions, attack neighbouring nests of $F$. fusca, and carry off the pupæ. When the latter come to maturity, they find themselves in a nest consisting partly of $F$. sanguineas, partly of $F$. fuscas, the results of previous expeditions. They adapt themselves to circumstances, assist in the ordinary household duties, and, having no young of their own species, feed and tend those of the $F$. sanguineas. But though the $F$. sanguineas are thus aided by the $F$. fuscas, they have not themselves lost the instinct of working. It seems not improbable that 
there is some division of functions between the two species, but we have as yet no distinct knowledge on this point; and at any rate the $F$. sanguineas can "do" for themselves, and carry on a nest, if necessary, without slaves.

In another species, however, Polyergus rufescens, (which is not British), this is not the case. They present a striking lesson of the degrading tendency of slavery, for they have become entirely dependent on their slaves. Even their bodily structure has undergone a change : their mandibles have lost their teeth, and have become mere nippers, deadly weapons indeed, but useless except in war. They have lost the greater part of their instincts : their art, that is, the power of building; their domestic habits, for they take no care of their own young, all this being done by the slaves; their industry - they take no part in providing the daily supplies; if the colony changes the situation of its nest, the masters are all carried by the slaves to the new one; nay, they have even lost the habit of feeding. Huber placed thirty of them with some larvæ and pupæ and a supply of honey in a box.

"At first," he says, "they appeared to pay some little attention to the larvæ; they carried them here and there, but presently replaced them. More than one-half of the Amazons died of hunger in less than two days. They had not even traced out a dwelling, and the few ants still in existence were languid and without strength. I commiserated their condition, and gave them one of their black companions. This individual, unassisted, established order, formed a chamber in the earth, gathered together the larvæ, extricated several young ants that were ready to quit the condition of pupæ, and preserved the life of the remaining Amazons." 1

1 Huber, Natural History of Ants. 
This observation has been fully confirmed by other naturalists. However small the prison, however large the quantity of food, these stupid creatures will starve in the midst of plenty, rather than feed themselves. I have had a nest of this species under observation for a long time, but never saw one of the masters feeding. I have kept isolated specimens for weeks by giving them a slave for an hour or two a day to clean and feed them, and under these circumstances they remained in perfect health, while, but for the slaves, they would have perished in two or three days. . I know no other case in nature of a species having lost the instinct of feeding.

In $P$. rufescens, the so-called workers, though thus helpless and stupid, are numerous, energetic, and in some respects even brilliant. In another slave-making species, however, Strongylognathus, the workers are much less numerous, and so weak that it is an unsolved problem how they contrive to make slaves.

Lastly, in a fourth species, Anergates atratulus, the workers are absent, the males and females living in nests with workers belonging to another ant, Tetramorium cospitum. In these cases the Tetramoriums, having no queen, and consequently no young of their own, tend the young of the Anergates. It is therefore a case analogous to that of 'Polyergus, but it is one in which slave-owning has almost degenerated into parasitism. It is not, however, a case of true parasitism, because the Tetramoriums take great care of the Anergates, and if the nest is disturbed, carry them off to a place of safety.

M. Forel, in his excellent work on ants, has pointed out that very young ants devote themselves at first to the care of the larræ and pupæ, and that they take no 
share in the defence of the nest or other out-of-door work until they are some days old. This seems natural, because at first their skin is comparatively soft; and it would clearly be undesirable to undertake rough work, or run into danger, until their armour had had time to harden. There are, however, reasons for thinking that the division of labour is carried still further. I do not allude merely to those cases in which there are completely different kinds of workers, but even to the ordinary workers. In $L$. flavus, for instance, it seems probable that the duties of the small workers are somewhat different from those of the large ones, though no such division of labour has yet been detected.

One of the most interesting problems with reference to ants is, of course, to determine the amount of their intelligence. In order to test this, it seemed to me that one way would be to ascertain some object which they would clearly desire, and then to interpose an obstacle which a little ingenuity would enable them to overcome. With this object in view, I placed food in a porcelain cup on a slip of glass surrounded by water, but accessible to the ants by a bridge, consisting of a strip of paper two-thirds of an inch long and one-third wide. Having then put a $F$. nigra from one of my nests to this food, she began carrying it off, and by degrees a number of friends came to help her. I then, when about twenty-five ants were so engaged, moved the little paper bridge slightly, so as to leave a chasm just so wide that the ants could not reach across. They came to the edge and tried hard to get over, but it did not occur to them to push the paper bridge, though the distance was only about onethird of an inch, and they might easily have done so. 
After trying for about a quarter of an hour they gave up the attempt, and returned home. This I repeated several times. Then, thinking that paper was a substance to which they were not accustomed, I tried the same with a bit of straw one. inch long and one-eighth of an inch wide. The result was the same. I repeated this twice. Again I placed particles of food close to and directly over the nest, but connected with it only by a passage several feet in length. Under these circumstances it would be obviously a saving of time and labour to drop the food on to the nest, or at any rate to spring down with it, so as to save one journey. But though I have frequently tried the experiment, my ants never adopted either of these courses. I arranged matters so that the glass on which the food was placed was only raised onethird of an inch above the nest. The ants tried to reach down, and the distance was so small that occasionally, if another ant passed underneath just as one was reaching down, the upper one could step on to its back, and so descend; but this only happened accidentally, and they did not think of throwing the particles down, nor, which surprised me very much, would they jump down themselves. I then placed a heap of fine mould close to the glass, but just so far that they could still not reach across. It would have been quite easy for any ant, by moving a particle of earth for a quarter of an inch, to have made a bridge by which the food might have been reached, but this simple expedient did not occur to them. On the other hand, I then put some provisions in a shallow box with a glass top, and a single hole on one side, and put some specimens of Lasius niger to the food. As soon as a stream of ants was at work, busily carrying 
supplies off to the nest, and when they had got to know the way thoroughly, I poured some fine mould in front of the hole, so as to cover it up to a depth of about half an inch. I then took out the ants which were actually in the box. As soon as they had recovered from the shock of this unexpected proceeding on my part, they began to run all round and about the box, looking for some other place of entrance. Finding none, however, after a while they dug down into the earth just over the hole, carrying off the grains of earth one by one, and depositing them, without any order, all round at a distance of from half an inch to six inches, until they had excavated down to the doorway, when they again began carrying off the food as before. This experiment I repeated several times, always with the same result.

Again, I suspended some honey over a nest of Lasius flavus, at a height of about half an inch, and accessible only by a paper bridge more than 10 feet long. Under the glass I then placed a small heap of earth. 'The ants soon swarmed over the earth on to the glass, and began feeding on the honey. I then removed a little of the earth, so that there was an interval of about one-third of an inch between the glass and the earth; but, though the distance was so small, the ants would not jump down, but preferred to go round by the long bridge. They tried in vain to stretch up from the earth to the glass, which, however, was just out of their reach, though they could touch it with their antennæ; but it did not occur to them to heap the earth up a little; though, if they had moved only half a dozen particles, they would have secured for themselves dircet access to the food.

S. E. 
This, however, appeared never to occur to them. At length they gave up all attempts to reach up to the glass, and went round by the long paper bridge. I left the arrangement for several weeks, but they continued to do the same.

Again I varied the experiment, as follows:-Having left a nest without food for a short time, I placed some honey on a small wooden brick, surrounded by a little moat of glycerine, about half an inch wide and about $\frac{1}{10}$ th of an inch in depth. Over this moat I placed a paper bridge, one end of which rested on some fine mould. I then put an ant to the honey, and soon a little crowd was collected round it. I then removed the paper bridge ; the ants could not cross the glycerine, they came to the edge and walked round and round, but were unable to get across; nor did it occur to them to make a bridge or bank across the glycerine by means of the mould which I had placed so conveniently for them. I was the more surprised at this, on account of the ingenuity with which they avail themselves of earth in constructing their nests. For instance, wishing, if possible, to avoid the trouble of frequently moistening the earth in my nests, I supplied one of my ant-nests of Lasius flavus with a frame, containing, instead of earth, a piece of linen, one portion of which projected beyond the frame, and was immersed in water. The linen sucked up the water by capillary attraction, and thus the air in the frame was kept moist. The ants approved of this arrangement, and touk up their quarters in the frame. To minimize evaporation, I usually closed the frames all round, leaving only one or two small openings for the ants, but in this case I left the outer side of the frame open. The ants, 
however, did not like being thus exposed; they therefore brought earth from some little distance, and built up a regular wall along the open side, blocking up the space between the upper and lower plates of glass, and leaving only one or two small openings for themselves. This struck me as very ingenious. The same expedient was, moreover, repeated under similar circumstances by the slaves belonging to my nest of Polyergus.

I have also made many experiments on the power possessed by ants of remembering their friends. It will be recollected that Huber gives a most interesting account of the behaviour of some ants, which, after being separated for four months, when brought together again, immediately recognised one another, and "fell to mutual caresses with their antennæ." Forel, however, regards these morements as having indicated fear and surprise rather than affection, though he also is quite inclined to believe, from his own observation, that ants would recognise one another after a separation of some months. The observation recorded by Huber was made casually ; and neither he nor any one else seems to have taken any steps to test it by subsequent experiments. The fact is one, however, of so much interest, that it seemed to me desirable to make further experiments on the subject. On the 4th of August, 1875, therefore, I separated one of my nests of $F$. fusca into two halves, which I kept entirely apart.

I then from time to time put an ant from one of these nests into the other, introducing also a stranger at the same time. The stranger was always driven out, or even killed. The friend, on the contrary, was never attacked, though I am bound to say that I could see no 
signs of any general welcome, or any especial notice taken of her.

I will not trouble you with all the evidence, but will content myself with one or two cases.

On the 12th November last, that is to say, after the ants had been separated for a year and three months, I put a friend and a stranger into one of the divisions. The friend seemed quite at home. One of the ants at once seized the stranger by an antenna, and began dragging her about. At 11.45 the friend was quite at home with the rest. The stranger was being dragged about.

12.0. The friend was all right. Three ants now had hold of the stranger by her legs and an antenna.

12.15, Do. do. 12.30, Do. do. 12.45, Do. do. 1.0, Do. do. 1.30, Do. One now took hold of the friend, but soon seemed to find out her mistake and let go again. 1.45. The friend was all right. The stranger was being attacked. The friend had also been almost cleaned; while on the stranger the color had been scarcely touched. 2.15. Two ants were licking the friend, while another pair was holding the stranger by her legs. 2.20. The friend was now almost clean, so that I could only just perceive any color. The stranger, on the contrary, was almost as much colored as ever. She was now near the door, and I think would have come out, but two ants met and seized her. 3.0. Two ants were attacking the stranger. The fricnd was no longer distinguishable from the rest. 3.30, Do. 4.0, Do. 5.0, Do. 6.0. The stranger now escaped from the nest, and I put her back among her own friends.

The difference of behaviour was therefore most 
marked. The friends were gradually licked clean, and except for a few moments, and that evidently by mistake, were never attacked. The strangers, on the contrary, were not cleaned, were at once seized, dragged about either by one, two, or three assailants, and at length either made their escape from the nest, or were killed.

It is certainly most remarkable that ants should thus recognise their friends, after an interval of more than a year. I have since repeated these experiments with similar results.

Thus, I separated a nest of $F$. fusca into two portions, on the 20th October, 1876, and kept them entirely separate.

On the 25th February, 1877 , at 8 a.m., I put an ant from the smaller lot back among her old companions. At 8.30 she was quite comfortably established among them. At 9, ditto. At 12, ditto, and at 4, ditto.

June 8th.-I put two specimens from the smaller lot back, as before, among their old friends. At 1, they were all right among the others. At 2, ditto. After this I could not distinguish them among the rest, but they were certainly not attacked.

June 9th.-Put in two more at the same hour. Up to 3 in the afternoon they were neither of them attacked. On the other hand, two strangers from different nests, whom I introduced at the same time, were both very soon attacked.

July 14th.-I put in two more of the friends at 10.1.5. In a few minutes they joined the others, and seemed quite at home. At 11, they were among the others; at 12, ditto ; and at 1, ditto. 
July 21st.-At 10.15 I put in two more of the old friends. At 10.30 neither were being attacked. At 11 , ditto. 12, ditto. 2, ditto. 4, ditto. 6, ditto.

October 7 th.-At $9.30 \mathrm{I}$ put in two, and watched them carefully till 1. They joined the other ants, and were not attacked. I also put in a stranger from another nest. Her behaviour was quite different. She kept away from the rest, running off at once in evident fear, and kept wandering about, seeking to escape. At 10.30 she got out. I put her back, but she soon escaped again. I then put in another stranger. She was almost immediately attacked. In the meantime, the old friends were gradually cleaned. At 1.30 they could scarcely be distinguished. They seemed quite at home, while the stranger was being dragged about. After 2, I could no longer distinguish the friends. They were however certainly not attacked. The stranger, on the contrary, was killed and brought out of the nest.

This case, therefore, entirely confirmed the preceding; while strangers were attacked, friends were amicably receivecl.

In most species of ants, the power of smell is very keen. I placed ants on a strip of paper, each end of which was supported on a pin, the foot of which was immersed in water. They ran backwards and forwards along the paper, trying to escape. If then a camel's-hair pencil was suspended just over the paper, they passed under it without taking any notice of it ; but if it was scented, say with lavender-water, they at once stopped when they come near it, showing in the most unmistakable manner that they perceived the odour. This sense appear's to reside, though not perhaps exclusively, in the antennæ. I tethered, for 
instance, a large specimen of Formica ligniperda with a fine thread to a board, and when she was quite quiet I approached a scented camel's-hair pencil slowly to the tip of the antenna, which was at once withdrawn, though the insect took no notice of a similar pencil, if not scented.

On the other hand, as regards their sense of hearing, the case is very different. Approaching an ant which was standing quietly, I have over and over again made the loudest and most shrill noises I could, using a penny pipe, a dog-whistle, a violin, as well as the most piercing and startling sounds I could produce with my own voice, without effect. At the same time I by no means would infer from this that they are really. deaf, though it certainly seems that their range of hearing is very different from ours. We know that certain allied insects produce a noise by rubbing one of their abdominal rings against another. Landois is of opinion that ants also make sounds in the same way, though these sounds are inaudible to us. Our range is, however, after all, very limited, and the universe is probably full of music which we cannot perceive. There are, moreover, in the antennæ of ants certain curious organs which may perhaps be of an auditory character. There are from ten to a dozen in the terminal segment of Lasius flavus, the small meadow ant, and indeed in most of the species which I have examined; and one or two, in each of the short intermediate segments. These organs consist of three parts : a small spherical cup opening to the outside, a long narrow tube, and a hollow body, shaped like an elongated clock-weight. They may serve to increase the resonance of sounds, acting, in fact, to use the words of 
Professor Tyndall, who was good enough to look at them with me, like microscopic stethoscopes.

The organs of vision are in most ants very complex and conspicuous. There are generally three ocelli arranged in a triangle on the top of their heads, and on each side a large compound eye.

The mode in which the eyes act is by no means understood. They consist of a number of facets, varying from $1-5$; in Ponera contracta, to more than 1,000 in each eye-as, for instance, in the males of $F$. pratensis. In fact these, so far fortunate, insects realize the wish of the poet :

"Thou lookest on the stars, my love;

Oh would that I could be

Yon starry skies with thousand eyes

That I might look on thee."

But if the male of $F$. pratensis sees 1,000 images of the queen at once, this would seem to be a bewildering privilege, and the prevailing opinion among entomologists is that each facet only takes in a portion of the field of view.

However this may be, the sight of ants does not seem to be very good. In order to test how far they are guided by vision, I made the following experiments. I placed a common lead-pencil on a board, fastening it upright, so as to serve as a landmark. At the base I placed a glass containing food, and put a $L$. niger to the food; when she knew her way from the glass to the nest and back again perfectly well, she went quite straight backwards and forwards. I then took an opportunity when the ant was on the glass, and moved the glass with the ant on it about three inches. Now, under 
such circumstances, if she had been much guided by sight, she could not of course have had any difficulty in finding her way to the nest. As a matter of fact, however, she was entirely at sea, and after wandering about for some time, got back to the nest by another and very roundabout route. I then again varied the experiment as follows. I placed the food in a small china cup on the top of the pencil, which thus formed a column seven and a half inches high. When the ant once knew her way, she went very straight to and from the food. I then moved the pencil six inches. This puzzled her very much: she went over and over the spot where the pencil had previously stood, retraced her steps several times almost to the nest, and then returned along the whole line, showing great perseverance, if not much power of vision. She found it at last, but only after many meanderings.

I repeated the observation on three other ants with the same result: the second was seven minutes before she found the pencil, and at last seemed to do so accidentally; the third actually wandered about for no less than half an hour, returning up the paper bridge several times.

Let us compare this relatively to man. An ant measuring, say one-sixth of an inch, and the pencil being seven inches high, it is consequently forty-two times as long as the ant. It bears, therefore, somewhat the same relation to the ant as a column two hundred and fifty feet high does to a man. The pencil having been mored six inches, it is as if a man in a country he knew well would be puzzled at being moved a few hundred feet; or, if put down in a square containing less than an acre, could not find a column two hundred 
and fifty feet high ; that is to say, higher than the Duke of York's column.

As additional evidence I may adduce the fact, that when my $L$. nigers were carrying off food placed in a cup on a piece of board, if I turned the board round, so that the side which had been turned towards the nest was away from it, and vice versâ, the ants always returned over the same track on the board, and consequently directly away from home. If I moved the board to the other side of my artificial nest, the result was the same. Evidently they followed the track, not the direction.

It is remarkable, that notwithstanding the labours of so many excellent observers, and though ants swarm in every field and every wood, we do not yet know how their nests commence.

Three principal modes have been suggested:- after the marriage flight the young queen may either

1. Join her own or some other old nest;

2. Associate herself with a certain number of workers, and with their assistance commence a new nest; or

3. Found a new nest by herself.

The question can, of course, only be settled by observation, and the experiments made to determine it have hitherto been indecisive. Blanchard indeed, in his work on the "Metamorphoses of Insects" (I quote from Dr. Duncan's translation, p. 205) says, “Huber observed a solitary female go down into a small underground hole, take off her own wings, and become, as it were, a worker; then she constructed a small nest, laid a few eggs, and brought up the larvæ by acting as mother and nurse at the same time." 
This however is not quite a correct version of what Huber says. His words are : "I enclosed several females in a nest full of light humid earth, with which they constructed lodges, where they resided; some singly, others in common. They laid their eggs and took great care of them; and notwithstanding the inconvenience of not being able to vary the temperature of thcir habitation, they reared some, which became larvæ of a tolerable size, but which soon perished from the effect of my own negligence."

It will be observed that it was the eggs-not the larvæ - which, according to Huber, these isolated females reared. It is true that he attributes the early and uniform death of the larvæ to his own negligence; but the fact remains, that in none of his observations did an isolated female bring her offspring to maturity. Other entomologists, especially Forel and Ebrard, have repeated the same observations, with similar results; and as yet in no single case has an isolated female been known to bring her young to maturity. Forel even thought himself justified in concluding from his observations, and those of Ebrard, that such a fact could not occur. Lepeletier de St. Fargeau was of opinion that ants' nests originate in the second mode indicated above, and it is indeed far from improbable that this may occur. No clear case has, however, yet been observed.

Under these circumstances, I made various experiments, in order if possible to solve the question. For instance, I took an old fertile queen from a nest of Lasius flavus, and put her to another nest of the same species. The workers became very excited and killed 
her. I repeated the experiment, with the same result, more than once.

I conclude then, that, at any rate in the case of Lasius flavus, the workers will not adopt an old queen from another nost.

The following facts show that whether ants' nests sometimes originate in the two former modes or not, at any rate in some cases isolated queen ants are capable of giving origin to a new community. On the 14th August, 1876, I isolated two pairs of Myrmica ruginodis, which I found flying in my garden. I placed them with damp earth, food, and water, and they continued perfectly healthy through the winter. In April, however, one of the males died, and the second in the middle of May. The first eggs were laid between the 12th and 23rd April. They began to hatch, the first week in June, and the first larva turned into a chrysalis on the 27th; a second on the 30 th; a third on the 1st of July, when there were also seven larvæ and two eggs. On the 8th there was another egg. On the 8th July a fourth larva had turned into a pupa. On the 11th July I found there were six eggs, and on the 14 th, about ten. On the 15th, one of the pupæ began to turn brown; and the eggs were about fifteen in number. On the 16th, a second pupa began to turn brown. On the 21st, a fifth larva had turned into a pupa, and there were about twenty eggs. On the 22nd July, the first worker emerged, and a sixth larva had changed. On the 25th, when I looked into the nest, I observed the young worker carrying the larvæ about. A second worker was coming out. On July 28th, a third worker emerged, and a fourth on 
the 5th August. The eggs appeared less numerous, some having probably been devoured.

This experiment shows that the queens of Myrmica ruginodis have the instinct of bringing up larvæ, and the power of founding communities.

The workers remained about six weeks in the egg, a month in the state of larva, and 25-27 days as pupæ.

A nest of ants must not be confused with an ant hill in the ordinary sense. Very often indeed a nest has only one dwelling, and in most species seldom more than three or four. Some communities, however, form numerous colonies. M. Forel even found a case in which one nest of $F$. exsecta had no less than two hundred colonies, and occupied a circular space with a radius of nearly two hundred yards. Within this area they had exterminated all the other ants, except a few nests of Tapinoma erraticum, which survived, thanks to the great agility of this species. In these cases, the number of ants thus associated together must have been enormous. Even in single nests, Forcl estimates the numbers at from five thousand to half a million.

In their modes of fighting, different species of ants have their several peculiarities. Some also are much less military than others. Myrmecina Latreillii, for instance, never attack, and scarcely even defend themselves. Their skin is very hard, and they roll themselves into a ball, not defending themselves, even if their nest be invaded; to prevent which, however, they make the entrances small, and often station at each a worker, who uses her head to stop the way. Their smell is also, perhaps, a protection. Tctramorium caspitum 
has the habit of feigning death. This species, however, does not roll itself up, but merely applies its legs and antennæe closely to the body.

Formica rufa, the common borse ant, attacks in serried masses, seldom sending out detachments, while single ants scarcely ever make individual attacks. They rarely pursue a flying foe, but give no quarter, killing as many enemies as possible, and never hesitating, with this object, to sacrifice themselves for the common good.

Formica sanguinea, on the contrary, at least in their slave-making expeditions, attempt rather to terrify than to kill. Indeed, when they are invading a nest, they do not attack the flying inhabitants, unless the latter are attempting to carry off pupæ, in which case they are forced to abandon these. When fighting, they attempt to crush their enemies with their mandibles.

Formica exsecta is a delicate, but very active species. They also advance in serried masses, but in close quarters they bite right and left, dancing about to avoid being bitten themselves. When fighting with larger species, they spring on to their backs, and then seize them by the neck or by an antenna. They also have the instinct of combining in small parties, three or four seizing an enemy at once, and then pulling different ways, so that she on her part cannot get at any one of her foes. One of them then jumps on her back and cuts, or rather saws off, her head. In battles between this ant and the much larger $F$. protensis, many of the latter may be seen, each with a little $F$. exsecta on her back, sawing off her head from behind.

One might, at first sight, be disposed to consider 
that the ants with stings must have a great advantage over those with none. In some cases, however, the poison is so strong, that it is sufficient for it to touch the foes to place them hors de combat, or at least to render them incapacitated, with every appearance of extreme pain. Such species have the abdomen unusually mobile.

The species of Lasius make up in numbers what they want in strength. Several of them seize an enemy at the same time, one by each of her legs or antennæ, and when they have once taken hold they will suffer themselves to be cut in pieces rather than let go.

Polyergus rufescens, the celebrated slave-making or Amazon ant, has a mode of combat almost peculiar to herself. Her jaws are very powerful, and pointed. If attacked-if, for instance, another ant seizes her by a leg-she at once takes her enemy's head into her jaws, thus generally making her quit her hold. If she does not, the Polyergus closes her mandibles, so that the points pierce the brain of her enemy, paralysing the nervous system. The victim falls in convulsions, setting free her terrible foe. In this manner a comparatively small force of Polyergus will fearlessly attack much larger armies of other species, suffering itself scarcely any loss.

I have elsewhere discussed the relations of flowers to insects, especially to bees, and particularly the mode in which flowers have been modified, so that the bees might transfer the pollen from one to another. Ants are also, as mentioned in the preceding lecture, of considerable importance to plants, especially in keeping down the number of insects which feed on them. 
So far as I know, however, there are no plants which are specially modified, in order to be fertilised by ants; and, indeed, even to those small flowers which any little insect might fertilise, the visits of winged insects are much more advantageous; because, as Mr. Darwin has shown in his excellent work on crossand self-fertilisation of plants, it is important that the pollen should be brought, not only from a different flower, but also from a different plant, while creeping insects, such as ants, would naturally pass from flower to flower of the same plant.

Under these circumstances, it is important to plants that ants should not obtain access to the flowers, which they would otherwise rob of their honey, without conferring on them any compensating advantage. Accordingly, we not only find in flowers various modes of attracting bees, but also of excluding ants; and in this way ants have exercised more influence on the vegetable kingdom than might be supposed. Sometimes, for instance, flowers are protected by chevaux de frise of spines and fine hairs pointing downwards (Carlina, Lamium); some have a number of glands secreting a glutinous substance, over which the ants cannot pass (Linncea, Gooseberry); in others the tube of the flower is itself very narrow, or is almost closed either by hairs or by internal ridges, which just leave space for the proboscis of a bee, but no more. Lastly, some, and especially pendulous flowers (Cyclamen, Snowdrop), are so smooth and slippery that ants cannot easily enter them, but often slip off in the attempt, and thus are excluded; just as the pendulous nests of the weaver-birds preclude the entrance of snakcs. 


\section{ON THE HABITS OF ANTS.}

LECTURE IV.

II.

Mr. Grote, in his Fragments on Ethical Subjects, regards it as an evident necessity that no society can exist without the sentiment of morality. "Every one," he says, "who has either spoken or written on the subject has agreed in considering this sentiment as absolutely indispensable to the very existence of society. Without the diffusion of a certain measure of this feeling throughout all the members of the social union, the caprices, the desires, and the passions of each separate individual would render the maintenance of any established communion impossible. Positive morality, under some form or other, has existed in every society of which the world has ever had experience." 1

If this be so, then ants must be moral and accountable beings. I cannot, however, urge this myself, having elsewhere attempted to show that, even with reference to man, the case is not by any means clear.

As regards ants, various observers have recorded instances of attachment and affection. In various memoirs 
published by the Linnean Society, I have discussed these cases, and have reluctantly come to the conclusion that some of them, at any rate, rest on a very doubtful foundation.

Yet I am far from denying that such instances do exist. For example, in one of my nests of Formica fusca was a poor ant which had come into the world without antennæ. Never having previously met with such a case, I watched her with great interest, but she never appeared to leave the nest. At length one day I found her wandering about in an aimless sort of manner, and apparently not knowing her way at all. After a while she fell in with some specimens of $L$. flavus, who directly attacked her. I at once set myself to separate them, but whether owing to the wounds she had received from her enemies, or to my rough, though well-meant, handling, or to both, she was evidently sorely wounded, and lay helpless on the ground. After some time, another $F$. fusca from her nest came by. She examined the poor sufferer carefully, then picked her up tenderly and carried her away into the nest. It would have been difficult for any one who witnessed the scene to have denied to this ant the possession of humane feelings. I might quote various more or less similar cases; nevertheless they are, according to my experience, exceptional. Indeed, I have often been surprised that in certain emergencies ants render one another so little assistance. The tenacity with which they retain their hold on an enemy they have once seized is well known. M. Mocquerys even assures us that the Indians of Brazil made use of this quality in the case of wounds, causing an ant to bite the two lips of the cut and thus bring them 
together, after which the Indians eut off the ant's head, which thus holds the lips of the wound together. $\mathrm{He}$ asserts that he has often seen natives with wounds in course of healing by the assistance of seven or eight ants' heads! ${ }^{1}$ I have often observed that some of my ants had the heads of others hanging on to their legs for a considerable time, and as this must certainly be very inconvenient, it seems remarkable that their friends should not relieve them of such an awkward encumbrance.

As mentioned in the previous lecture, one of my queen ants (Formica fusca) had a large mite on the underside of her head. She could not remove it, and not one of her companions, for more than three months, performed this kind office for her. Being a queen, she never left the nest, and I therefore had no opportunity of helping her. Since then I have met with several similar cases. Moreover, I have often put ants, which had become smeared with a sticky substance, on the boards close to my nests, and very rarely indeed did their companions take any notice of, or seek to disentangle them.

Again, if an ant be fighting with one of another species, her friends rarely come to her assistance. They seem generally (unless a regular battle is taking place) to take no interest in the matter, and do not even stop to look on. Some species, indeed, never in such contests appear to help one another; and even when they do so, as, for instance, in the genus Lasius, the truth seems to be that several of them attack the same enemy,

${ }^{1}$ Ann. Soc. Ent. France, 2 Sér. tom. ii. p. 67. 
- their object being to destroy the foe, not to save their friend.

To test the affection of ants for one another, I have made a number of experiments, from which I will extract a few, as specimens of the whole. Thus, January 3, 1876, I immersed an ant ( $F$. nigra) in water for half an hour, and when she was then, to all appearance, drowned, I put her on a strip of paper, leading to some food. The strip was half an inch wide, and one of my marked ants belonging to the same nest was passing continually to and fro over it. The immersed ant lay there an hour before she recovered herself, and during this time the marked ant passed by eighteen times without taking the slightest notice of her.

I then immersed another ant in water for an hour, after which I placed her on the strip of paper, as in the preceding case. She was three-quarters of an hour before she recovered; during this time two marked ants were passing to and fro; one of them went by eighteen times, the other twenty times, two other ants also went over the paper, but none of them took the slightest notice of their half-drowned friend."

As evidence both of their intelligence and of their affection for their friends, it has been said by various observers that when ants have been accidentally buried, they have been very soon dug out and rescued by their companions. Without for a moment doubting the facts as stated, we must remember the habit which ants have of burrowing in loose fresh soil, and especially their practice of digging out fresh galleries, when their nests are disturbed. It seemed to me, however, that it would not be difficult to test whether the excavations made by ants 
under the circumstances were the result of this general habit, or really due to a desire to extricate their friends. With this view, I tried (20th August) the following experiments. I placed some honey near a nest of Lasius niger on a glass surrounded with water, and so arranged that in reaching it the ants passed over another glass covered with a layer of sifted earth about one-third of an inch in thickness. I then put some ants to the honey, and by degrees a considerable number collected round it. Then at 1.30 P.M., I buried an ant from the same nest under the earth, and left her there till 5 P.M., when I uncovered her. She was none the worse, but during the whole time, not one of her friends had taken the least notice of her.

Again, September 1st, I arranged some honey in the same way. At 5 P.M. about fifty ants were at the honey, and a considerable number were passing to and fro. I then buried an ant as before, of course taking one from the same nest. At 7 P.M. the number of ants at the, honey had nearly doubled. At 10 P.M. they were still more numerous, and had carried off about two-thirds of the honey. At 7 A.M. the next morning the honey was all gone; two or three ants were still wandering about, but no notice had been taken of the prisoner, whom I then let out. In this case I allowed the honey to be finished, because I thought it might perhaps be alleged that the excitement produced by such a treasure distracted their attention; or even, on the principle of doing the greatest good to the greatest number, that they were intelligently wise in securing a treasure of food before they rescued their comrade, who, though in confinement, was neither in pain nor danger. 
So far as the above ants, however, are concerned, this cannot be urged. I may add that I repeated the same experiment several times, in some cases with another species, Myrmica mininodis, and always with the same results.

I then tried the following experiment. A number of the small yellow ants ( $L$. flavus) were out feeding on some honey. I took five of them, and also five others of the same species, but from a different nest, chloroformed them, and put them close to the honey, and on the path which the ants took in going to and from the nest, so that these could not but see them. The glass on which the honey was placed was surrounded by a moat of water. This, I thought, would give me an opportunity of testing both how far they would be disposed to assist a fellow-creature, and what difference they would make between their nest companions, and strangers from a different community of the same species. The chloroformed ants were put down at 10 in the morning. For more than an hour, though many ants came up and touched them with their antennæx, none did more. At length one of the strangers was picked up, carried to the edge of the glass, and quietly thrown, or rather dropped, into the water. Shortly afterwards a friend was taken up and treated in the same way. By degrees they were all picked up and thrown into the water. One of the strangers was, indeed, taken into the nest, but in about half an hour she was brought out again and thrown into the water like the rest. I repeated this experiment with fifty ants, half friends and half strangers. In each case twenty out of the twenty-five ants were thrown into the water as described. A few were left lying where they 
were placed, and these also, if we had watched longer, would no doubt have been also treated in the same way. One out of the twenty-five friends, and three out of the twenty-five strangers, were carried into the nest, but they were all brought out again, and thrown away like the rest. Under such circumstances, then, it seems that ants make no difference between friends and strangers.

It may, however, be said, as to this experiment, that since ants do not recover from chloroform, and these ants were therefore to all intents and purposes dead, we should not expect that much difference would be made between friends and strangers. I therefore tried the same experiment again, only, instead of chloroforming the ants, I made them intoxicated. This was rather more difficult. No ant would voluntarily degrade herself by getting drunk, and it was not easy in all cases to hit off the requisite degree of this compulsory intoxication. In all cases they were made quite drunk, so that they. lay helplessly on their backs. The sober ants seemed much puzzled at finding their friends in this helpless and discreditable condition. They took them up and carried them about for a while in a sort of aimless way; as if they did not know what to do with their drunkards, any more than we do. Ultimately, however, the results were as follows. The ants removed twenty-five friends and thirty strangers. Of the friends twenty were carried into the nest, where no doubt they slept off the effect of the spirit-at least we saw no more of themand five were thrown into the water. Of the strangers; on the contrary, twenty-four were thrown into the water; only six were taken into the nest, and four at least of these were afterwards brought out again and thrown away. 
The difference in the treatment of friends and strangers was therefore most marked. Dead ants, I may add, are always brought out of the nest, and I have more than once found a little heap on one spot, giving it all the appearance of a burial-ground.

Again I tried the following experiment. I took six ants from a nest of Formica fusca, and imprisoned them in a small bottle, one end of which was left open, but covered by a layer of muslin. I then put the bottle close to the door of the nest. The muslin was of open texture, the meshes, however, being sufficiently small to prevent the ants from escaping. They could not only, however, see one another, but communicate freely with their antennæ. We now watched to see whether the prisoners would be tended or fed by their friends. We could not, however, observe that the least notice was taken of them. The experiment, nevertheless, was less conclusive than could be wished, because they might have been fed at night, or at some time when we were not looking. It struck me, therefore, that it would be interesting to treat some strangers also in the same manner.

On Sept. 2, therefore, I put two ants from one of my nests of $F$. fusca into a bottle, the end of which was tied up with muslin as described, and laid it down close to the nest. In a second bottle I put two ants from another nest of the same species. The ants which were at liberty took no notice of the bottle containing their imprisoned friends. The strangers in the other bottle, on the contrary, excited them considerably. The whole day one, two, or more ants stood sentry, as it were, over the bottle, in a state of considerable excitement. 
By the evening, no less than twelve were collected round it, a larger number than usually came out of the nest at any one time. The whole of the next two days, in the same way, there were more or less ants round the bottle containing the strangers; while, as far as we could see, no notice whatever was taken of the fricnds. Eventually the ants succeeded in biting through the muslin and effecting an entrance, when they attacked the strangers. On the other hand, the friends were throughout quite neglected.

Sept. 21.-I then repeated the experiment, putting three ants from another nest in a bottle as before. The same scene was repeated. The friends were ncglected. On the other hand, some of the ants were always watching over the bottle containing the strangers, and biting at the muslin which protected them. The next morning, at 6 A.M., I found five ants thus occupied. One had caught hold of the leg of one of the strangers, which had unwarily been allowed to protrude through the meshes of the muslin. They worked and watched, though not, as far as I could see, upon any system, till 7.30 in the evening, when they effected an entrance, and inmediately attacked the strangers.

Sept. 24.-I repeated the same expcriment with the same nest. Again the ants came and sat over the bottle containing the strangers, while no notice was taken of the friends.

The next morning, again, when I got up, I found five ants round the bottle containing the strangers, none near the friends. As in the former case, one of the ants had seized a stranger by the leg, and was trying to drag her through the muslin. All day the ants clustered round 
the bottle, and bit perseveringly, though not systematically, at the muslin. The same thing happened also on the following day.

These observations seemed to me sufficiently to test the behaviour of the ants belonging to this nest, under these circumstances. I thought it desirable, however, to try also other communities. I selected, therefore, two other nests. One was a community of Polyergus rufescens with numerous slaves. Close to where the ants of this nest came to feed, I placed, as before, two small bottles closed in the same way-one containing two slave ants from the nest, the other two strangers. These ants, however, behaved quite unlike the preceding, for they took no notice of either bottle, and showed no sign either of affection or hatred. One is almost tempted to surmise that the warlike spirit of these ants was broken by slavery.

The other nest which I tried, also, a community of Formica fusca, behaved exactly like the first. They took no notice of the bottle containing the friends, but clustered round, and eventually forced their way into that containing the strangers.

It seems, therefore, that in these curious insects hatred is a stronger passion than affection.

Moreover, as regards the affection of bees for one another, it is no doubt true that when they have got any honey on them they are always licked clean by the others, but I am satisfied that this is more for the sake of the honey, than of the bee. I have, for instance, several times experimented with two bees; one of which had been drowned, while the other was smeared with honey. The latter was soon licked clean; of the 
former no notice whatever was taken. I have, moreover, repeatedly placed dead bees close to honey on which live ones were feeding, but the latter never took the slightest notice of the corpses.

It is clear from the experiments recorded in the present and in my last lecture, that ants recognise all their fellows in the same nest, but it is very difficult to understand how this can be effected. The nests vary very much in size, but in several species 100,000 individuals may probably be by no means an unusual number, and in some instances even this is largely exceeded. Now it seems almost incredible that in such nests every ant should know every other one by sight.

It has been suggested, in the case of bees, that each nest might have some sign or password.

The whole subject is full of difficulty. It occurred to me, however, that experiments with pupæ might throw some light upon it. Although the ants of different nests are generally deadly enemies, still, if larvæ or pupæ from one nest are transferred to another of the same species, they are kindly received, and tended with apparently as much care as if they really belonged to the nest. In ant warfare, though sex is no protection, the young are spared-at least when they belong to the same species. Moreover, though the habits and disposition of ants are greatly changed if they are taken away from their nest and kept in solitary confinement, or only with a few friends, still under such circumstances they will carefully tend any young which may be confided to them. Now, if the recognition were effected by means of some signal or password, then, as it can hardly be supposed that the larvæ or pupæ would be sufficiently 
intelligent to appreciate, still less to remember it, the pupæ which were entrusted to ants from another nest would have the password, if any, of that nest : and not of the one from which they had been taken. Hence, if the recognition were effected by some password, or sign with the antennæ, they would be amicably received in the nest from which their nurses had been taken, but not in their own. I therefore took a number of pupæ out of some of my nests of Formica fusca and Lasius niger, and put them in small glasses, some with ants from their own nest, some with ants from another nest of the same species. The result of my observations was that 32 ants belonging to Formica fusca and Lasius niger, removed from their nest as pupæ, attended by friends, and restored to their own nest, were all amicably received.

What is still more remarkable: of 22 ants belonging to Formica fusca, removed as pupæ, attended by strangers, and returned to their own nest, 20 were amicably received, though in several cases after some hesitation. As regards one, I was doubtful : this last was crippled in coming out of the pupa case, and to this perhaps her unfriendly reception may have been due. Of the same number of Lasius niger, developed in the same manner, from pupæ tended by strangers belonging to the same species, and then returned into their own nest, 17 were amicably received, three were attacked, and about two I felt doubtful.

On the other hand, 15 specimens, belonging to the same species, removed as pupæ, tended by strangers belonging to the same species, and then put into the strangers' nest, were all attacked. 
The results may be tabulated as follows:

Pupæ brought up by friends Pupæ brought up by strangers. and replaced in their own nest. Put in own nest. Put in strangers' nest. Attacked . . . 0 ( $7^{1}$ Received amicably $\quad 33 \quad 37$

I hope to make further experiments in this direction, but the above results seem very interesting. They appear to indicate that ants of the same nest do not recognise one another by any password. On the other hand, if ants are removed from a nest in the pupa state, tended by strangers, and then restored, some at least of their relatives are certainly puzzled, and, in many cases, doubt their claim to consanguinity. Strangers, under the same circumstances, would be immediately attacked ; these ants, on the contrary, were in most cases-sometimes, however, only after examination-amicably received by the majority of the colony, and it was often several hours before they came across a single individual who did not recognise them.

Most of our European ants feed on honey, or on other insects. Some few, however, store up grain.

A Texan ant, Pogonomyrmex barbatus, is also a harvesting species, storing up especially the grains of Aristida oligantha, the so-called "ant rice," and of a grass, Buchloe dactyloides. These ants clear disks, ten or twelve feet in diameter, round the entrance to their nest, a work of no small labour in the rich soil, and under the hot sun, of Texas. I say clear a disk, but some, though not all, of these disks are occupied, especially round the edge, by a growth of ant rice.

I About three of these I did not feel sure. 
Dr. Lincecum, who first gave an account of these insects, maintained not only that the ground was carefully cleared of all other plants, but that this grass was intentionally cultivated by the ants. Mr. McCook, by whom the subject has been recently studied, fully confirms Dr. Lincecum that the disks are kept carefully clean, that the ant rice alone is permitted to grow on them, and that the produce of this crop is carefully harvested; but he thinks that the ant rice sows itself, and is not actually planted by the ants.

Much of what has been said as to the powers of communication possessed by bees and ants depends on the fact that if one of them in the course of her rambles has discovered a supply of food, a number of others soon find their way to the store. This, however, does not necessarily imply any power of describing localities. If the bees or ants merely follow a more fortunate companion, or if they hunt her by scent, the matter is comparatively simple; if, on the contrary, the others have the route described to them, the case becomes very different. To determine this, therefore, I have made a great number of experiments, of which, however, I will here only mention a few. Under ordinary circumstances, if an ant discovers a stock of food, she carries as much as possible away to the nest, and then returns for more, accompanied generally by several friends. On their return these bring others, and in this way a string of ants is soon established. Unless, therefore, various precautions are taken, and this, so far as I know, has never been done in any previous observations, the experiment really tells very little.

The following may be taken as a type of what happens 
under such circumstances. On June 12, I put a Lasius niger, belonging to a nest which I had kept two or three days without food, to some honey. She fed as usual, and then was returning to the nest, when she met some friends, whom she proceeded to feed. When she had thus distributed her stores, she returned alone to the honey, none of the rest coming with her. When she had a second time laid in a stock of food, she again in the same way fed several ants on her way towards the nest; but this time five of those so fed returned with her to the honey. In due course these five would no doubt have brought others, and so the number at the honey would have increased.

Some species, however, act much more in association than others-Lasius niger, for instance, much more than Formica fusca. I have already given an illustration of what happens when a Lasius niger finds a store of food. The following is a great contrast. On the 28th March, I was staying at Arcachon. It was a beautiful and very warm spring day, and numerous ants were coursing about on the flagstones in front of our hotel.

At about 10.45 I put a Formica fusca to a raisin. She fed till 11.2, when she went almost straight to her nest, which was about 12 feet away. In a few minutes she came out again, and returned to the fruit, after a few small wanderings, at about 11.18. She then fed till 11.30, when she returned to the nest.

At 11.45 another ant accidentally found the fruit. I imprisoned her.

At 11.50 the first returned, and fed till 11.56, when she went off to the nest. On the way she met and talked with three ants, none of whom, however, came 
to the raisin. At 12.7 she returned, again alone, to the fruit.

On the following day I repeated the same experiment. There were perhaps even more ants about than on the previous day.

At 9.45 I put one (N 1) to a raisin.

9.55 I put another $(\mathrm{N} 2)$ to the raisin.

10.0 N 1 came back.

10.7

$10.11 \mathrm{~N} 2^{\prime \prime}$

$10.12 \mathrm{~N} 1$

10.13 put another (N 3) to the raisin.

$10.16 \mathrm{~N} 1$ back.

$10.22 \mathrm{~N} 2$

\section{(N 2 met with}

(N 2 met with an accident and returned no more.) [nest. $10.24 \mathrm{~N} 1$ back. $10.30 \mathrm{~N} 1$, $10.33 \mathrm{~N} 3$, $10.35 \mathrm{~N} 1 \%$ (She met with an accident. At first she seemed a good deal hurt, but gradually recovered.)

$10.40 \mathrm{~N} 3$ back.

At 10.46 she went to

10.46 a stranger came; I imprisoned her.

10.47

$10.52 \mathrm{~N} 1$ back.

10.57 N 3 ,

11.8 N 3 ,

11.10 a stranger came ; I removed her to a little distance.
11.11

$11.16 \mathrm{~N} 3$ back.

$11.23 \mathrm{~N} 4$

$11.24 \mathrm{~N} 3$,

$11.27 \mathrm{~N} 4$,

$11.31 \mathrm{~N} 3$,

$11.32 \mathrm{~N} 4$,

$11.40 \mathrm{~N} 3$ came.

$11.40 \mathrm{~N} 4$,

$11.45 \mathrm{~N} 3$ ",

11.45 a stranger came.
At 9.50 she went to the nest.

$10.0 \quad "$,
$10.2 \quad "$
$10.9 \quad "$
$10.13 \quad "$
$10.14 \quad "$
$10.18 \quad "$
$10.17 \quad "$
$10.24 \quad "$

At 10.26 went to the

10.32

10.32 ,

10.35

[the nest.

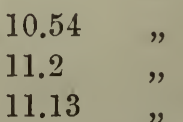
marked her $\mathrm{N} 4$.

At 11.18 went.

11.25 ,

11.26 ,

11.29 "

11.34 ,

11.35 "

11.42

11.42,

11.47, 


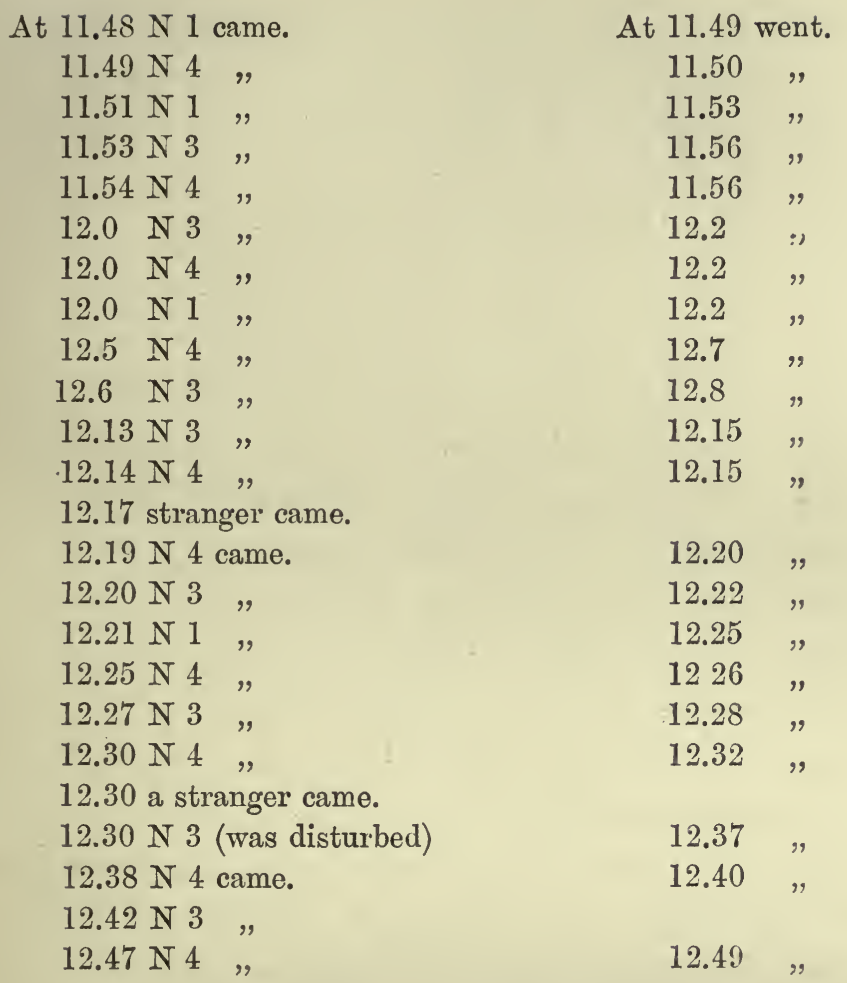

Thus, during these three hours only six strangers came. The raisin must have seemed almost inexhaustible, and the watched ants in passing and repassing went close to many of their friends; these took no notice of them, however, and did not bring any out of the nest to co-operate with them in securing the food, though their regular visits showed how much they appreciated it.

Again (on the 15th July) an ant belonging to one of my nests of Formica fusca was out hunting. At 8.8, I put a spoonful of honey before her. She fed till 8.24, when she returned to the nest. Several others were

S. E. 
running about. She returned regularly at short intervals, but during the whole day she brought no friend, and only one other ant found the honey, evidently an independent discovery.

The species of Lasius, as already mentioned, behave very differently. To determine, if possible, whether they can send, as well as bring, their friends to stores of food, I made a number of experiments. For instance, one of my nests of the small brown garden ant, Lasius niger, was connected with a board, on which I was in the habit of placing a supply of food and water. At a short distance from the board I placed two glasses $\left(b b^{\prime}\right)$, and on $b$ I placed some food. I then connected the glass $b$ with the board $a$ by three slips of paper, $c, d, e$, and put an ant to the food. She carried off a supply to the nest, returning for more, and so on. Several friends came with her, and I imprisoned them till the experiment was over. When she had passed several times over the paper bridges, I proceeded as follows. Any friends who came with her were excluded from the bridges when she was on them. If she was not there, as soon as a friend arrived at the bridge $c$, I took up the paper $e$ in my fingers and rubbed it lightly, with a view of removing or blurring the scent; and as soon as the ant arrived on $d$, I took up the bridge $c$, and put it across the chasm from $d$ to $b^{\prime}$. Now, if the ant acted on information received, she would of cnurse cross $e$ to $b$. If, on the other hand, she went by scent, then she would be at least as likely to go over $c$ to $b^{\prime}$. The result was, that out of about one hundred and twenty friends who passed over $d$, only twenty went to the food; while nearly one hundred passed over $c$ to the empty 
glass. In this case, the friends generally came more or less in sight of one another to the bridge $c$, and once there, could hardly avoid arriving either at $b$ or $b^{\prime}$. I therefore modified the experiment as follows. I established and endowed an ant as before, imprisoning the friends who came with her. When she knew her way thoroughly, I allowed her to return to the nest on her own legs, but as soon as she emerged again I took her up on a slip of paper, and transferred her to the food.

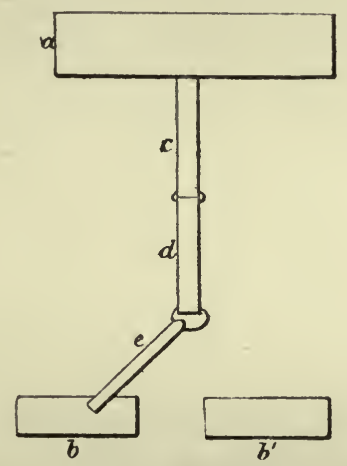

FIG. 46.

Under these circumstances, as will be seen, very few ants indeed ever found their way to the food. I began at 5.30, at which time the ant returned to the nest. At 5.34 she came out with no less than ten friends, and was then transferred to the food. The others wandered about a little, but by degrees returned to the nest, not one of them finding her way to the food. The first ant took some food, returned, and again came out of the nest at 5.39 with eight friends, when exactly the same happened. She again came out 
At 5.44 with 4 friends.

\begin{tabular}{|c|c|c|}
\hline , 5.47 & , & 4 \\
\hline , 5.49 & " & 1 \\
\hline , 5.52 & & \\
\hline , 5.54 & , & 5 \\
\hline „5.58 & , & 2 \\
\hline , 5.59 & , & 2 \\
\hline 6.1 & , & 5 \\
\hline, 6.4 & " & 1 \\
\hline 6.7 & & \\
\hline, 6.11 & , & 3 \\
\hline , 6.14 & 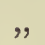 & 4 \\
\hline, 6.17 &, & 6 \\
\hline , 6.20 & & \\
\hline , 6.23 & , & 5 \\
\hline, 6.25 & " & 6 \\
\hline , 6.29 & " & 8 \\
\hline , 6.32 & $"$ & 2 \\
\hline 6.35 & & \\
\hline 6.42 & " & 4 \\
\hline
\end{tabular}

At 6.44 with 0 friends.

\begin{tabular}{|c|c|c|c|}
\hline & & & \\
\hline & $"$ & 0 & " \\
\hline 6.49 & $"$ & 2 & ", \\
\hline , 6.56 & & & \\
\hline , 6.59 & & & \\
\hline, 7.2 & $"$ & 2 & $"$ \\
\hline " 7.4 & & & \\
\hline, 7.6 & $"$ & 3 & , \\
\hline, 7.8 & $"$, & 3 & ", \\
\hline , 7.10 & $"$ & 5 & , \\
\hline " 7.13 & & & \\
\hline ,, 7.17 & $"$ & 3 & " \\
\hline ,, 7.19 & , & 7 & , \\
\hline , 7.21 & $"$ & 5 & , \\
\hline, 7.24 & & & \\
\hline, 7.26 & $"$ & 3 & , \\
\hline, 7.29 & $"$ & 1 & , \\
\hline " 7.31 &, & 2 & " \\
\hline , 7.35 & & & \\
\hline
\end{tabular}

(39 journeys ; 11 alone, 28 with 120 friends.)

Thus, during these two hours, more than one hundred and twenty ants came out of the nest, in company with the one under observation. She knew her way perfectly, and it is clear that if she had been let alone, all these ants would have accompanied her to the store of food. Three of them were accidentally allowed to do so, but of the remainder only five found their way to the food; all the others, after wandering about a while, returned empty-handed to the nest.

I conclude, then, that when large numbers of ants come to food they follow one another, being also to a certain extent guided by scent. The fact, therefore, does not imply any considerable power of intercommunication. There are, moreover, some circumstances which 
seem to point in an opposite direction. For instance, I have already mentioned that if a colony of Polyergus changes the situation of its nest, the masters are all carried to the new nest by the slaves. Again, if a number of $F$. fusca are put in a box, and if in one corner a dark place of retreat be provided for them, with some earth, one soon finds her way to it. She then comes out again, and going up to one of the others, takes her by the jaws. The second ant then rolls herself into a heap, and is carried off to the place of shelter. They then both repeat the same manœuvre with other ants, and so on until all their companions are collected together. Now it seems to me difficult to imagine that so slow a course would be adopted, if they possessed any power of communicating description.

On the other hand, they certainly can, I think, transmit simpler ideas. In support of this I may adduce the following experiment. Two strips of paper were attached to the board just mentioned (p. 114), parallel to one another; and at the other end of each I placed a piece of glass. In the glass, at the end of one tape, I placed a considerable number (three to six hundred) of larvæ. In the second I put two or three larvæ only. I then took two ants, and placed one of them to the glass with many larvæ, the other to that with two or three. Each of them took a larva and carried it to the nest, returning for another, and so on. After each journey I put another larva in the glass with only two or three larvæ, to replace that which had been removed. Now, if other ants came, under the above circumstances, as a mere matter of accident, or accompanying one another by chance, or if they simply saw the larvæ which were being brought, 
and consequently concluded that they might themselves also find larvæ in the same place, then the numbers going to the two glasses ought to be approximately equal. In each case the number of journeys made by the ants would be nearly the same; consequently, if it were a matter of smell, the two routes would be in the same condition. It would be impossible for an ant. seeing another in the act of bringing a larva, to judge for herself whether there were few or many larvæ left behind. On the other hand, if the strangers were brought, then it would be curious to see whether more were brought to the glass with many larvæ than to that which only contained two or three. I should mention that every stranger was imprisoned, until the end of the experiment. I select a few of the results :-

Exp. 1. Time occupied, one hour. The ant with few larvæ made 6 visits, and brought no friends. The one with many larvæ made 7 , and brought 11 friends.

Exp. 3. 'lime occupied, three hours. The ant with few larvæ made 24 journeys, and brought 5 friends. The one with many larvæ made 38 journeys, and brought 22 friends.

Exp. 5. Time occupied, one hour. The ant with few larvæ made 10 journeys, and brought 3 friends. The other made 5 journeys, and brought 16 friends.

Exp. 9. Time occupied, one hour. The ant with few larvæ made 11 journeys, and brought 1 friend. The one with many larvæ made 15 journeys, anci brought 13 friends.

Exp. 10. I now reversed the glasses, the same two ants being under observation; but the ant which in the previous observation had few larvæ to carry off now 
consequently had many, and vice versî. Time occupied, two hours. The ant with few larvæ made 21 journeys, and brought 1 friend. The one with many larvæ made 22 journeys, and brought 20 friends. These two experiments are, I think, especially striking.

Taken as a whole, I found that in about fifty hours, the ants which had access to many larvæ brought 257 friends, while those visiting the glass with few larvæ only brought 82 . This result will appear still more striking, if we remember that a certain number, say perhaps 25, would have come to the larvæ anyhow, which would make the numbers 232 , as against 57 ; a very large difference.

Experiments with bees and wasps have led me to very similar results. As regards wasps, a typical case has been already given (ante p. 10). In the case of bees, I have generally found that when they first discover a treasure of food, they bring a few friends with them, who in their turn are accompanied by others; and so on. If, bowever, for the first few hours of the experiment, the friends thus brought are driven away or imprisoned, other bees soon cease to come. ${ }^{1}$ For instance, one bee which I watched for five days during this period only brought half a dozen friends. In my first experiments, however; the quantity of honey used was but small; I thought, therefore, that it would be well to repeat them with a larger quantity. Accordingly, on the 19th July, I put a bee (No. 10) to a honeycomb containing twelve $12 \mathrm{lbs}$. of honey

$1 \mathrm{My}$ experiments were made at an upper window. If they had been made at a lower level the results might have been different. 


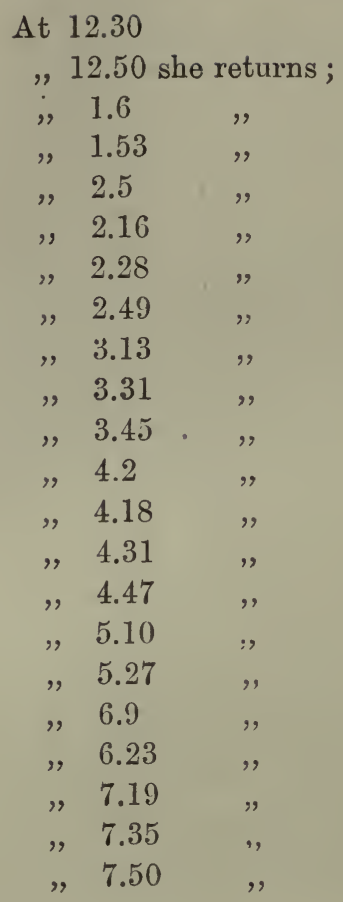

At 12.36 she went back to the hive.

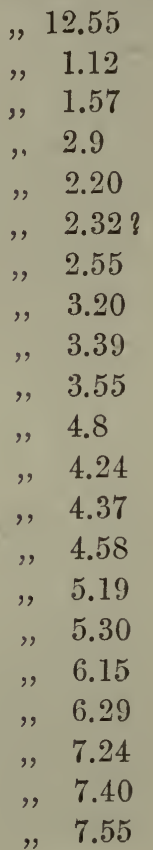

\begin{tabular}{|c|c|}
\hline$"$ & $"$ \\
\hline ", & ", \\
\hline$"$ & " \\
\hline "' & $"$ \\
\hline$"$ & ", \\
\hline$"$ & ", \\
\hline ", & ", \\
\hline$"$ & , \\
\hline " & , \\
\hline$"$ & $"$ \\
\hline ", & " \\
\hline$"$ & $"$ \\
\hline$"$ & $"$ \\
\hline :" & , \\
\hline ", & " \\
\hline ", & ", \\
\hline " & , \\
\hline ", & " \\
\hline , & ", \\
\hline$"$ & " \\
\hline " & $"$ \\
\hline
\end{tabular}

And during all this time no other bee came to the comb.

On the following morning, July 20th, this bee (No. 10) came to the honeycomb at 6 in the morning, and we watched her till 2 P.M. ; but during the whole of this time no other bee had come to the comb.

Bees seem also to be less clever in finding their way about than might have been expected. In some cases, indeed, flies are more intelligent. Thus, I put a bee into a bell glass 18 inches long and a mouth $6 \frac{1}{2}$ inches wide, turning the closed end to the window; she buzzed about till 11.15, when, as there seemed no chance of her getting out, I put her back into the hive. Two flies, on the contrary, which I put in with her, got out at once. At 11.30 I put another bee and a fly into the same glass ; 
the latter flew out at once. For half an hour, the bee tried to get out at the closed end; I then turned the glass with its open end to the light, when she flew out at once. To make sure, I repeated the experiment once more, with the same result.

Some bees, however, have seemed to me more intelligent in this respect than others. A bee which I had fed several times and which had flown about in the room, found its way out of the glass in a quarter of an hour, and when put in a second time, came out at once. Another bee, when I closed the postern door, used to come round to the honey through an open window.

In the previous lecture, I have mentioned that I was never able to satisfy myself that ants heard any sounds which I could produce. I would not however by any means infer from this that they are incapable of hearing.

Micromegas indeed concluded that ashe heard no sound, men did not speak; indeed, he asks how is it possible that such infinitesimal atoms should have organs of voice? and what could they have to say? Moreover, he continues, to speak it is necessary to think, or nearly so : now, to think requires a mind, and to attribute a mind to these little creatures would be absurd. We must be careful not to fall into a similar series of errors.

It is far from improbable that ants may produce sounds entirely beyond our range of hearing. Indeed, it is not impossible that insects may possess a sense, or rather perhaps sensations, of which we can no more form an idea, than we should have been able to conceive red or green, if the human race had been blind. Helmholtz and Depretz have shown that the human ear is sensitive 
to vibrations reaching to 38,000 in a second. The sensation of red is produced when 470 millions of millions of vibrations of ether enter the eye in a similar time; but between 38,000 and 470 millions of millions, vibrations produce on us the sensation of heat only. We have no special organs of sense adapted to them, but there is no reason in the nature of things why this should be the case with other animals, and the problematical organs possessed by many of the lower forms favour the suggestion. If any apparatus could be devised by which the number of vibrations produced by any given cause could be lowered so as to be brought within the range of our ears it is probable that the result would be most interesting.

I have tried unsuccessfully various experiments in order to ascertain whether the ants themselves produced any sounds for the purpose of conveying signs or ideas. Prof. Tyndall was so good as to arrange for me one of his sensitive flames, but 1 could not perceive that it responded in any way to my ants. 'The experiment was not, however, very satisfactory, as I was not able to try the flame with a very active nest. Prof. Bell was also kind enough to set up for me an extremely sensitive microphone : it was attached to the underside of one of my nests, and though we could distinctly hear the ants walking about, we could not distinguish any other sound.

It is however of course possible, as I have already suggested, that ants may be sensitive to, and also themselves produce, sounds which from the rapidity. of their vibrations, or some other cause, are beyond our range of hearing. Having failed therefore in hearing them or 
making them hear me, I endeavoured to ascertain whether they could hear one another.

To ascertain if possible whether ants have the power of summoning one another by sound, I tried the following experiments. I put out on the board where one of my nests of Lasius flavus was usually fed, six small pillars of wood about an inch and a-half high, and on one of them I put some honey. A number of ants were wandering about on the board itself in search of food, and the nest itself was immediately above, and about 12 inches from the board. I then put three ants to the honey, and when each had sufficiently fed I imprisoned her and put another; thus always keeping three ants at the honey, but not allowing them to go home. If then they could summon their friends by sound, there ought soon to be many ants at the honey. The results were as follows :-

September 8th.-Began at 11 A.M. Up to 3 o'clock only seven ants found their way to the honey, while about as many ran up the other pilliars. The arrival of these seven, therefore, was not more than would naturally result from the numbers running about close by. At 3, I allowed the ants then on the honey to return home. The result was that from 3.6, when the first went home, to 3.30 , eleven came; from 3.30 to 4 , no less than forty-three. Thus in four hours only seven came, while it was obvious that many would have wished to come if they had known about the honey, because in the next three-quarters of an hour, when they were informed of it, fifty-four came.

On the 10th September I tried the same again, keeping as before three ants on the honey, but not allowing 
any to go home. From 12 to 5.30, only eight came. They were then allowed to take the news. From 5.30 to 6 , four came ; from 6 to 6.30 , four ; from 6.30 to 7 , eight; from 7.30 to 8 , no less than fifty-one.

Again, on September 30th, I tried the same arrangement, again beginning at 11 . Up to 3.30 , seven ants came. We then let them go. From 3.30 to 4.30, twenty-eight came. From 4.30 to 5, fifty-one came. Thus in four hours and a-balf only seven came; while when they were allowed to return, no less than seventynine came in an hour and a-half. It seems obvious therefore that in these cases no communication was transmitted by sound.

In order further to test how far ants are guided by sight and how much by scent, I tried the following experiment with Lasius niger. Some food was put out at

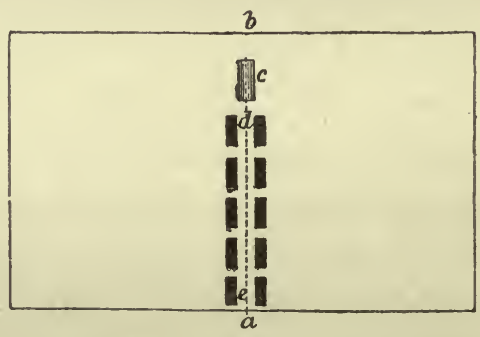

Fig. 47 .

the point $a$ on a board measuring 20 inches by 12 (Fig. 47 ), and so arranged that the ants in going straight to it from the nest would reach the board at the point $b$, and after passing under a paper tunnel, $c$, would proceed between five pairs of wooden bricks, each three inches in length and $1^{\frac{3}{4}}$ in height. When they got to know their 
way, they went quite straight along the line $d e$ to $a$. The board was then twisted as shown in Fig. 48. The

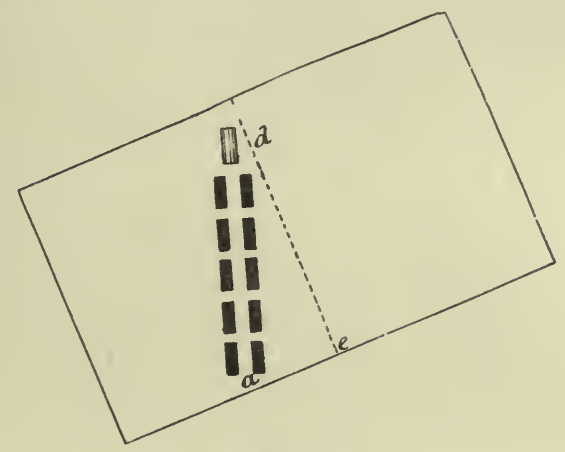

FIG. 48.

bricks and tunnel being arranged exactly in the same direction as before, but the board having been moved, the line $d e$ was now outside them. This change, however, did not at all discompose the ants; but instead of going, as before, through the tunnel and between the

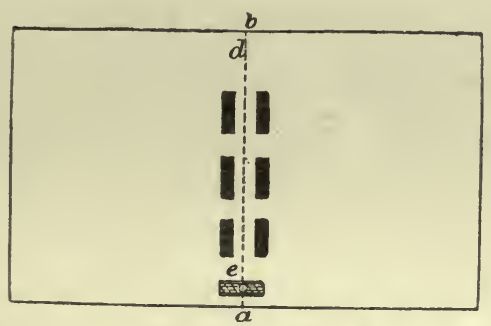

FIG. 49.

rows of bricks to $a$, they walked exactly along the old path to $e$.

I then arranged matters as before, but without the tunnel and with only three pairs. of bricks (Fig. 49). When an ant had got quite used to the path $d$ to $e, I$ 
altered the position of the bricks and food to $f$ (Fig. 50), making a difference of 8 inches in the position of the

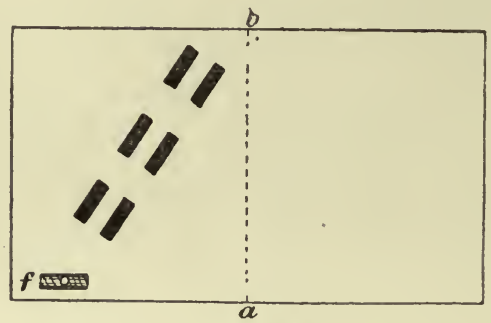

FIG. 50.

latter. The ant came as before, walked up to the first brick, touched it with her antennæ, but then followed her old line to $a$. From there she veered towards the food, and very soon found it. When she was gone, I altered it again, as shown in Fig. 51 ; she returned after the usual

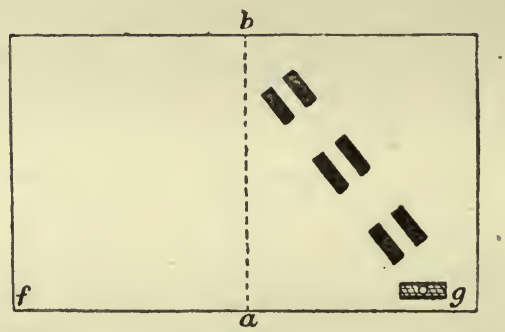

FIg. 51.

interval, and went again straight to $\alpha$; then, after some wanderings, to $f$, and at length, but only after a lapse of 25 minutes, found the food at $g$. These experiments were repeated more than once, and always with similar results. I then varied matters by removing the bricks; this, however, did not seem to make any difference to the ants.

From the observations of Sprengel, there could of 
course be little, if any, doubt, that Bees are capable of distinguishing colors; but I have in my previous papers, read before the Linnean Society, recorded some experiments which put the matter beyond a doubt. Under these circumstances, I have been naturally anxious to ascertain, if possible, whether the same is the case with ants. I have, however, found more difficulty in doing so, because, as shown in the observations just recorded, ants find their food so much more by smell than by sight.

I tried, for instance, placing food at the bottom of a pillar of colored paper, and then moving both the pillar and the food. The pillar, however, did not seem to help the ant (Lasius niger) at all to find her way to the food. I then, as recorded in my previous paper, placed the food on the top of a rod of wood 8 inches high, and when the ant knew her way perfectly well to the food, so that she went quite straight backwards and forwards to the nest, I found that if I moved the pillar of wood only 6 inches, the ant was quite bewildered, and wandered about backwards and forwards, round and round, and at last only found the pillar, as it were, accidentally.

Therefore, I could not apply to ants those tests which had been used in the case of bees. At length, however, it occurred to me that I might utilize the dislike which ants, when in their nests, have to light. Of course they have no such feeling when they are out in search of food; but if light be let in upon their nests, they at once hurry about in search of the darkest corners, and there they all congregate. If, for instance, I uncovered one of my nests and then placed an opaque 
substance over one portion, the ants invariably collected in the shaded part.

I therefore procured four similar strips of glass, colored respectively green, yellow, red, and blue, or rather, violet. The yellow was rather paler in shade, and that glass consequently rather more transparent than the red or violet. I then laid the strips of glass on one of my nests of Formica fusca, containing about 170 ants. These ants, as I knew by many previous observations, seek darkness, and would certainly collect under any opaque substance.

I then, after counting the ants under each strip, moved the colors gradually at intervals of about half an hour, so that each should by turns cover the same portion of the nest. The results were as follows-the numbers indicating the approximate number of ants under each glass (there were sometimes a few not under any of the strips of glass) :-

\begin{tabular}{|c|c|c|c|c|c|}
\hline & . & $\begin{array}{c}\text { Green. } \\
50\end{array}$ & $\begin{array}{c}\text { Yellow. } \\
40\end{array}$ & $\begin{array}{c}\text { Red. } \\
80\end{array}$ & $\begin{array}{c}\text { Violet. } \\
0\end{array}$ \\
\hline & . & $\begin{array}{c}\text { Violet. } \\
0\end{array}$ & $\begin{array}{c}\text { Green. } \\
20\end{array}$ & $\begin{array}{c}\text { Yellow. } \\
40\end{array}$ & $\begin{array}{l}\text { Red. } \\
100\end{array}$ \\
\hline & . & $\begin{array}{c}\text { Red. } \\
60\end{array}$ & $\begin{array}{c}\text { Violet. } \\
0\end{array}$ & $\begin{array}{c}\text { Green. } \\
50\end{array}$ & $\begin{array}{c}\text { Yellow. } \\
50\end{array}$ \\
\hline & . & $\begin{array}{c}\text { Yellow. } \\
50\end{array}$ & $\begin{array}{c}\text { Red. } \\
70\end{array}$ & $\begin{array}{c}\text { Violet. } \\
1\end{array}$ & $\begin{array}{c}\text { Green. } \\
40\end{array}$ \\
\hline & . & $\begin{array}{c}\text { Green. } \\
30\end{array}$ & $\begin{array}{c}\text { Yellow. } \\
30\end{array}$ & $\begin{array}{l}\text { Red. } \\
100\end{array}$ & $\begin{array}{c}\text { Violet. } \\
0\end{array}$ \\
\hline & . & $\begin{array}{c}\text { Violet. } \\
0\end{array}$ & $\begin{array}{c}\text { Green. } \\
14\end{array}$ & $\begin{array}{c}\text { Yellow. } \\
5\end{array}$ & $\begin{array}{l}\text { Red. } \\
140\end{array}$ \\
\hline & . & $\begin{array}{c}\text { Red. } \\
50\end{array}$ & $\begin{array}{c}\text { Violet. } \\
0\end{array}$ & $\begin{array}{c}\text { Green. } \\
40\end{array}$ & $\begin{array}{c}\text { Yellow. } \\
70\end{array}$ \\
\hline & . & $\begin{array}{c}\text { Yellow. } \\
40\end{array}$ & $\begin{array}{c}\text { Red. } \\
50\end{array}$ & $\begin{array}{c}\text { Violet. } \\
1\end{array}$ & $\begin{array}{c}\text { Green. } \\
70\end{array}$ \\
\hline & - & $\begin{array}{c}\text { Green } \\
60\end{array}$ & $\begin{array}{c}\text { Yellow. } \\
35\end{array}$ & $\begin{array}{c}\text { Red. } \\
65\end{array}$ & $\begin{array}{c}\text { Violet. } \\
0\end{array}$ \\
\hline
\end{tabular}




\begin{tabular}{|c|c|c|c|c|c|c|}
\hline 10 & . & • & $\begin{array}{c}\text { Violet. } \\
1\end{array}$ & $\begin{array}{c}\text { Green. } \\
50\end{array}$ & $\begin{array}{c}\text { Yellow. } \\
40\end{array}$ & $\begin{array}{c}\text { Red. } \\
70\end{array}$ \\
\hline 11 & . & . & $\begin{array}{c}\text { Red. } \\
50\end{array}$ & $\begin{array}{c}\text { Violet. } \\
2\end{array}$ & $\begin{array}{c}\text { Green. } \\
50\end{array}$ & $\begin{array}{c}\text { Yellow. } \\
60\end{array}$ \\
\hline 0 & . & 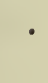 & $\begin{array}{c}\text { Yellow. } \\
35\end{array}$ & $\begin{array}{l}\text { Red. } \\
55\end{array}$ & $\begin{array}{c}\text { Violet. } \\
0\end{array}$ & $\begin{array}{c}\text { Green. } \\
70\end{array}$ \\
\hline
\end{tabular}

Adding these numbers together, there were, in the twelve observations, under the red 890 , under the green 544 , under the yellow 495, and under the violet only 5 . The difference between the red and the green is very striking, and would doubtless have been more so, but for the fact, that when the colors were transposed, the ants which had collected under the red sometimes remained quiet, as, for instance, in cases 7 and 8.

The case of the violet glass is more marked and more interesting. To our eyes, the violet was as opaque as the red, more so than the green, and much more so than the yellow. Yet, as the numbers show, the ants had scarcely any tendency to congregate under it. There were nearly as many under the same area of the uncovered portion of the nest as under that shaded by the violet glass.

Lasius flavus also showed a marked avoidance of the violet glass.

I then experimented in the same way with a nest of Formica fusca, in which there were some pupæ, which were generally collected in a single heap. I used glasses colored dark yellow, dark green, light yellow, light green, red, violet, and dark purple. The colors were always in the preceding order, but, as before, their place over the nest was changed after every observation.

To our eyes, the purple was almost black, the violet and dark green very dark and quite opaque; the pupæ 
could be dimly seen through the red, rather more clearly through the dark yellow and light green, while the light yellow were almost transparent. There were about 50 pupæ, and the light was the ordinary diffused daylight of summer.

These observations showed a marked preference for the greens and yellows. The pupæ were $6 \frac{1}{2}$ times under dark green, 3 under dark yellow, $3 \frac{1}{2}$ under red, and once each under light yellow and light green, the violet and purple being altogether neglected.

I now tried the same ants under the same colors, only in the sun; and placed a shallow dish containing some 10 per cent. solution of alum, sometimes over the yellow, sometimes over the red. I also put four thicknesses of violet glass, so that it looked almost black.

Under these circumstances, the pupæ were placed under the red $7 \frac{1}{2}$ times, dark yellow $5 \frac{1}{2}$, and never under the violet, purple, light yellow, dark or light green.

The following day I placed, over the same nest, in the sun, dark green glass, dark red and dark yellow (two layers of each). In nine observations, the pupæ were carried 3 times under the red, and 9 times under the yellow glass.

I then put two ants on a paper bridge, the ends supported by pins, the bases of which were in water. The ants wandered backwards and forwards, endeavouring to escape. I then placed the bridge in the dark, and threw the spectrum on it, so that successively the red, yellow, green, blue, and violet rays fell on the bridge.

The ants, however, walked backwards and forwards, without (perhaps from excitement) taking any notice of the color. 
I then allowed some ants (Lasius niger) to find some larvæ, to which they obtained access over a narrow paper bridge. When they had got used to it, I arranged so that it passed through a dark box, and threw on it the principal colors of the spectrum, namely, red, yellow, green, blue, and violet, as well as the ultra-red and ultraviolet; but the ants took no notice.

At the suggestion of Prof. Stokes, I then tried the following experiments. Mr. Spottiswoode not only most kindly placed the rich resources of his laboratory at my disposal, but he and his able assistant Mr. WVard were good enough to arrange the apparatus for me.

We tried the ants (Formica cineren, Lasius niger, and Myrmica ruginodis) with colored lights in a Bunsen's burner, using chloride of strontium and carbonate of lithia for red, chloride of barium for green, and chloride of sodium for yellow. The lithium gives an almost pure red, the strontium and barium give a little yellow, but so little that I do not think it would affect the ants.

The yellow of the soda-flame certainly affected the Formica cinerea, but the others seemed to take no notice of it.

The barium also affected the $F$. cinerea, but neither of the others; I could not feel sure whether it was the green or the accompanying yellow which disturbed them. The red of the lithium was not so brilliant, still the $F$. cinerea seemed to perceive it.

The strontium-flame did not seem to have any effect on the ants.

It is obvious that these facts suggest a number of interesting inferences. I must, however, repeat the observations, and make others; but we may at least, I 
think, conclude from the preceding that-(1) ants have the power of distinguishing color; (2) that they are very sensitive to violet; and it would also seem (3) that their sensations of color must be very different from those produced upon us.

When I began keeping ants, I surrounded the nests by moats of water. This acted well, but the water required to be continually renewed, especially, of course, in summer, just when the ants were most active. At length, in considering the habits of ants and their relations to flowers, another plan suggested itself to me. The hairs by which plants are clothed fulfil various functions; one is, I believe, to prevent ants and other creeping insects from obtaining access to the flowers, and thus robbing them of their honey.

It occurred to me, therefore, that instead of water, I might use fur, with the hairs pointing downwards. This I have found to answer perfectly, and I mention it because the same arrangement may perhaps be found practically useful in hot climates. It is very possible, of course, that tropical species of ants might be able to climb up the fur; but at any rate the experiment would be worth trying.

I never succeeded in keeping a bee long under observation. On the other hand, I once kept a wasp ( $P$. gallica) for more than nine months. I took her, with her nest, in the Pyrenees, early in May. The nest consisted of about 20 cells, the majority of which contained an egg; but as yet no grubs had been hatched out, and, of course, my wasp was as yet alone in the world. I had no difficulty in inducing her to feed on my hand; but at first she was shy and nervous. She kept her sting in 
constant readiness, and once or twice in the train, when the officials came for tickets, and I was compelled to hurry her back into the bottle in which she lived, she stung me slightly-I think, however, entirely from fright. Gradually she became quite used to me, and when I took her on my hand apparently expected to be fed. She even allowed me to stroke her without any appearance of fear, and for some months I never saw her sting.

When the cold weather came on, she fell in a drowsy state, and I began to hope she would hibernate and survive the winter. I kept her in a dark place, but watched her carefully, and fed her if ever she seemed at all rest]ess. She came out occasionally, and seemed as well as usual till near the end of February, when one day I observed she had nearly lost the use of her antennæ, though the rest of the body was as usual. She would take no food. Next day I tried again to feed her; but the head scemed dead, though she could still move her legs, wings, and abdomen. The following day I offered her food for the last time; but both head and thorax were dead or paralysed; she could but wag her tail ; a last token, as I could almost fancy, of gratitude and affection. As far as I could judge, her death was quite painless, and she now occupies a place in the British Museum.

As already mentioned, there are certain species of ants in which there are two distinct kinds of workers, doubtless with different functions. But even when all the workers are of one form, it is possible that there is some division of labor. Thus in the autumn of 1875 , I noticed an ant belonging to one of my nests of $F$. fusca, out feeding alone. The next day the same 
ant was again out by herself, and for some weeks no other ant, so far as I observed, came out to the food. I did not, however, watch her with sufficient regularity. Last winter, therefore, I kept two nests under close observation, having arranged with my daughters and their governess, Miss Wendland (most conscientious observers), that one of us should look at them once an hour during the day. One of the nests contained about 200 individuals, the other, a nest of $P$.rufescens, with the usual slaves, about 400 . The mistresses themselves never come out for food, leaving all this to the slaves.

We began watching on the 1st November, but did not keep an hourly register till the 20 th, after which date the results up to the 24 th February are given in tables which have been published in the Linnean Journal. The first relates to a nest of $F$. fusca, and the ants are denoted by numbers. An ant marked in my register as No. 3, was at this time acting as feeder to the community. From the time we began to watch, no other ant came to the honey till the 22nd November, when another ant came out, whom we registered as No. 4: while another on the 28th November was registered as No. 6. These ants were subsequently assisted by five or six others, and in the three months during which the nest was under observation, the supplies for the community were carried in by these few ants.

The second set of observations were made on a nest of Polyergus and $F$. fusca. The feeders in this case were, at the beginning of the experiment, those known to us as Nos. 5, 6, and 7. On the 22nd November, a friend, registered as No. 8, came to the honey, and 
again on the 11th December, but with these two exceptions, the whole of the supplies were carried in by Nos. 5 and 6 , with a little help from No. 7.

Thinking now it might be alleged that possibly these were merely unusually active and greedy individuals, I imprisoned No. 6, when she came out to feed on the 5th. As will be seen from the table, no other ant had been out to the honey for some days; and it could therefore hardly be accidental that on that very evening another ant (then registered as No. 9) came out for food. This ant then took the place of No. 6, and (No. 5 being imprisoned on the 11th January) took in all the supplies, again with a little help from No. 7. So matters continued till the 17 th, when I imprisoned No. 9, and then again, i.e. on the 19th, another ant (No. 10) came out for the food, aided on and after the 22nd by another, No. 11. This seems to me very curious. From the 1st November to the 5th January, with two or three casual exceptions, the whole of the supplies were carried in by three ants, one of whom, however, did comparatively little. The other two were imprisoned, and then, but not till then, a fresh ant appeared on the scene. She carried in the food for a week, and then, she being imprisoned, two others undertook the task. On the other hand, in Nest 1, where the first foragers were not imprisoned, they continued during the whole time to carry the necessary supplies. The facts therefore certainly seem to indicate that certain ants are told off as foragers, and that during winter, when but little food is required, two or three are sufficient to provide it.

I have already mentioned that while Lasius niger, the 
brown garden-ant, habitually makes use of the outof-door Aphides, the yellow meadow-ant keeps the underground kinds. M. Lespés even considered some communities of $L$. niger to be more advanced in civilisation than others of the same species. He assures us that if he took specimens of their domestic beetles from one nest, and placed them in another, always, be it understood, of the same species, the beetles were attacked and eaten. I have not had the opportunity of repeating these experiments, but I have moved specimens of the blind woodlouse, Platyarthrus, from one nest to another, and even from nests of one species to those of another, and they were always amicably received. But whether there are differences in advancement within the limits of the same species or not, there are certainly considerable differences between the different species, and one may almost fancy that we can trace stages, corresponding to the principal steps in the history of human development.

I do not now refer to slave-making ants, which represent an abnormal, or perhaps only temporary, state of things, for slavery seems to lead in ants; as in men, to the degradation of those by whom it is adopted; and it is not impossible that the slave-making species will eventually find themselves unable to compete with those which are more self-dependent, and have reached a higher phase of civilisation. But, putting these slavemaking ants on one side, we find in the different species of ants different conditions of life, curiously answering to the earlier stages of human progress. For instance, some species, such as Formica fusca, live principally on the produce of the chase; for though they feed partly on the honey-dew of Aphides, they have not 
domesticated their insects. These ants probably retain the habits once common to all ants. They resemble the lower races of men, who subsist mainly by hunting. Like them, they frequent woods and wilds, live in comparatively small communities, and the instincts of collective action are but little developed among them. They hunt singly, and their battles are single combats, like those of Homeric heroes. Such species as Lasius flavus represent a distinctly higher type of social life; they show more skill in architecture, may literally be said to have domesticated certain species of Aphides, and may be compared to the pastoral stage of human progress - to the races which live on the produce of their flocks and herds. Their communities are more numerous, they act much more in concert, their battles are not mere single combats, but they know how to act in combination. I am disposed to hazard the conjecture that they will gradually exterminate the mere hunting species, just as savages disappear before more advanced races. Lastly, agricultural nations may be compared with harvesting ants.

Thus, there seem to be three principal types, offering a curious analogy to the three great phases: the hunting, pastoral, and agricultural stages, in the history of human development.

Let me in conclusion once more say, that notwithstanding the labors of those great naturalists to whom I gratefully referred in commencing, it seems to me that there are in natural history few more promising or extensive ficlds for research than the habits of ants. 


\section{LECTURE V.}

INTRODUCTION TO THE STUDY OF PREHISTORIC

ARCH AOLOGY. ${ }^{1}$

Prenistoric Archaology has but lately made good its right to recognition as a branch of science; and still, perhaps, there are some who are disposed to question the claim. We can never, they say, become wise beyond what is written: ancient poems and histories contain all that we can ever know about old times and bygone races of men; by the study of antiquities we may often corroborate, and occasionally perhaps even correct, the statements of ancient writers, but beyond this we can never hope to penetrate. The ancient monuments and remains themselves may excite our interest, but can teach us nothing. This opinion is as old as the time of Horace: in one of his best known Odes he tells us that-

\section{"Vixere fortes ante Agamemnona \\ Multi ; sed omnes illacrymabiles \\ Urgentur, ignotique longâ \\ Nocte, carent quia vate sacro."}

1 I have discussed the Antiquity of Man, and his primitive condition in its more material aspects, at greater length in my work on Prehistoric Times, and have endeavoured to trace up the course of his social and moral development in a second, On the Origin of Civilisation. 
If this apply to nations as well as to individuals-if our knowledge of the past be confined to that which has been handed down to us in books-then is Archæology indeed restrained within fixed and narrow limits; it is reduced to a mere matter of criticism, and almost unworthy to be called a science.

My object in the present address is to vindicate the claims of archæology; to point out briefly the light which has, more particularly in the last few years, been thrown upon the past; and, above all, if possible, to show that the antiquaries of the present day are no visionary enthusiasts, but that the methods of archæological investigation are as trustworthy as those of any natural science. I purposely say the methods, rather than the results; because while I believe that the progress recently made has been mainly due to the use of those methods which have been pursued with so much success in geology, zoology, and other kindred branches of science-and while fully persuaded that in this manner we must eventually ascertain the truth-I readily admit that there are many points on which further evidence is required. Nor need the antiquary be ashamed to own that it is so. Biologists differ about the Darwinian theory; until very lately the emission theory of light was maintained by some of the best authorities: Tyndall and Magnus are at issue as to whether aqueous vapour does or does not absorb heat; astronomers have recently admitted an error of nearly 4,000,000 miles in their estimate of the distance between the earth and the sun; nor is there any single proposition in theology to which an universal assent would be given. Although, therefore, there are no doubt great diversities of opinion 
among' antiquaries, archæology is in this respect only in the same condition as all other branches of knowledge.

Conceding then, frankly, that from several of the following conclusions some good archæologists would entirely dissent, I will now endeavour to state briefly the principal results of modern research, and especially to give, as far as can be done within the limits of a few pages, an idea of the kind of evidence on which these conclusions are based.

I must also add, that my remarks are confined, excepting when it is otherwise specified, to that part of Europe which lies to the north of the Alps; and that by the Primæval period, I understand that which extended from the first appearance of man down to the commencement of the Christian era.

'This period may be divided into four epochs :-Firstly, the Palæolithic, or First Stone Age ; secondly, the Neolithic, or Second Stone Age; thirdly, the Bronze Age; and lastly, the Iron Age. Attempts have been made, with more or less success, to establish subdivisions of these periods, but into these I do not now propose to enter : even if we can do no more as yet than establish this succession, that will itself be sufficient to show that we are not entirely dependent upon history.

We will commence, then, with the Palæolithic Age. This is the most ancient period in which we have as yet any decisive proofs of the existence of man. M. Desnoyers some years ago called attention to some bones from the Pliocene beds of St. Prest, which appear to show the marks of knives, and M. l'Abbé Bourgeois has since found in the same locality some flints, which he believes to have been worked by man; Mr. Whincopp 
also has in his possession a bone from the crag, which certainly looks as if it had been cut with some sharp instrument. Other archæologists have more recently adduced similar cases. None of them, however, are perfectly conclusive, and as yet the implements found in the river-drift gravels are the oldest undoubted traces of man's existence-older far than any of those in Egypt or Assyria, though belonging to a period which, from a geological point of view, is very recent.

\section{The Palcoolithic Age.}

As regards the Palæolithic Age, we may, I think, regard the following conclusions as fully borne out by the evidence :-

1. The antiquities referable to this period are usually found in beds of gravel and loam, or, as it is technically called, "loëss," extending along our valleys, and reaching sometimes to a height of 200 feet above the present water-level.

2. These beds were deposited by the existing rivers, which then ran in the same directions as at present, and drained nearly the same areas.

3. With the exception of the coast-line, the geography of Western Europe cannot have been very different at the time those gravels were deposited from what it is now.

4. 'The fauna of Europe at that time comprised the mammoth, the woolly-haired rhinoceros, the hippopotamus, the urus, the musk-ox, \&c., as well as most of the existing animals.

5. The climate was much more extreme, and at times certainly much colder than at present. 
6. Though we have no exact measure of time, we can at least satisfy ourselves that this period was one of very great antiquity.

7. Yet man already inhabited Western Europe.

8. He used rude implements of stone;

9. Which were never polished, and of which some types differ remarkably from any of those that were subsequently in use.

10. He was ignorant of pottery, and (11) of metals.

I will now proceed to examine these eleven conclusions at somewhat greater length :-

1. That these beds of gravel and loam, or, as it is technically called, "loëss," extend along the slopes of the valleys, and reach sometimes to a height of 200 feet above the present water-level, is a mere statement of fact, about which no difference of opinion has arisen.

2. That these beds of gravel and loëss were not deposited by the sea, is proved by the fact that the remains which occur in them are all those of land or fresh-water, and not of marine species. That they were deposited by the existing rivers is evident, because in each river-valley they contain fragments of those rocks only which occur in the area drained by the river itself. As, therefore, the rivers drained the same areas then as now, the geography of Western Europe cannot have been at that period very different from what it is at present.

3. The fauna, however, was very different, the most important species being-Ursus spelceus (the cavebear), U. priscus, Hycena spelcea (the cave- hyæna), Felis spelaea (the cave-lion), Canis lagopus (the Arctic fox), 
Elephas primigenius (the mammoth), $E$. antiquus, Rhinoceros tichorhinus (the hairy rhinoceros), $R$. leptorhinus, $R$. hemitcechus, Hippopotamus major (the hippopotamus), Ovibos moschatus (the musk ox), Megaceros hibernicus (the Irish elk), E. fossilis (the wild horse), Gulo luscus (the glutton), Cervus tarandus (the reindeer), Bison Europceus (the aurochs), Bos primigenius (the urus); besides some smaller, but still very interesting species.

4. The greater severity of the climate is indicated by the nature of the fauna. The musk-ox, the woollyhaired rhinoceros, the mammoth, the lemming, \&c., are Arctic species, and the reindeer then extended to the South of France. Another argument is derived from the presence of great sandstone blocks in the gravels of some rivers, as, for instance, of the Somme: these, it appears, must have been transported by ice. ${ }^{1}$ On the other hand, the geological evidence, together with the presence of the hippopotamus, and other southern species, indicates that the cold was not continuous, but that warm periods intervened.

5. The great antiquity of the period now under discussion is evident from several considerations. The extinction of the large mammalia must have been a work of time; and neither in the earliest writings, nor in the vaguest traditions, do we find any indication of their presence in Western Europe. Still more conclusive evidence is afforded by the condition of our valleys. The beds of gravel and loam cannot have been deposited

1 Since this lecture was written two excellent works have been published on this part of the subject-Geikie's Great Ice Age, and Croll's Climate and Time. 
by any sudden cataclysm, both on account of their regularity, and also of the fact, already mentioned, that the materials of one river-system are never mixed with those of another. To take an instance. The gravel of the Somme valley is entirely formed of débris from the chalk and tertiary strata occupying that area; but at a right angle to, and within a very few miles of, the headwaters of the Somme, comes the valley of the Oise. In this valley are other older strata, no fragments of which have found their way into the Somme valley, though they could not have failed to do so, had the gravels in question been the result of any great cataclysm, or had the Somme then drained a larger area than at present. The beds in question are found in some cases 200 feet above the present water-level, and the bottom of the valley is occupied by a bed of peat, which in some places is as much as 30 feet in thickness. We have no means of making an accurate calculation; but even if we allow, as we must, a good deal for the floods which would be produced by the melting of the snow, still it is evident that for the excavation of the valley by the river to a depth of more than 200 feet, ${ }^{1}$ and then for the formation of so thick a bed of peat, much time must have been required. If, moreover, we consider the alteration which has taken place in the climate, as well as in the fauna; and, finally, remember also that the last eighteen hundred years have produced scarcely any perceptible change, we cannot but come to the conclusion that many, very many, centuries have

1 Many persons find a difficulty in understanding how the river could have deposited gravel at so great a height, forgetting that the valley was not then excavated to anything like its present depth. 
elapsed since the river ran at a level so much higher than the present, and the country was occupied by a fauna so unlike that now in existence there.

6. The presence of man is proved by the discovery of stone implements ${ }^{1}$ (Figs. 52 and 53). Strictly speaking, these only prove the presence of reasoning beings; but this being granted, few, if any, would doubt that the beings in question were men. Human bones, moreover, have been found in cave-deposits, which, in the opinion of the best judges, belonged to this period; and M. Boucher de Perthes considers that various fragments of human bone found at Moulin Quignon are also genuine. On this point long discussions have taken place, into which I will not now enter. The question before us is, whether men existed at all, not whether they had bones. On the latter point no dispute is likely to arise, and as regards the former, the works of man are as good evidence as his bones could be. Moreover, there seems to me nothing wonderful in the great scarcity of human bones. A country where the inhabitants subsist on the produce of the chase can never be otherwise than scantily peopled. If we admit that for each man there must be a thousand head of game existing at any one time-and this seems a moderate allowance; remembering also that most mammalia are less long-lived than men, we should naturally expect to find human remains very rare as compared with those of other animals. Among a people who burnt their dead, of course this disproportion would be immensely increased. That the flint implements found in these gravels are implements it is unnecessary

1 For a general account of stone implements I may refer to Mr. Evans' admirable work on that subject.

S. E. 
to argue. Their regularity, and the care with which they have been worked to an edge, prove that they have
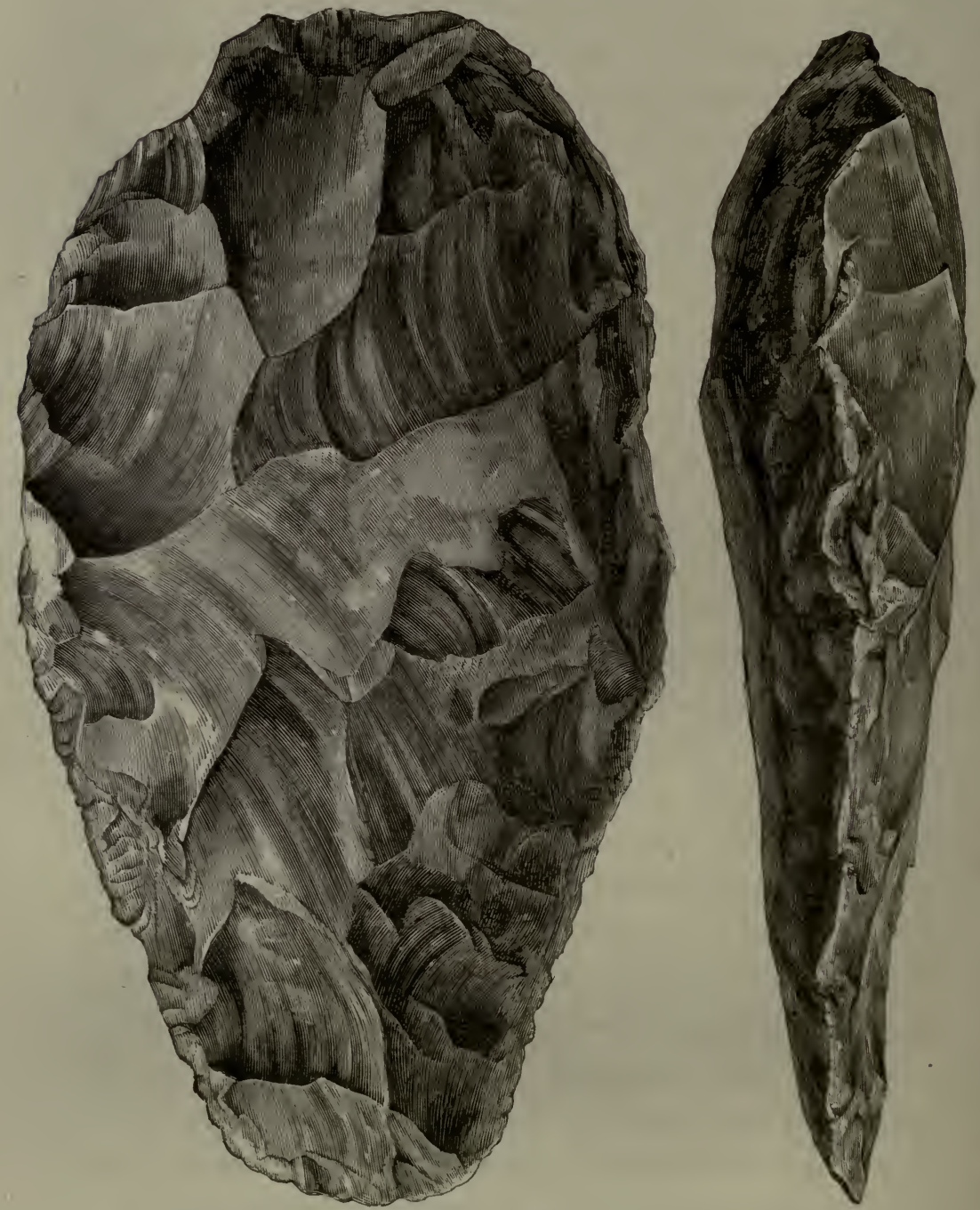

FıG. 52.-Flint Implement from St. Acheul, near Amiens. Natural size. ( In my collection.)

been intentionally chipped into their present forms, and are not the result of accident. That they are not 

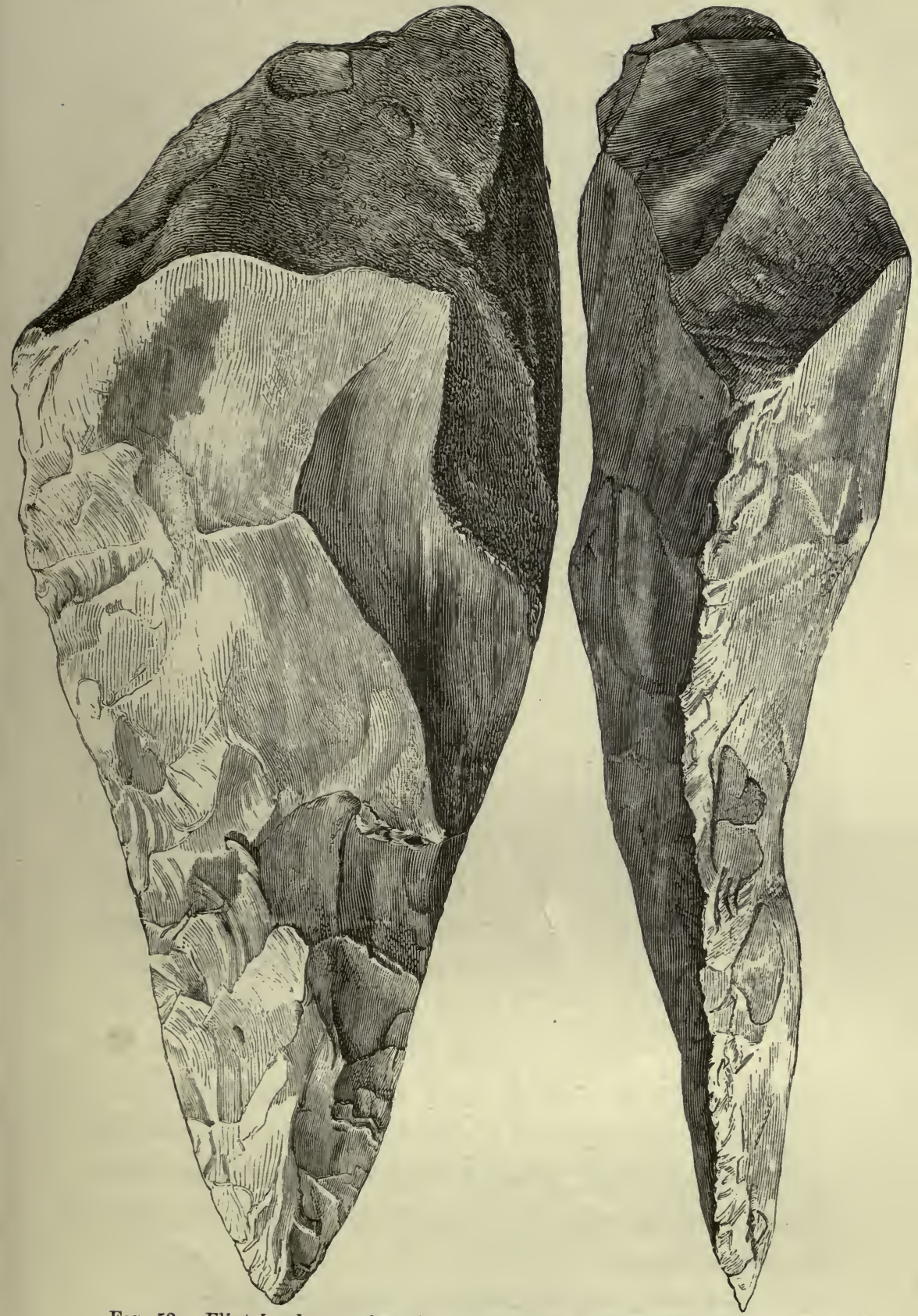

FIG. 53.-Flint Implement from St. Acheul, near Amiens. Natural size. ( (n my collection.) 
forgeries we may be certain: firstly, because they have been found in situ by many excellent observers-by all, in fact, who have looked perseveringly for them; and secondly, because, as the discoloration of their surface is quite superficial, and follows the existing outline, it has evidently been produced since the flints were brought to their present forms. This is

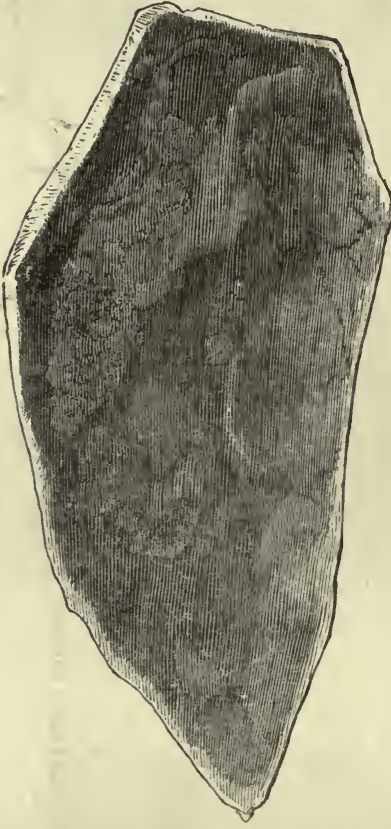

Fig. 54.-Section of Fig. 53 showing discoloration of surface. clearly shown in fig. 54, which represents a fractured surface of fig. 53, and shows the dark natural flint surrounded by the altered surface. The forgeries-for there are forgeries -are of a dull lead colour, like other freshly-broken surfaces of flint. The same evidence justifies us in concluding that the implements are coeval with the beds of gravel in which they are found.

7. Without counting flakes, several thousand flint implements of the Palæolithic Age have been discovered in northern France and southern England. These are all of types which differ considerably from those which came subsequently into use, and they are none of them polished; we may therefore, I think, infer that the art of polishing stone implements was as yet unknown.

8 and 9. In the same manner, I think, we may safely conclude that the use of metal and of pottery 
was then unknown, as is the case even now with many races of savages.

Although flint implements were observed in the driftgravels more than half a century ago by Mr. Frere, still his observations were forgotten until the same discovery was again made by M. Boucher de Perthes. For our knowledge of the gravel-beds in which they occur, however, we are principally indebted to Mr. Prestwich. Sir Charles Lyell has the high merit of having carefully examined the facts, and given to the antiquity of man the authority of his great name; nor must the labours of Mr. Evans be passed unnoticed. To him we owe the first comparison between the flint implements of this and those of the Neolithic period.

As long ago as 1828: MM. Tournal and Christol found in the caves of the south of France human remains associated with those of extinct animals, and shortly afterwards M. Schmerling made similar observations in Belgium. Kent's Hole, near Torquay, was carefully examined by Mr. McEvery in 1825, but his researches remained in manuscript until they were published by Mr. Vivian in 1859. In 1840, however, Mr. Godwin Austin had also made researches in Kent's Hole, and convinced himself that uran co-existed in this country with the mammoth, \&c. Since that time various caverns have been examined most carefully by Christy, Iartet. Falconer, Dupont, Busk, Powelly, Boyd Dawkins, Sandford, Mirk, Tiddeman, \&c. To Mr. Boyd Dawkins, moreover, we are indebted for a special work on Cave Hunting.

The general facts may be stated to be, that while thousands of implements made out of stone, bone, and 
horn, have been collected, no trace of pottery, nor evidence of the use of metals, not even a polished stone implement, has yet been met with. The people who lived in the South of France at that period seem, in a great many respects, to have resembled the Esquimaux. Their principal food was the reindeer, and though traces of the musk-ox, mammoth, cave-lion, as well as other animals of the quaternary fauna have been met with, it is still possible that these may not belong to the same period. These cavemen were very ingenious, and excellent workers in flint; but though their bone-pins, \&c., are beautifully polished, this is never the case with their flint weapons. The habit of allowing offal and bones to accumulate in their dwellings is indicative, probably, of a cold climate.

Perhaps, however, the most remarkable fact of all is, that although in other respects so slightly advanced in civilisation, these ancient French cavemen, like the Esquimaux, show a wonderful genius for art. Many very spirited drawings of animals have been found represented on fragments of bone, stone, and horn, and M. Lartet has found in the rock-shelter at La Madelaine a fragment of mammoth-tusk, on which was engraved a representation of the animal itself.

\section{The Neolithic Age.}

We now pass to the later Stone or Neolithic Age, with reference to which the following propositions may, I think, be regarded as satisfactorily established :-

1. There was a period when polished stone axes were extensively used in Europe. 
2. The objects belonging to this period do not occur in the river-drift gravel-beds;

3. Nor in association with the great extinct mammalia.

4. They were in use long before the discovery or introduction of metals.

5. The Danish shell-mounds, or Kjökkenmöddings, belong to this period;

6. As do many of the Swiss lake-dwellings;

7. And of the tumuli, or burial-mounds.

8. Rude stone implements appear to have been in use longer than those more carefully worked.

9. Hand-made pottery was in use during this period.

10. In Central Europe the ox, sheep, goat, pig, and dog were already domesticated.

11. Agriculture had also commenced.

12. Flax was cultivated and woven into tissues.

13. At least two distinct races already occupied Western Europe.

1. That there was a period when polished axes and other implements of stone were extensively used in Western Europe is sufficiently proved by the great numbers in which these objects occur: for instance, the Dublin Museum contains more than 2,000, that of Copenhagen more than 10,000, and that of Stockholm not fewer than 15,000 .

2. The objects characteristic of this period do not occur in the river-drift gravels. Scme of the simpler ones, indeed-as, for instance, flint-flakes-were used both in the Neolithic and Palæolithic periods, and indeed much later. The polished axes, chisels, gouges, \&c., are very distinct, lowever, from the ruder implements of 
the Palæolithic Age, and are never found in the river-drift gravels. Conversely, the Palæolithic types have never yet been met with in association with those characteristic of the later epoch.

Again, while the Neolithic implements are remarkably numerous in Denmark and Sweden, the Palæolithic types are absolutely unknown there, as well as in Eastern Europe. It is probable, therefore, that the northern part of our Continent was not inhabited by man during the earlier period.

3. Nor do the types of the Neolithic age ever occur in company with the mammoth, Rhinoceros tichorinus, and other animals characteristic of the Quaternary fauna, under circumstances which would justify us in regarding them as coeval.

4. The implements in question were in use before the introduction or discovery of metal. It is a great mistake to suppose that implements of stone were abandoned directly metal was discovered. For certain purposes, as for arrow-heads, stone would be quite as suitable as the more precious substance. Flint flakes, moreover; were so useful, and so easily obtained, that they were occasionally employed even down to a very late period. Even for axes and chisels, the incontestable superiority of metal was counterbalanced for a while by its greater costliness. Captain Cook, indeed, tells us that in Tahiti the implements of stone and bone were in a very few years replaced by those of metal; a stone hatchet was then, he says, "as rare a thing as an iron one was eight years ago, and a chisel of bone or stone is not to be seen." The rapidity with which the change from stone to metal is effected depends upon the supply 
of the latter. In the above case Cook had with him an abundance of metal, in exchange for which the islanders supplied his vessels with great quantities of fresh meat, vegetables, and other more questionable articles of merchandise. The introduction of metal into Europe was certainly far more gradual; stone and metal were long used side by side, and it would be unsafe to refer every stone implement to the Stone Age. It would be easy to quote numerous instances in which implements have been, without any sufficient reason, referred to the Stone Age, merely because they were formed of stone. The two Stone Ages are characterised not merely by the use of stone, but by the use of stone to the exclusion of metal. I cannot therefore too strongly impress on archæologists that many stone implements belong to the metallic period. Why, then, it will be asked, may they not all have done so? and this question I will now endeavour to answer.

5. The Danish shell-mounds are the refuse heaps of the ancient inhabitants round whose dwellings the bones and shells of the animals on which they fed gradually accumulated. Like a modern dustheap, these shellmounds contain all kinds of household objects--some purposely thrown away as useless, but some also accidentally lost. These mounds have been examined with great care by the Danish archæologists, and especially by Professor Steenstrup. Many thousand implements of stone and bone have been obtained from them; and as, on the one hand, from the absence of extinct animals, ${ }^{1}$ and of implements belonging to the Palæo-

1 The Reindeer also, which at an earlier period was common in central Europe, is entirely absent. 
lithic Age, we conclude that these shell-mounds do not belong to that period, so, on the other hand, from the absence of all trace of metal, we are justified in referring them to a period when metal was unknowu.

6. The same arguments apply to some of the Swiss lake-dwellings, the discovery of which we owe to Dr. Keller, ${ }^{1}$ and which have been so admirably studied by Desor, Morlot, Troyon, and other Swiss archæologists. A glance at the Table A will show that, while in some of them objects of metal are very abundant, in others, which have been not less carefully or thoughtfully explored, stone implements are met with to the exclusion of metallic ones. It may occur, perhaps, to some, that the absence of metal in some of the lake-villages, and its presence in others, is to be accounted for by its scarcity - that, in fact, metal will be found when the localities shall have been sufficiently searched. But a glance at the table will show that the settlements in which metal occurs are deficient in stone implements. Take the same number of objects from Wangen and Nidau, and in the one case 90 per cent. will be of metal, while in the other the whole number are of stone or bone. This cannot be accidental-the numbers are too great to admit of such a hypothesis; nor can the fact be accounted for by contemporaneous differences of civilisation, because the localities are too close together; neither is it an affair of wealth, because we find such articles as fishhooks, \&c., made of metal.

7. We may also, I think, safely refer some of the tumuli or burial mounds to this period. When we find

1 Dr. Keller's Memoirs have been collected and translated into English by Mr. Lee. 
a large tumulus, the erection of which must have been extremely laborious, it is evident that it must have been erected in honour of some distinguished individual; and when his flint daggers, axes, \&c. - which, from the labour and difficulty of making them, must have been of great value-were deposited in the tomb, it is reasonable to conclude that if he had possessed any arms of metal, they also would have been buried with him. This we know was done in subsequent periods. In burials of the Stone Age the corpse was either deposited in a sitting posture, or burnt, but rarely, if ever, extended at full length. ${ }^{1}$

8. It is an error to suppose that the rudest flint implements are necessarily the oldest. The Palæolithic implements show admirable workmanship. Moreover, every flint instrument is rude at first. A bronze celt may be cast perfect; but a flint implement is rudely blocked out in the first instance, and then, if any concealed flaw comes to light, or if any ill-directed blow causes an inconvenient fracture, the unfinished implement is perhaps thrown away. Moreover, the simplest flint-flake forms a capital knife, and accordingly we find that some simple stone implements were in use long after metal had replaced the beautifully-worked axes, knives, and daggers, which must always have been very difficult to make. The period immediately before the introduction of metal may resonably be supposed to be that of the best stone implements, but the use of the

1 For accounts of tumuli belonging to this period see Hoare's Ancient Wiltshire, Nilsson's Stone Age, Warne's Ancient Dorset, Bateman's Antiquities of Derbyshire, and Ten Years' Diggings, Borlase's Nenia Cornubice, Greenwell's British Barrows, \&c. 
simpler ones lingered long. Moreover, there are some reasons to believe that pierced stone axes are. characteristic of the early metallic period.

9. Hand-made pottery is abundant in the shellmounds and the lake-villages, as well as in the tumuli which appear to belong to the Stone Age. No conclusive evidence that the potter's wheel was yet in use has been discovered.

10. The animals characteristic of the Palæolithic period have disappeared. Even the reindeer has retreated from Central Europe.

11. The dog is the only domestic animal found in the shell-mounds; but remains of the ox, sheep, goat, and pig appear in the lake-villages. There is some doubt about the horse; and the barn-door: fowl, as well as the cat, was unknown.

12. The presence of corn-crushers, as well as of carbonised wheat, barley, and flax, in the Swiss lakedwellings, proves that agriculture was already pursued with success in Central Europe. Oats, rye, and hemp were unknown.

13. Tissues of woven flax have been found in some of the Swiss lake-villages.

14. At least two forms of skull, one long and one round, are found in the tumuli which appear to belong to this period. Until now, however, we have not a single human skull from the Danish shell-mounds, nor from any Swiss lake-dwelling, which can be referred with certainty to this period. 


\section{The Bronze Age.}

1. The Neolithic Age was followed by a period when bronze was extensively used for arms and implements.

2. Stone, however, was also in use, especially for certain purposes; as, for instance, for arrow-heads, and in the form of flakes for cutting.

3. Some of the bronze axes appear to be mere copies of the earlier stone ones.

4. Many of the Swiss lake-villages and of the tumuli belong to this period.

5. This is shown, not merely by the presence of metal, but also by other considerations.

6. The pottery of the Bronze Age is better than that of the earlier period.

7. Gold, amber, and glass, were used for ornamental purposes.

8. Silver, lead, and zinc appear to have been unknown.

9. This was also the case with iron.

10. Coins were not in use.

11. Skins were probably worn, but tissues of flax and wool were also in use.

12. The ornamentation of the period is characteristic, and consists of geometrical markings.

13. The handles of the arms, the bracelets, \&c., indicate a small race.

14. Writing appears to have been unknown;

15. Yet there was a very considerable commerce.

16. It is more than probable that the knowledge of bronze was introduced into, not discovered in, Europe. 
1. It is admitted by all that there was a period when bronze was extensively used for arms and implements. The great number of such objects which are preserved in our museums places this beyond doubt. For France alone Monsieur Chantre, in his Age du Bronze, gives the following numbers.-Celts, 9,153; swords and daggers, 727 ; lances, 513 ; knives, 342 ; sickles, 225 ; pins, 1,220 ; needles, 204 ; bracelets 1,086 ; rings and chains, 1,572; arrow-heads, 213 ; hammers, 23 ; anvils, 5 ; chisels, 58 ; gouges, 31 ; razors, 62 ; saws, 8 ; hooks, 172 ; moulds, 74 ; and a variety of other articles, making altogether no less than 20,000 objects. In Switzerland, again, more than 10,000 have been discovered: the numbers for some of the principal lake-villages are given in Table $\mathrm{B}$.

2. It would, however, be a mistake to suppose that stone implements were entirely abandoned. Arrowheads and flakes of flint are found abundantly in some of those Swiss lake-villages which contain bronze. In these cases, indeed, it may be argued, that the same site had been occupied both before and after the introduction of bronze. The evidence derived from the examination of tumuli is, however, not open to the same objection, and in these objects of bronze and of stone are very frequently found together. Thus I have shown, by an analysis of the investigations recorded by Mr. Bateman, that in three-fourths of the tumuli containing bronze (29 out of 37 ) stone objects also occurred.

3. Some of the bronze axes appear to be mere copies of the stone ones. Such simple axes of iron are still used in Central Africa, where no evidence of a Bronze 
Age has yet been found, but in Europe they are not met with.

4. Many of the Swiss lake-villages belong to this period. The Table B (very kindly drawn up, at my request, by Dr. Keller) places this beyond a doubt, and gives a good idea of the objects in use during the Bronze Age, and the state of civilisation during that period.

5. The absence of metal, though the principal, is by no means the only point which distinguishes the Stone Age villages from those of the Bronze period. If we compare Nidau, as a type of the last, with Moosseedorf, as the best representative of the former, we shall find that, while bones of wild animals preponderate in the one, those of tame ones are most numerous in the latter. The vegetable remains point also to the same conclusion. Even if we knew nothing about the want of metal in the older lake-villages, we should still, says Professor Heer, be compelled from botanical considerations to admit their greater antiquity.

Moreover, so far as they have been examined, the piles themselves tell the same tale. Those of the Bronze Age settlements were evidently cut with metal; those of the earlier villages with stone, or at any rate with rude and blunt instruments.

6. The pottery was much better than that of the earlier period. A great deal of it was still hand-made, but some is said to show marks of the potter's wheel.

7. Gold, amber, and glass, were used for ornamental purposes.

8. Silver, zine, and lead, on the contrary, were apparently unknown.

9. The same appears to have been the case with iron. 
10. Coins have never been found with bronze arms. To this rule I only know of three apparent exceptions. Not a single coin has been met with in any of the Swiss lake-villages of this period.

11. The dress of this period no doubt still consisted in great part of skins. Tissues of flax have been found, however, in some of the lake-villages, and fragments of woollen material have been found in tumuli, nay, in one case, a whole suit (consisting of a cloak, a shirt, two shawls, a pair of leggings, and two caps) was found in a Danish tumulus which evidently belonged to the Bronze Age ; as it contained a sword, a brooch, a knife, an awl, a pair of tweezers, and a large stud, all of bronze, besides a small button of tin, a javelin-head of flint, a bone comb, and a bark box.

We have independent evidence of the same fact in the presence of spindle-whorls.

12. The ornamentation on the arms, implements, and pottery is peculiar. It consists of geometrical patterns -straight lines, circles, triangles, zigzags, \&c. Animals and vegetables are very rarely attempted, and never with success.

13. Another peculiarity of the bronze arms lies in the small size of the handles. The same observation applies to the bracelets, \&c. They could not be used by the present inhabitants of Northern Europe.

14. No traces of writing have been met with in any finds of the Bronze Age. There is not an inscription on any of the arms or pottery found in the Swiss lakevillages, and I only know one instance of a bronze cutting instrument with letters on it.

15. The very existence of bronze appears to indicate 
that of a considerable and extensive commerce, inasmuch as there are only two places-namely, Cornwall and the Island of Banca-whence tin can have been obtained in large quantities. There are, indeed, some other places where it occurs, as, for instance, Spain, Saxony, and Brittany, but only (now at least) in small amounts; though possibly it may once have been more abundant. The earliest source of tin, was not, I think, any one of those now known to us, but it is probable that for many centuries before our era, the principal supply was derived from Cornwall. The intercourse then existing between different parts of Europe is also proved by the great, not to say complete, similarity of the arms from very different parts of Europe.

16. Finally, as copper must have been in use before bronze, and as arms and implements of that metal are almost unknown in Western Europe, it is reasonable to conclude that the knowledge of bronze was introduced into, not discovered in, Europe.

Archæologists are, however, by no means agreed as to the race by whom these bronze weapons were made, or at least used. Mr. Wright, for instance, attributed them to the Romans, Professor Nilsson to the Phœenicians. The first of these theories I believe to be utterly untenable. In addition to the facts already brought forward, there are two which by themselves are almost sufficient to disprove the hypothesis. Firstly, the word ferrum was employed in Latin as a synonym for a sword. This would scarcely have been the case if another metal had been generally used for the purpose. Secondly, the distribution of bronze weapons and implements does not favour such a theory. The Romans never entered 
Denmark; it has been doubted whether they ever landed in Ireland. Yet, while more than 350 bronze swords have been found in Denmark, and a very large number in Ireland also, ${ }^{1}$ I have only been able to hear of about fifty bronze swords found in Italy. The rich museums at Florence, Rome, and Naples, do not appear to contain any of those typical, leaf-shaped bronze swords, which are, comparatively speaking, so common in the North. That bronze swords should have been introduced into Denmark by a people who never occupied that country, and from a part of Europe in which they are so rare, is surely a most untenable hypothesis. It is doubtless true that a few cases are on record in which bronze weapons are said to have been, and very likely were, found in association with Roman remains. Mr. Wright has pointed out three, none of which seem to me clearly established, while one of them is clearly not a case in point. But, under any circumstances, we must expect to meet with some such instances. My only wonder is that so few of them exist.

As regards Professor Nilsson's theory, according to which the Bronze Age objects are of Phœnician origin, I will only say that the Phœnicians in historical times were well acquainted with iron, and that their favourite ornamentation was of a different character from that of the Bronze Age. If, then, Professor Nilsson be correct, the bronze weapons must belong to an earlier period in Phœnician history than that with which we are partially familiar.

1 The Museum at Dublin contains 282 swords and daggers : unluckily, the number of swords is not stated separately. 
It would now be natural that I should pass on to the Iron Age, but the transition period between the two is illustrated by a discovery so remarkable that I cannot pass it over altogether in silence. M. Ramsauer, for many years head of the salt-mines at Hallstadt, near Salzburg, in Austria, has opened not less than 980 graves in a country apparently belonging to an ancient colony of miners. The results comprise about 4,000 objects of bronze, and 600 of iron. The following table (p. 170) gives M. Ramsauer's figures, but the numbers bave since been considerably increased.

That the period to which these graves belonged was that of the transition between the Bronze and Iron Ages, is evident, both because we find cutting instruments of iron as well as of bronze, and also because both are of somewhat unusual, and we may almost say of intermediate, types. The same remark applies to the ornamentation. Animals are frequently represented, but very poorly executed, while geometrical patterns are well drawn. Coins are entirely absent. That the transition was from bronze to iron, and not from iron to bronze, is clear; because here, as elsewhere, while iron instruments with bronze handles are common, there is not a single case of a bronze blade with an iron handle. This shows that when both metals were in use, iron was preferred for blades. Another interesting point in the Hallstadt Bronze is the absence of silver, lead, and zinc (excepting, of course, as a mere impurity in the bronze). This is the more remarkable, inasmuch as the presence, not only of tin itself, but also of glass, amber, and ivory, indicates the existence of an extensive commerce. 


\section{The Iron Age.}

The Iron Age is the period when this metal was first used for weapons and cutting instruments. During this epoch we emerge into the broad, but in many respects delusive, glare of history.

No one of course will deny that arms of iron were in use by our ancestors at the time of the Roman invasion.

I have already attempted to show, from the frequent occurrence of iron blades with bronze handles, and the entire absence of the reverse, that iron must have succeeded and replaced bronze. Other arguments might be adduced; but it will be sufficient to state broadly that which I think no experienced archæologist will deny-namely, that the objects which accompany bronze weapons are much more archaic in character than those which are found with weapons of iron.

That the bronze swords and daggers were not used by the Romans in Cæsar's times, I have already attempted to prove. That they were not used at that period by the northern races is distinctly stated in history. I will, however, endeavour also to make this evident on purely archæological grounds. We have several important finds of this period, among which I may specially call attention to the lake-village of $\mathrm{La}$ Tene, in the Lake of Neufchâtel. At this place no flint implements (excepting flakes) have occurred. Only fifteen objects of bronze have been found, and only one of them was an axe. Moreover, this was pierced for a handle, and belonged therefore to a form rarely, if ever, occurring in finds of the Bronze Age. On the other 
hand, the objects of iron are numerous, and comprise fifty swords, twenty-three lances, and five axes. Coins have also been met with at this station, while they are entirely absent in those of the Bronze Age.

The only other find of the Iron Age to which I will now refer is that of Nydam, recently described at length by M. Engelhardt in his excellent work on Denmark in the Early Iron Age. At this place have been found an immense number of the most diverse objects-clothes, brooches, tweezers, beads, helmets, shields, coats of mail, buckles, harness, boats, rakes, brooms, mallets, bows, vessels of wood and pottery, 80 knives, 30 axes, 40 awls, 160 arrow-heads, 180 swords, and nearly 600 lances. All these weapons were of iron, though bronze was freely used for ornaments. That this find, as well as the very similar one at 'I'horsbjerg, in the same neighbourhood, belonged to the Roman period, is clearly proved by the existence of numerous coins belonging to the first two centuries after Christ, although not one has occurred in any of the Bronze Age lake-villages, or in the great find at Hallstadt.

It is quite clear, therefore, that neither bronze nor stone weapons were in use in Northern Europe at the commencement of our era.

A closer examination would much strengthen this conclusion. For instance, at Thorsbjerg alone there are seven inscriptions, either in Runes or Roman characters; while, as I have already stated, letters are quite unknown, with one exception, on any object of the Bronze Age, or in the great transition find at Hallstadt. Again, the significance of the absence of silver in the Hallstadt find is greatly increased when we see that in the true 
Iron Age, as in the Nydam and other similar finds, silver was used to ornament shield-bosses, shield-rims, sandals, brooches, breast-plates, sword-hilts, swordsheaths, girdles, harness, \&c.; and also for clasps, pendants, boxes, and tweezers; while in one case a helmet was made of this comparatively rare material.

The pottery also shows much improvement, the forms of the weapons are quite different, and the character of the ornamentation is very unlike, and much more advanced than that of the Bronze Age. Moreover, the bronze used in the Iron Age differs from that of the Bronze Age, in that it frequently contains lead and zinc in considerable quantities. These metals have never been found, excepting as mere impurities, in the bronzes of the true Bronze Age, nor even in those of Hallstadt.

These finds, moreover, clearly show that the inhabitants of Northern and Western Europe were by no means such mere savages as we have been apt to suppose. As far as our own ancestors are concerned, this is rendered even more evident by the discoveries of those ancient British coins which have been so well described and figured by Mr. John Evans. ${ }^{1}$

In conclusion, I would venture to suggest that some steps ought to be taken to provide for the preservation of our ancient National Antiquities. We cannot put Stonehenge or the Wansdyke into a museum-all the more reason why we should watch over them where they are; and even if the destruction of our ancient monuments should, under any circumstances, become necessary, careful drawings ought first to be made, and their 
removal should take place under proper superintendence. We are apt to blame the Eastern peasants who use the grand old monuments of Egypt or Assyria as mere stone-quarries, but we forget that even in our own country, Avebury, the most magnificent of Druidical remains, was almost destroyed for the profit of a few pounds; while recently the Jockey Club has mutilated the remaining portion of the Devil's Dyke on Newmarket Heath, in order to make a bank for the exclusion of scouts at trial races. In this case, also, the saving, if any, must have been very small; and I am sure that no society of English gentlemen would have sanctioned such a proceeding, had they given the subject a moment's consideration.

In this short Introduction I have purposely avoided all reference to history, and the use of historical data, because I have been particularly anxious to show that in Archæology we can arrive at definite and satisfactory conclusions on independent grounds, without any such assistance; consequently, regarding times before writing was invented, and therefore before written history had commenced.

I have endeavoured to select only those arguments which rest on well-authenticated facts. For my own part, however, I care less about the results than about the method. For an infant science, as for a child, it is of small importance to make rapid strides at first: and while I believe that our present views will stand the test of further investigations, it is of the greatest importance that our method should be one which will eventually lead us to the truth. 


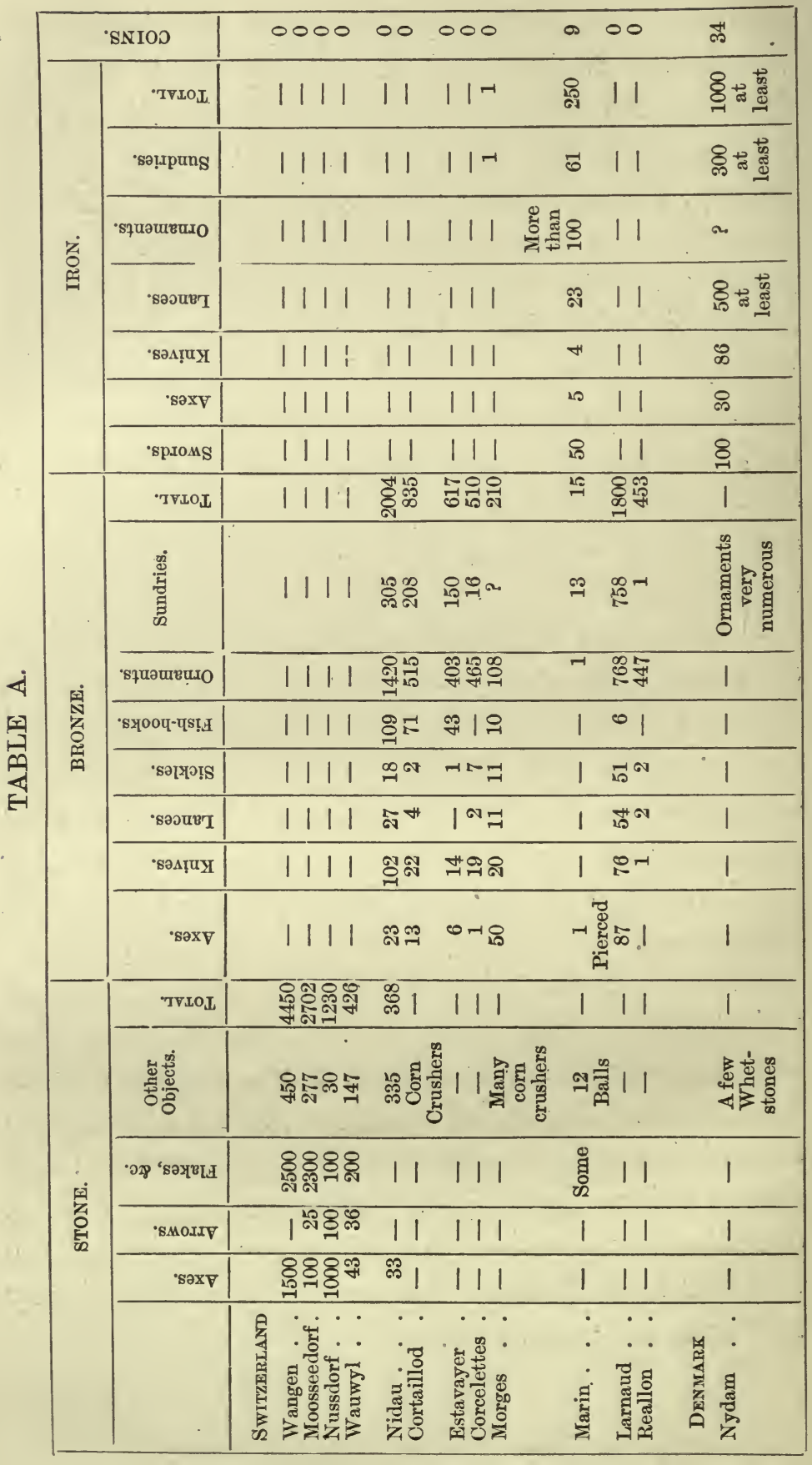


TABLE B.

\begin{tabular}{|c|c|c|c|c|c|c|c|c|c|c|c|}
\hline \multicolumn{4}{|c|}{7} & 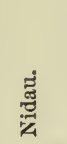 & 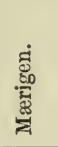 & 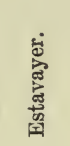 & 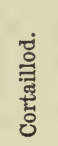 & 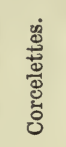 & 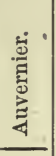 & 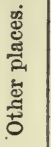 & 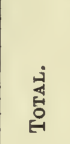 \\
\hline Celts and fra & agment & ts . & . & 23 & 7 & 6 & 13 & 1 & 6 & 11 & 67 \\
\hline Swords . • & $\cdot$, & . . & & - & - & - & - & 一 & - & 4 & $\cdot 4$ \\
\hline Hammers . & $\ddot{*} \cdot$ & . $\cdot$ & . & 4 & - & 1 & - & - & - & - & 5 \\
\hline Knives and $\mathrm{fr}$ & ragme & ents & . & 102 & 19 & 14 & 22 & 19 & 8 & 9 & 193 \\
\hline Pins . . & •. & . . & . & 611 & 53 & 239 & 183 & 237 & 22 & 22 & 1,367 \\
\hline Small rings & $\cdot \cdot$ & . . & - . & 496 & 28 & 115 & 195 & 202 & 14 & 3 & 1,053 \\
\hline Earrings . & • $\cdot$ & . . & - . & 238 & 42 & 36 & 116 & - & 3 & 5 & 440 \\
\hline Bracelets and & d fragr & ment & ts . & 55 & 14 . & 16 & 21 & 26 & 11 & 2 & 145 \\
\hline Fish-hooks & - $\cdot$ & . $\cdot$ & • $\cdot$ & 189 & 12 & 43 & 71 & 9 & 2 & 1 & 248 \\
\hline Awls . . & $\cdot \cdot$ & . . & · $\cdot$ & 95 & 3 & 49 & 98 & 17 & - & - & 262 \\
\hline Spiral wires & . & . . & $\cdot \cdot$ & - & - & 46 & 50 & 5 & - & - & 101 \\
\hline Lance-heads & . $\cdot$ & . . & . $\cdot$ & 27 & 7 & - & 4 & 2 & 5 & 2 & 47 \\
\hline Arrow-heads & . . & . $\cdot$ & . $\cdot$ & 一 & 一 & 5 & 1 & - & - & - & 6 \\
\hline Buttons . & $\cdot \cdot$ & . $\cdot$ & - $\cdot$ & 一 & 1 & 28 & 10 & 10 & 一 & - & 49 \\
\hline Needles & $\cdot \cdot$ & . $\cdot$ & - & 20 & 2 & 3 & 4 & 1 & - & - & 30 \\
\hline Various orna & aments & s. . & . & 15 & 5 & 7 & 18 & 3 & 1 & - & 49 \\
\hline Saws. . & $\cdot \cdot$ & . . & . & 一 & - & 3 & - & - & - & - & 3 \\
\hline Daggers . & $\cdot \cdot$ & . $\cdot$ & · & 一 & 一 & - & - & - & - & 2 & 2 \\
\hline Sickles . • & . $\cdot$ & - · & • & 18 & 12 & 1 & 2 & 7 & 1 & 4 & 45 \\
\hline Double-point & ted pir & ins . & - & 75 & - & - & - & 一 & - & - & 75 \\
\hline Small bracele & ets . & . . & - & 20 & - & - & 11 & - & - & - & 31 \\
\hline Sundries . & $\cdot \cdot$ & . · & · & 96 & 3 & 5 & 16 & - & - & 4 & 124 \\
\hline TOtAL & . & . $\cdot$ & - . & 2084 & 208 & 617 & 835 & 539 & 73 & 69 & 4,346 \\
\hline
\end{tabular}




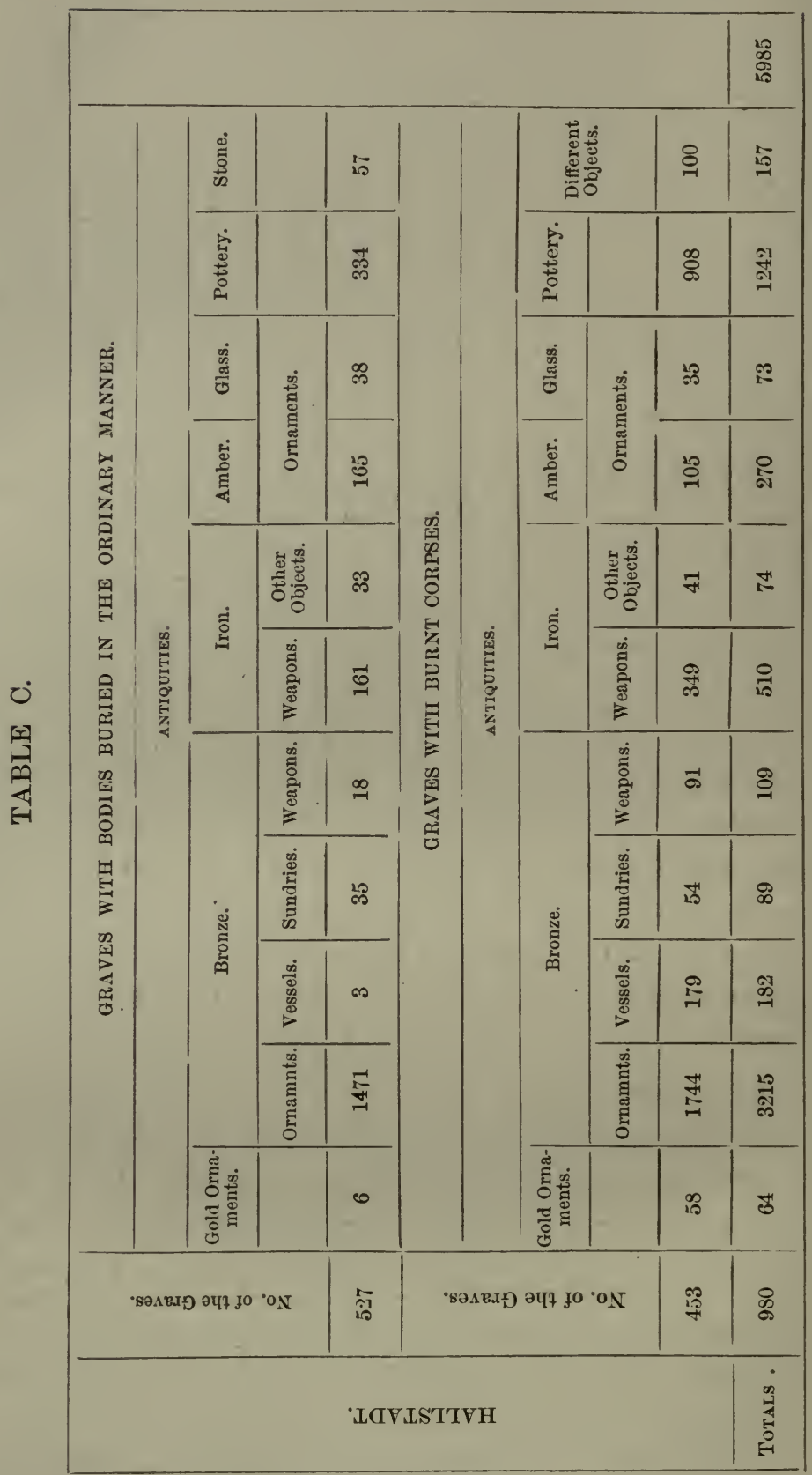




\section{LECTURE VI.}

ADDRESS TO THE WILTSHIRE ARCHEOLOGICAL AND NATURAL HISTORY SOCIETY.

When your excellent Secretary, Mr. Smith, first communicated to me the wish of your Committee that I should become your President for this year, I must confess to some natural hesitation in accepting your very flattering invitation. I have so recently become directly connected with the county, there are so many gentlemen well qualified, not only to fill, but to adorn the office, that I could not but be doubtful how far the suggestion would be approved by, and advantageous to, the Society. Nevertheless I have long felt so deep an interest in this, the central,-and, archæologically, the richest district of England, I am always so happy in the sunshine of your glorious downs, or under the shadow of your beautiful cathedral, that I could not refuse myself the pleasure, and-for it is never very difficult to convince one's self of what one wishes to believe-it seemed to me that the responsibility of the selection would after all in no sense rest upon me.

It is indeed always a pleasure to come into Wiltshire, and much more too than a mere idle one. I sometimes think that every one-at any rate, every Schoolmaster and every Member of Parliament, ought to make the tour of the county and visit its principal antiquities. 
There are still many who go abroad to visit distant antiquities, neglecting those at home, like the "Wander Witt of Wiltshire," mentioned by Gibbons in 1670, who, having "screwed" himself into the company of some Roman antiquaries, confessed that he had never seen Stonage, as he calls it, "whereupon they kicked him out of doors, and bade him goe home and see Stonage; and I wish," adds Gibbons, " all such Esopicall cocks, as slight these admired stones, and other our domestick monuments (by which they might be admonished to eschew some evil, and doe some good,) and scrape for barley cornes of vanity out of forreigne dunghills, might be handled, or rather footed, as he was."

Indeed, it would be difficult to find a pleasanter or more instructive tour. The visitor would begin, perhaps, with Marlborough, pass the large Castle Mound, and coming soon within sight of the grand hill of Silbury, leave the high road and drive, partly up the ancient roadway, into the venerable circle of Abury, perhaps the most interesting of our great national monuments.

There he would walk round the ancient vallum, he would search out the remaining stones among the cottages and farmsteads, and wonder at the mechanical skill which could have moved such ponderous masses; and at the modern barbarism which could have destroyed such interesting, I might almost say sacred, monuments of the past.

From Abury he would pass on across the great wall of Wansdyke, which he would trace on each side of the road, stretching away as far as the eye could reach, and he would sleep at the ancient city of the Devizes.

On Salisbury Plain he would visit Stonehenge, the 
sanctity of which is attested, not only by its own evidence, but by the tumuli which cluster reverently round it. At old Sarum he would for the first time come across real and written history. Lastly, at Salisbury he would see one of our most beautiful Cathedrals, and an excellent Museum, which we owe to the liberality of Dr. Blackmore, while for the admirable arrangement of it we are indebted to Mr. Stevens.

The question naturally arises, "To what age do these monuments belong?" "When and by whom were Stonehenge and Abury erected ?" As regards the latter, history is entirely silent. Stonehenge, with the exception possibly of an allusion in Hecatæus, is unmentioned by, any Greek or Roman writer; nor is there any reference to it in Gildas, Nennius, Bede, or in the Saxon Chronicle. Henry of Huntingdon, in the twelfth century, alludes to it with admiration, but expresses no opinion as to its date or origin.

In the same century, Geoffrey of Monmouth, who; in the words of Dr. Guest, " is everywhere found darkening the pure light of our early history," gave to the world that which some call an historical account of Stonehenge, namely, that it was erected in the fifth century, to commemorate the treacherous murder of the British by Hengist.

The stones are said to have come from Africa, whence they were transported by giants to the plains of Kildare; and from thence, by the enchantments of Merlin, carried to Salisbury Plain. The question has been well discussed by one of our members, Mr. Long, in his recent work on "Stonehenge and its Barrows," in which he has usefully brought together our present information on the 
subject; and I will therefore only add that, for my own part, I look upon the account given by Geoffrey as altogether mythical.

It is remarkable that the source of the small inner stones, which, as Stukely first pointed out, are of a different material from the others, is still uncertain, ${ }^{1}$ but the large ones are certainly "Sarcen " stones, such as are still shown in many places on the Plain. The best evidence as to the age of Stonehenge seems to me derivable from the contents of the tumuli surrounding it. Within a radius of three miles round Stonehenge there are no less than 300 tumuli; which is, I need not say, a much larger number than are found anywhere else within an equal area. We can hardly doubt, I think, that these tumuli cluster round the great monument; or, at least, that the same circumstances which induced the erection of Stonehenge on its present site, led also, either directly or indirectly, to the remarkable assemblage of tumuli round it. Now, 250 of these tumuli were opened by our great Antiquary, Sir Richard Colt Hoare, and are described in his "Ancient Wiltshire." If these belonged to the post Roman period, we should naturally expect to find iron weapons, and, especially knives, coins,

I There are, in fact, four kinds of stones in Stonehenge. The great outer circle and the trilithons are "Sarcen" stones, that is to say, they are formed from the sandstone blocks of the neighbourhood. The majority of the small pillars forming the inner circle consist of an igneous rock known as Diabase, but four stones of this series are schistoid, and resemble some of the Silurian and Cambrian rocks of North Wales and Cumberland. Lastly, the socalled altar-stone is grey sandstone, resembling some of the Devonian and Cambrian rocks. - Maskelyne, Wilts. Arch. and Nat. Hist. Magazine, Oct. 1877. 
well-burnt pottery, and other relics, characteristic of the period. Is this so ? Not at all. The primary interment was not in any case accompanied by objects of iron, while in no less than thirty-nine cases, bronze was present.

We have then, I think, strong grounds for referring these monuments to the Bronze Age; and if this be true of Stonehenge, it probably is the case with Abury also, which seems decidedly more archaic, the stones, for instance, being rough, while those of Stonehenge are hewn.

Now when was the Bronze Age? And what do archæologists mean by the Bronze Age? I ask this question because, though it has been repeatedly answered, there is still a great misapprehension even in the minds of some who have written on the subject.

By the Bronze Age, then, we mean a period when the weapons were made almost entirely, and ornaments principally, of Bronze; that is to say, of Copper and Tin; Gold being rare, Iron and Silver still more so, or even unknown, as was also the case with Coins and Glass.

Some archæologists, indeed, have considered the Bronze swords and daggers which characterise the Bronze Age to be really Roman. This question has been much discussed, and I will not now enlarge on it, but will only say, that in my judgment these arms are not found with Roman remains, and that the Roman weapons were made of iron, the word "ferrum" being synonymous with a sword. On this point, I have taken some pains to ascertain the opinions of Italian archæologists. Bronze swords, daggers, \&c., occur south of the Alps, the very patterns being in some places identical with those of 
Northern Europe. But I believe it may be asserted that no object characteristic of the Bronze Age has ever been found in a Roman tomb; none have been met with at Pompeii ; and those Italian archæologists whom I have been able to consult, all agree that they are undeniably. Pre-Roman.

If indeed the Bronze swords and daggers were of Roman origin, they ought to be more numerous in Italy than in the north. Now what are the facts? The museum of the Royal Irish Academy contains no less than 300 swords and daggers of Bronze. As regards other countries, M. Chantre, who has been collecting statistics on the subject, has been good enough to inform me that the French Museums contain 409, those of Sweden (including poniards) 480, and of Denmark 600, while in Italy he knows of 60 only. These numbers seem to me to militate very strongly against the views of those who would ascribe those weapons to the Romans. When, then, was the Bronze Age? We know that Iron was known in the time of Homer, which seems to have been, as regards the South of Europe, the period of transition from the age of Iron to that of Bronze. In the Pentateuch, excluding Deuteronomy (which probably belongs to a much later date) Brass, that is to say, Bronze, is frequently mentioned, while Iron is only alluded to four times.

Coins were first struck about 900 B.c., as it is generally said, by the Eginetans under Pheidon, King of Argos, though Herodotus ascribes them to the Lydians.

It is true that the use of iron may have been known in Southern Europe long before it was introduced in the north. On the whole, however, I am disposed to think 
that when iron was once discovered, its use would spread somewhat rapidly ; and the similarity of form, of pattern, and of ornaments existing between the Bronze arms and implements throughout Europe, seems to negative the idea that Bronze was in use for such purposes in the north for any great length of time after it had been replaced by Iron in the south.

It is, however, more than likely that many of our smaller Wiltshire tumuli belong to a still earlier period, namely, to the Neolithic, or later Stone Age, though it is not easy to say which of them do so. This is probably also the case with the large chambered tumuli, in which as yet no metal has been discovered. As regards the Stone Age, the same word of eaution is as necessary as in that of Bronze. There are still some who deny the very existence of such a period, alleging generally as their reason against this proposed classification that implements and weapons of stone were used in conjunction with those of metal. This, however, no one denies. The characteristic of the Stone Age is not the presence of stone, but the absence of metal; and if the name were to be a definition, the period would be more correctly designated as non-metallic. That there was indeed a time when stone axes, knives, and javelin heads were used in Europe, and when metal was unknown, cannot I think be for a moment doubted or denied by any one who has carefully looked into the evidence. These objects of stone, so well described by Mr. Evans in his excellent work on the Ancient Stone Implements of Great Britain are of the most varied character ; mere flakes used as knives, scrapers for preparing skins, axes, adzes, hammers, gouges, chisels, arrowheads, javelin 
heads, swords, picks, awls, slingstones and many other forms ; these, too, found not singly or in small numbers but by hundreds and thousands, I might say tens of thousands, attest the important part which has been played by stone in the early stages of the development of the human race. For our knowledge of this period we are mainly indebted, firstly, to the shell mounds or refuse heaps of Denmark so well studied by Steenstrup and Wörsaae; secondly, to the tumuli or burial mounds ; thirdly, to the remains found in caves; and fourthly, to the Swiss lake dwellings, first made known to us by Keller, and afterwards studied with so much zeal and ability by Morlot, Troyon, Desor, Schwab and other Swiss archæologists.

From these sources we get some idea of the conditions of life existing during the Stone Age.

The use of pottery was known, but the potter's wheel does not seem to have been as yet discovered. Man was clothed in skins, but partly also, in all probability, in garments made of flax. His food was derived principally from animals killed in the chase, but he had probably domesticated the ox as well as the goat, the pig and the dog, nor was he altogether ignorant of agriculture. Traces of dwellings of this period have been found in various parts of England; and in this county, the curious circular depressions at Stourhead, known as the Pen pits, perhaps belong to it. These dwellings consisted of pits sunk into the ground, and probably covered by a roof consisting of branches of trees, over which again a coating of turf and earth may probably have been placed. The Swiss lake dwellings of this period were constructed on platforms supported on piles driven into the muddy 
bottom of the lakes, and in some cases still further supported by having stones heaped up round them. In one case a large canoe has been met with, evidently wrecked while on its way to one of the lake settlements, loaded with a freight of such stones. It must be admitted indeed that our knowledge of the Stone Age is still scanty, fragmentary and unsatisfactory; on the other hand, the stone weapons and implements found in Europe so very closely resemble those in use amongst various races of existing savages that they give us vivid, and I think to a great extent, accurate ideas of the mode of life which prevailed at that distant period; distant indeed it was, according to the ideas of chronology which almost universally prevailed until within the last quarter of a century, for we can scarcely doubt that even the later Stone Age goes back to a period more remote than the 6,000 years which were traditionally supposed to be the limit of man's existence on earth. No doubt, indeed, the difficulties of the received chronology had long been felt. Well-marked varieties of the human race are shown by the Egyptian monuments to have existed as early, at any rate, as the fifteenth century before Christ. The antiquity of Man is also indicated by the differences of language, and by the existence of powerful and flourishing monarchs at a very early period; for the pyramids themselves are considered by M. Mariette and other high authorities to have been constructed about 4,000 years B.c., and even at that early period it would appear that the Sphinx was suffering from age, for we possess a decree by which Cheops provides for its repair.

Quitting now the Neolithic, or second Stone Age, we come to the Palæolithic or first Stone Age. At this 
period man appears to have been ignorant not only of metals, but of pottery. The stone implements are much ruder, and are simply chipped into form, being never ground or polished. We have no evidence of the existance of any domestic animals, and man probably lived mainly on the produce of the chase, contending for the possession of Europe with animals which now exist only in distant regions, or have become entirely extinct. So unexpected were these facts, so improbable did they appear, that geologists accepted them only after reiterated and incontrovertible proofs. The researches of MM. Tournal and Christol in the caves of the south of France, now just half a century ago-the still more complete investigations of Dr. Schmerling in those of Belgium, during the years 1833-34-scarcely raised even a doubt upon the subject. Those of Mr. McEnery in Kent's Cavern attracted little attention; subsequent observations made there by Mr. Vivian were refused publication, on account of the inherent improbability of the conclusions to which they pointed. The discoveries of M. Boucher de Perthes were neglected for a quarter of a century, and it is not too much to say that if geologists are open to blame at all for their behaviour with reference to this question, it would certainly be rather for their incredulity-for their blind adherence to traditional chronology-than for too ready an acceptance of new views. Yet they may well be pardoned for long hesitation before they could bring themselves to believe that man really inhabited Europe at a time when not only the urus and the bison and the reindeer occupied the whole of Europe as far south as the Alps, but when the cave lion, the cave bear, the 
long-haired rhinoceros, the mammoth, the musk sheep, and the hippopotamus also formed part of the European fauna; when the climate was very different and liable to great oscillations; when our rivers had but begun to excavate their valleys, and the whole condition of the country must therefore have been singularly different from what it is now. Gradually, however, the evidence became overwhelming: the statements of Tournal and Christol were confirmed by Lartet and Christy, by De Vibraye and others; those of Schmerling by Dupont; of McEnery by Vivian and Pengelly; and at length the evidence, well summed up in his work on "Cave Hunting," by Mr. Boyd Dawkins, himself a successful worker in this field of research, left no room for doubt. As regards the Drift Gravels, M. de Perthes not only discovered unmistakable flint implements in the drift gravel of the Somme valley, but he convinced every one that these implements really belonged to the gravels in which they occurred, and he taught us to find similar implements for ourselves in the corresponding strata of the river systems. For the full significance, however; of these facts, we are indebted to the profound geological knowledge of Mr. Prestwich; while Mr. Evans taught us to appreciate the essential characteristics which distinguish the stone implements of the two periods, to which I have ventured to give the names Palæolithic and Neolithic.

Characteristic remains of the Palæolithic period have been found in this neighbourhood by Dr. Blackmore, Mr. Stevens, Mr. James Brown, and others We shall see an interesting series of them when we visit the Museum.

Whether man existed in Europe at a still earlier period, in preglacial, or even, as some suppose, in miocene 
times, is a question still under diseussion, into which I will not now enter. Under any circumstances, the antiquity of the human race must be very considerable.

This conclusion rests upon three distinct considerations. The forms of the implements are indeed unlike those which characterise the Neolithic period. But although it is a remarkable fact, and one the significance of which must not be overlooked, that while on the one hand, the forms of the Palæolithic period are entirely wanting in our tumuli; so on the other, the polished implements, the finely carved spearheads of the Neolithic period, have never yet been found in the drift gravel. Nevertheless, their antiquity does not depend on these considerations. The three reasons which have induced geologists and antiquaries to ascribe so great an age to these remains are-firstly, the mammalian relics with which they are associated; secondly, and still more, the nature and position of the deposits in which they occur; lastly, and most of all, the changes of climate which are indicated by the facts. 'The animal remains which characterise this period are certainly of very great interest. Who would have thought, not many years ago, that the remarkable fauna to which I have just alluded had ever inhabited our valleys, wandered in our forests and over our downs.

A striking illustration of this fauna is that discovered in the Cave of Kesserloch, near Thayngen, in Switzerland, recently explored by Mr. Merk, whose memoir has been translated into English by Mr. Lee.

Not only, however, is this fauna remarkable from the list of species, but also with reference to their relative abundance, Thus, the Alpine and the field hare were 
both present, but the former was by far the most abundant. The reindeer, again, was fifty times as numerous as the red deer; but, perhaps, the most surprising case is that of the foxes. About eighty individuals were represented, and of these more than forty-five belonged to the Canis fulvus, or North American fox; more than twenty to the Arctic fox (Canis lagopus), which has also been met with in England by Mr. Busk under similar circumstances, and will, probably, be found to have been sometimes mistaken for the common fox; while of the common European fox, only two or three could be determined. In other respects, the fauna of this ancient period is interesting, as tending to connect forms now distinct. Thus, according to Mr. Busk, than whom there is no higher authority on the Pleistocene mammalia, some remains of bears found in the bone caves are identical with those of the American grizzly bear; and the ancient bison was intermediate between the existing bison of America and the European aurochs.

The next consideration on which the antiquity of these remains depends, is the nature and position of the river gravels in which they are found. These gravels have evidently been formed and deposited by the rivers themselves, when they ran at a higher level, that is to say, before they had excavated their valleys to the present depth. Even at that time, the areas of drainage, at least of the principal rivers in question, for instance the Somme, the Seine, the Oise, the Thames, \&c., were the same as now. This is proved by the fact that the pebbles which constitute the gravels are always such as might have been derived from the area of drainage. Thus the gravels of the Somme are made up of flint pebbles, the 
district drained by that river being entirely a chalk area. But if the river during the Palæolithie period had extended only six miles further inland, it would have entered upon an area containing rocks of earlier periods, fragments of which must in such a case have formed a constituent part of its gravels. This consideration is very important, because it shows that the valleys must have been excavated by the present rivers; even admitting that from the then condition of the climate, and from other considerations, floods of that period may have been both more frequent and more violent. Still the excavation of the valleys must have been due to the rainfall of each respective area, and thus not ascribable either to one great cataclysm or to the fact of the rivers having drained larger areas than at present. In many cases, the excavation of the valley is even greater than might at first be supposed. The valley of the Somme, for instance, is forty feet deeper in reality than its present form would indicate, the river having filled it up again to that extent.

The valley itself is from 200 to 250 feet in depth, and although this affords us no means of making even an approximate calculation as to time, still it is obvious that to excavate a valley, such as that of the Somme, to a depth of 250 feet, and to fill it up to the extent of thirty or forty feet with sand, silt and peat, must have required a very considerable lapse of time.

Passing on now to the question of climate, it will be observed that the assemblage of mammalia to which I have already referred, is remarkable in several ways. It is interesting to find that man coexisted in our woods and valleys - on Salisbury Plain, and on the banks of the 
Avon-with animals which are now to be found only in remote regions, or which are altogether extinct. It is sufficiently surprising to reflect that on this very spot where we are now assembled there once ranged large herds of those strange and gigantic animals; but another most interesting consideration is, that when we come to consider them more closely, we shall find that they constitute in reality two distinct groups. The hippopotamus, for instance, and probably the hyena, extended into Great Britain, the porcupine into Belgium, the African elephant into Spain and Sicily; facts all indicating a climate warmer than the present. On the other hand, the mammoth and the long-haired rhinoceros, the reindeer and the marmot, the arctic hare and fox, the ibex, chamois, and the musk-sheep, point decidedly to arctic conditions. The musk-sheep indeed has the most northern range of any known mammal.

Passing over for the present those mammalia which seem to indicate a tropical climate, let us consider what may be called the arctic group, and I may observe in passing that the existence of a very cold climate during the latest geological period had been inferred from other considerations, even when our knowledge of the mammalian fauna was much less considerable and consequently. less suggestive. Various theories have been suggested to account for the fact that at a period, geologically speaking so recent, the climate of Europe should have been so different from what it is at present, and the best authorities seem now to consider that the true explanation is to be found in astronomical causes. If the plane of the equator coincided exactly with that of the ecliptic, every day would be succeeded by a night of equal length. 
In consequence, however, of the obliquity of the ecliptic, this only happens twice in the year, namely, on the 20th of March and 23rd of September, which days divide the year into two halves, the day being longer than the night in the spring and summer, and shorter, on the other hand, in autumn and winter. Under existing circumstances then, we have in the northern hemisphere seven days more of summer than of winter, while in the southern hemisphere they have, on the other hand, seven days more of winter than of summer. This, however, has not been, nor will it be always the case; on the contrary, a gradual change is continually taking place, during a cycle of 21,000 years. Taken by itself, the balance of astronomical authority is not, I think, of opinion that this would greatly influence our climate. The effect, however, which the obliquity of the ecliptic would exercise depends greatly on the degree of eccentricity of the earth's orbit. This is continually changing, and the more elliptical it is, the greater is the effect produced by the above mentioned causes. At present the orbit is nearly circular, and consequently the difference of temperature between the two hemispheres is less than usual.

Mr. Croll and Mr. Stone have calculated the eccentricity for the last million of years and have shown that there are two periods especially, one namely from 850,000 to 750,000 years ago, the other from 200,000 to 100,000 years ago, when the eccentricity of the orbit was far greater than usual, and when, therefore, the difference of temperature between the two hemispheres must also have been unusually great. From 100,000 to 200,000 years ago, then, there was a period when our climate underwent violent oscillations, being for 10,500 years 
far colder than now, then for a similar period far hotter, then far colder again, and so on for several variations. These alternations of hot and cold periods beautifully explain the difficult problem of how to account for the existence of remains belonging to tropical and to arctic animals, associated together in the same river gravels. It also throws light on the fact, first pointed out by my friend, M. Morlot, that there are in Switzerland geological indications of several periods of extreme cold, with others of more genial climate, and Mr. Croll in his "Climate and Time," has pointed out, from the evidence of 250 borings in the Scotch glacial beds, that many of them show evidence of the existence of warm interglacial periods.

The antiquity of this period, therefore, really must be solved by the mathematician and physicist, rather than by the antiquary, and it affords us an excellent illustration of the manner in which the different branches of science depend upon one another, and of the fact that the more science advances, the more necessary it is that. our higher education should be based on a wide foundation.

THE END. 
LONDON :

R. CLAY, SONS, AND TAYLUR, BRFAD STREET H'LL, 1:C. 


\section{BY THE SAME AUTHOR.}

\section{PREHISTORIC TIMES, AS ILLUSTRATED BY ANCIENT}

REMAINS AND THE MANNERS AND CUSTOMS OF MODERN SAVAGES. 4th Edition. 1878.

ON THE ORIGIN OF CIVILISATION AND PRIMITIVE CONDITION OF MAN. 3rd Edition. 1875.

MONOGRAPH OF THE COLLEMBOLA AND THYSANURA. 1871.

ON THE ORIGIN AND METAMORPHOSES OF INSECTS. With Illustrations. 2nd Edition. 1874. Crown 8vo. 3s. 6d.]

[Macmillan and Co.

ON BRITISH WILD FLOWERS CONSIDERED IN RELATION TO INSECTS. With Illustrations, 2nd Edition. 1875. Crown 8 vo. $4 s, 6 d$, 


\section{MACMILLAN \& CO.'S PUBLICATIONS.}

\section{By H. CHARLTON BASTIAN, M.D., F.R.S.}

THE BEGINNINGS OF LIFE: Being some Account of the Nature, Modes of Origin, and Transformations of Lower Organisms. In Two Volumes. With upwards of 100 Illustrations. Crown 8vo. $28 s$.

EVOLUTION AND THE ORIGIN OF LIFE. Crown 8vo. 6s. $6 d$.

COAL : ITS HISTORY AND ITS USES. By Professors Green, Miall, Thorpe, Rücker, and Marshall, of the Yorkshire College, Leeds. With Illustrations. 8 vo. $12 s .6 d$.

CAVE-HUNTING : Researches on the Evidence of Caves respecting the Early Inhabitants of Europe. By W. Boyd Dawkins, F.R.S., \&c., Professor of Geology at Owens College, Manchester. With Coloured Plate and Woodcuts. 8vo. $21 s$.

THE FORCES OF NATURE: A Popular Introduction to the Study of Physical Phenomena. By AMḱDÉE Gulllemin. Translated from the French by Mrs. Norman Lockyer; and Edited, with Additions and Notes, by J. Norman Lockyer, F.R.S. Illustrated by Coloured Plates, and 455 Woodcuts. Third and Cheaper Edition. Royal 8vo. 218.

THE APPLICATIONS OF PHYSICAL FORCES. By A. Guillemin. Translated from the French by Mrs. Lockyer, and Edited, with Notes, and Additions, by J. N. LockYER, F.R.S. With Coloured Plates and numerous Illustrations. Cheaper Edition. Imperial $8 \mathrm{vo}$, cloth, extra gilt. $36 s$.

Also in Eighteen Monthly parts, price 1s. each. Part I. in November, 1878.

By Sir J. D. HOOKER, K.C.S.I., C.B., F.R.S., M.D., D.C.L.

THE STUDENT'S FLORA OF THE BRITISH ISLANDS. Second Edition, revised and improved. Globe 8vo. 10s. $6 d$.

PRIMER OF BOTANY. With Illustrations. 18mo. 1s. New Edition, revised and corrected.

GLAUCUS: OR, THE WONDERS OF THE SHORE. By Charles Kingsley, Canon of Westminster. New Edition, with numerous Coloured Plates. Crown 8vo. $6 s$.

ON THE GENESIS OF SPECIES. By St. George Mivart, F.R.S. Crown 8 vo. Second Edition, to which notes have been added in reference and reply to Darwin's "Descent of Man." With numerous Illustrations. pp. xv. 296 . $9 s$. 


\section{MACMILLAN \& CO.'S PUBLICATIONS.}

By the Rev. HUGH MACMILLAN.

HOLIDAYS ON HIGH LANDS; or, Rambles and Incidents in Search of Alpine Plants. Globe 8vo, cloth. $6 s$.

FIRST FORMS OF VEGETATION. Second Edition, corrected and enlarged. With Coloured Frontispiece and numerous Illustrations. Globe 8vo. $6 s$.

NOTES BY A NATURALIST ON THE CHALLENGER, being an Account of various Observations made during the Voyage of. H.M.S. Challenger round the World in the Years 1872-76. By H. N. Moseley, M.A., F.R.S., Member of the Scientific Staff of the Challenger. With Map, Coloured Plates, and Woodcuts. 8vo. $21 s$.

HABIT AND IN'TELLIGENCE: A Series of Essays on the Laws of Life and Mind. By Joseph John Murphy. Second Edition, thoroughly revised and mostly rewritten. With Illustrations. 8vo. $16 s$.

LESSONS IN ELEMENTARY BOTANY. By Professor Oliver, F.R.S., F.L.S.. With nearly 200 Illustrations. New Edition. Fcap. 8 vo. $4 s .6 d$.

By Sir WYVILLE THOMSON, K.C.B., F.R.S.

THE DEPTHS OF THE SEA: An Account of the General Results of the Dredging Cruises of H.M.SS. Porcupine and Lightning during the Summers of 1868-69-70, under the Scientific Direction of Dr. Carpenter, F.R.S., J. Gwyn Jeffreys, F.R.S., and Sir Wyville Thomson, F.R.S. With nearly 100 Illustrations and 8 Coloured Maps and Plans. Second Edition. Royal 8vo, cloth, gilt. 31s.6d.

THE VOYAGE OF THE CHALLENGER.-THE ATLANTIC. A Preliminary Account of the Exploring Voyages of H.M.S. Challenger, during the year 1873 and the early part of 1876 . With numerous Illustrations, Coloured Maps, and Charts, and Portrait of the Author, engraved by C. H. JeEns. 2 vols. Medium 8 vo. $42 s$.

\section{BY ALFRED RUSSEL WALLACE.}

CONTRIBUTIONS TO THE THEORY OF NATURAL SELECTION. A Series of Essays. New Edition, with Corrections and Additions. Crown 8vo. 8s. $6 d$.

THE GEOGRAPHICAL DISTRIBUTION OF ANIMALS, with a study of the Relations of Living and Extinct Faunas as Elucidating the Past Changes of the Earth's Surface. 2 vols., 8vo. With Maps and nurncrous Illustrations by Zwecker. $42 s$.

TROPICAL NATURE: with other Essays. 8vo. $12 s$.

$$
\text { MACMILLAN AND CO., LONDON. }
$$


Published every Thursday, price 6d.; Monthly Parts 2s. and 2s.6d., Half-Yearly Volumes, $15 s$.

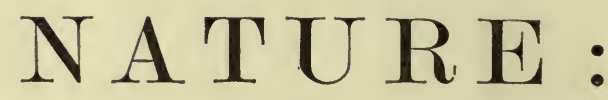

AN ILLUSTRATED JOURNAL OF SCIENCE.

NATURE expounds in a popular and yet authentic manner, the Grand RESULTS of SCIENTIFIC RESEARCH, discussing the most recent scientific discoveries, and pointing out the bearing of Science upon civilisation and progress, and its claims to a more general recognition, as well as to a higher place in the educational system of the country.

It contains original articles on all subjects within the domain of Science ; Reviews setting forth the nature and value of recent Scientific Works; Correspondence columns, forming a medium of Scientific discussion and of intercommunication anong the most distinguished men of Science; Serial Columns, giving the gist of the most important papers appearing in Scientific Journals, both Home and Foreign; Transactions of the principal Scientific Societies and Academies of the World, Notes, \&c.

\section{NATURE SERIES.}

THE SPECTROSCOPE AND ITS APPLICATIONS. BY J.N. LOCKYER, F.R.S. With Illustrations. Second Edition. Crown 8vo. 3s.6d.

THE ORIGIN AND METAMORPHOSES OF INSECTS. By Sir JOHN LUBвоск, M.P., F.R.S. With Illustrations. Crown 8vo. 3s.6d. Second Edition.

THE TRANSIT OF VEN US. By G. Forbes, B.A., Professor of Natural Philosophy in the Andersonian University, Glasgow. With numerous Illustrations. Crown 8 vo. $3 s .6 d$.

THE COMMON FROG. By St. George Mivart, F.R.S. Illustrated. Crown 8vo. 3s. $6 d$.

POLARISATION OF LIGHT. By W. SpotTiswcode, LL.D., President of the Royal Society. Illustrated. Second Edition. Crown 8vo. 3s.6d.

ON BRITISH WILD FLOWERS CONSIDERED IN RELATION TO INSECTS. By Sir JoHN LUBBock, M.P., F.R.S. Illustrated. Second Edition. Crown 8vo. 4s. $6 d$.

THE SCIENCE OF WEIGHING AND MEASURING. By H. W. Chisholm, Warden of the Standards. Illustrated. Crown 8vo. 4s. $6 d$.

HOW TO DRAW A STRAIGHT LINE: A Lecture on Linkages. By A. B. KEMPE, B.A. Illustrated. Crown 8vo, $1 s, 6 d$.

LIGHT; A Series of Simple, Entertaining, and Useful Experiments in the Phenomena of Light, for the Use of Students of every Age. By ALFrRd M. Mayer and Charles Barnard. With Illustrations. Crown 8vo. 2s. $6 d$.

SOUND : A Series of Simple, Entertaining, and Inexpensive Experiments in the Phenomena of Sound, for the Use of Students of every Age. By A. M. MaYer, Professor of Physics in the Stevens Institute of Technology, \&c. With numerous Illustrations. Crown 8vo. 3s. $6 d$. 
Bedford Street, Covent Garden, London, March 1879.

MACMILLAN \& Co.'S CATALOGUE of WORKS in MATHEMATICS and PHYSICAL SCIENCE; including PURE and APPLIED MATHEmatics; Physics, Ástronomy, GEOLOGY, CHEMISTRY, ZOOLOGY, BOTANY; and of WORKS in MENTAL and MORAL PHILOSOPHY and Allied Subjects.

\section{MATHEMATICS.}

Airy.-Works by Sir G. B. AIry, K.C.B., Astronomer Royal :-

ELEMENTARY TREATISE ON PARTIAL DIFFERENTIAL EQUATIONS. Designed for the Use of Students in the Universities. With Diagrams. New Edition. Crown 8vo. 5s. $6 d$.

ON THE ALGEBRAICAL AND NUMERICAL THEORY OF ERRORS OF OBSERTATIONS AND THE COMBINA. TION OF OBSERVATIONS. Second Edition. Crown 8vo. 6s. $6 d$.

UNDULATORY THEORY OF OPTICS. Designed for the Use of Students in the University. New Edition. Crown 8vo. $6 s .6 \%$.

ON SOUND AND ATMOSPHERIC VIBRATIONS. With the Mathematical Elements of Music. Designed for the Use of Students of the University. Second Edition, revised and enlarged. Crown 8vo. 9s.

A TREATISE ON MAGNETISM. Designed for the Use of Students in the University. Crown 8 vo. $9 s .6 d$.

Ball (R. S., A.M.)-EXPERIMENTAL MECHANICS. A Course of Lectures delivered at the Royal College of Science for Ireland. By Robert Stawell Ball, A.M., Professor of Applied Mathematics and Mechanics in the Royal College of Science for Ireland (Science and Art Department). Royal 8vo. $16 s$.

"We have not met with any book of the sort in English. It elucidates instructively the methods of a teacher of the very highest rank. We most cordially recommend it to all our readers."Mechanics' Magazine. 
Bayma.-THE ELEMENTS OF MOLECULAK MECHANICS. By Joseph BAYMa, S.J., Professor of Philosophy, Stonyhurst College. Demy 8vo. cloth. Ios. $6 d$.

Boole.-Works by G. Boole, D.C.L, F.R.S., Professor of Mathematics in the Queen's University, Ireland :-

A TREATISE ON DIFFERENTIAL EQUATIONS. Third E.dition. Edited by I. TODHUNTER. Crown.8vo. cloth. 14s.

"A treatise incomparably superior to any other elementary book on the subject with which we are acquainted." - Philosophical Magazine.

A TREATISE ON DIFFERENTIAL EQUATIONS. Supplementary Volume. Edited by I. TodHUnTER. Crown 8vo. cloth. 8s. $6 d$.

THE CALCULUS OF FINITE DIFFERENCES. Crown 8vo. cloth. IOs. $6 d$. New Edition revised.

Cheyne. - AN ELEMENTARY TREATISE ON THE PLANETARY THEORY. With a Collection of Problems. By C. H. H. Cheyne, M.A., F.R.A.S. Second Edition. Crown 8vo. cloth. $6 s .6 d$.

Clifford.-THE ELEMENTS OF DYNAMIC. An Introduction to the study of Motion and Rest in Solid and Fluid Bodies. By W. K. CLIfFord, F.R.S., Professor of Applied Mathematics and Mechanics at University College, London. Part I.-Kinematic. Crown 8 vo. $7 s .6 d$.

Cumming.-AN INTRODUCTION TO THE THEORY OF ELECTRICITY. With numerous Examples. By LINNÆUS Cumming, M.A., Assistant Master at Rugby School. Crown 8vo. 8s. $6 d$.

Cuthbertson.-EUCLIDIAN GEOMETRY. By F. CuTHBERTSON, M.A., Head Mathematical Master of the City of London School. Extra fcap. 8 vo. 4s. $6 d$.

Ferrers.-Works by the Rev. N.M. Ferrers, M.A.,F.R.S., Fellow and Tutor of Gonville and Caius College, Cambridge :-

AN ELEMENTARY TREATISE ON TRILINEAR CO-ORDI. NATES, the Method of Reciprocal Polars, and the Theory of Projectors. Third Edition, revised. Crown 8vo. 6s. $6 d$.

SPHERICAL HARMONICS AND SUBJECTS CONNECTED WITH THEM. Crown 8vo. 7 s. $6 d$. 
Frost.-Works by Percival Frost, M.A., late Fellow of St. John's College, Mathematical Lecturer of King's Coll. Cambridge:-

THE FIRST THREE SECTIONS OF NEWTON'S PRINCIPIA. With Notes and Illustrations. Also a Collection of Problems, principally intended as Examples of Newtor's Methods. Third Edition. 8vo. cloth. I2s.

\section{AN ELEMENTARY TREATISE ON CURVE TRACING.} 8vo. I2s.

SOLID GEOMETRY. Being a New Edition, revised and enlarged, of the Treatise by Frost and Wolstenholme. Vol. I. 8vo. i6s.

Godfray.-Works by HUgh Godfray, M.A., Mathematical Lecturer at Pembroke College, Cambridge :-

A TREATISE ON ASTRONOMY, for the Use of Colleges and Schools. 8vo. cloth. I2s, $6 d$.

"It is a working book," says the Guardian, "taking Astronomy in its proper place in the Mathematical Sciences. . . . It is a book which is not likely to be got up unintelligently."

AN ELEMENTARY TREATISE ON THE LUNAR THEORY, with a Brief Sketch of the Problem up to the time of Newton. Second Edition, revised. Crown 8vo. cloth. 5s. $6 d$.

"As an elementary treatise and introduction to the subject, we think it may justly claim to supersede all former ones."-London, Edinburgh, and Dublin Phil. Magazine.

Green (George).-MATHEMATICAL PAPERS OF THE LATE GEORGE GREEN, Fellow of Gonville and Caius College, Cambridge. Edited by N. M. Ferrers, M.A., Fellow and Tutor of Gonville and Caius College. 8vo. I5s.

"It has been for some time recognized that Green's writings are amongst the most valuable mathematical productions zee possess."Athenæum.

Hemming. - AN ELEMENTARY TREATISE ON THE DIFFERENTIAL AND INTEGRAL CALCUI.US. For the Use of Colleges and Schools. By G. W. Hemming, M.A., Fellow of St. John's College, Cambridge. Second Edition, with Corrections and Additions. 8vo. cloth. 9s.

Jackson.-GEOMETRICAL CONIC SECTIONS. An Eiementary Treatise in which the Conic Sections are defined as the Plane Sections of a Cone, and treated by the Method of Projections. By J. Stuart Jackson, M.A., late Fellow of Gonville and Caius College. Crown 8vo. 4 s. 6 . 
Kelland and Tait.-AN INTRODUCTION TO QUATERNIONS. With numerous Examples. By P. KELland, M.A., F.R.S., and P. G. TAIT, M.A., Professors in the department of Mathematics in the University of Edinburgh. Crown 8vo. $7 s .6 d$.

Kempe.-HOW TO DRAW A STRAIGHT LINE. A Lecture on Linkages. By A. B. Kem PE, B.A. Illustrated. Crown 8vo. Is. $6 d$.

Merriman.-ELEMENTS OF THE METHOD OF LEAST SQUARES. By MANSFieln MERriman, Professor of Civil and Mechanical Engineering, Lehigh Univer:ity, Bethlehem, Penn., U.S.A. Crown 8 vo. $7 s .6 d$.

Morgan.-A COLLECTION OF PROBLEMS AND EXAMPLES IN MATHEMATICS. With Answers. By H. A. Murgan, M.A., Sadlerian and Mathematical Lecturer of Jesus College, Cambridge. Crown 8vo. cloth. $6 s .6 d$.

Newton's Principia.-4to. cloth. 31s. $6 d$.

It is a sufficient guarantee of the reizability of this complete edition of Newton's Principia that it has been printed for and under the care of Professor Sir Willian Thomson and Professor Blackburn, of Glasgowe University.

Parkinson.-A TREATISE ON OPTICS. By S. PARKINson, D.D., F.R.S., Fellow and Tutor of St. John's College, Cambridge. Third Edition, revised and enlarged. Crown 8 vo. cloth. IOs. $6 d$.

Phear.-ELEMENTARY HYDROSTATICS. With Numerous - Examples. By J. B. Phear, M.A., Fellow and late Ássistant Tutor of Clare Coll. Cambridge. Fourth Edition. Cr. 8vo. cloth. 5s.6d.

Pirrie.-LESSONS ON RIGID DYNAMICS. By the Rev. G. PIrrie, M.A., Fellow and Tutor of Queen's College, Cambridge. Crown 8 vo. $6 s$.

Puckle.-AN ELEMENTARY TREATISE ON CONIC SECTIONS AND ALGEBRAIC GEOMETRY. With numerous Examples and Hints for their Solution. By G. HALE PUCKLE, M.A. Fouth Edition, enlarged. Crown 8vo. $7 s .6 d$.

Rayleigh.-THE THEORY OF SOUND. By LORD RAYIEIGH, F.R.S., formerly Fellow of Trinity College, Cambridge. 8 vo. Vui. I. 12s. 6d.; Vol. II. 12s. $6 d$.

[Vol. III. in preparation.

Reuleaux.-THE KINEMATICS OF MACHINERY. Outlines of a Theory of Machines. By Professor F. Reuleaux. Translated and edited by A. B. W. KEnNEDY, C.E., Professor of Civil and Mechanical Engineering, University College, London. With 450 Illustrations. Royal 8vo. 20s. 
Routh.-Works by Edward John Routh, M.A., F.R.S., late Fellow and Assistant Tutor of St. Peter's College, Cambridge; Examiner in the University of London :-

AN ELEMENTARY TREATISE ON THE DYNAMICS OF THE SYSTEM OF RIGID BODIES. With numerous Examples. Third Edition, enlarged. 8vo. $21 s$.

STABILITY OF A GIVEN STATE OF MOTION, PARTICULARLY STEADY MOTION. The Adams' Prize Essay for 1877. 8vo. 8s. 6d.

Tait and Steele.-DYNAMICS OF A PARTICLE. With numerous Examples. By Professor TAIt and Mr. SteELE. Fourth Edition, revised. Crown 8vo. $12 s$.

Thomson.-PAPERS ON ELECTROSTATICS AND MAGNETISM. By Professor Sir William Thomson, F.R.S. 8vo. $18 s$.

Todhunter.-Works by I. Todhunter, M.A., F.R.S., of St. John's College, Cambridge :-

"Mr. Todhunter is chiefly known to students of mathematics as the author of a series of admirable mathematical text-books, which possess the rare qualities of being clear in style and absolutely free from mistakes, typographical or other."-Saturday Review.

A TREATISE ON SPHERICAL TRIGONOMETRY. New Edition, enlarged. Crown 8vo. cloth. 4s. $6 d$.

PLANE CO-ORDINATE GEOMETRY, as applied to the Straight Line and the Conic Sections. With numerous Examples. New Edition. Crown Svo. 7s. $6 d$.

A TREATISE ON THE DIFFERENTIAL CALCULUS. With numerous Examples. New Edition. Crown 8vo. IOs. $6 d$.

A TREATISE ON THE INTEGRAL CALCULUS AND ITS APPLICATIONS. With numerous Examples. New Edition, revised and enlarged. Crown 8vo. cloth. Ios. $6 d$.

EXAMPLES OF ANALYTICAL GEOMETRY OF THREE DIMENSIONS. New Edition, revised. Crown 8vo. cloth. $4 s$.

A TREATISE ON ANALYTICAL STATICS. With numerous Examples. New Edition, revised and enlarged. Crown Svo. cloth. IOs. 6 .

A HISTORY OF THE MATHEMATICAL THEORY OF PROBABILITY, from the Time of Pascal to that of Laplace. 8vo. $18 s$.

RESEARCHES IN THE CALCULUS OF VARIATIONS, Principally on the Theory of Discontinuous Solutions: An Fssay to which the Adams' Prize was awarded in the University of Cambridge in 1871 . 8vo. $6 s$. 


\section{Todhunter-continued.}

A HISTORY OF THE MATHEMATICAL THEORIES OF ATTRACTION, and the Figure of the Earth, from the time of Newton to that of Laplace. Two vols. 8vo. 24s.

"Probably no man in England is so qualified to do justice to the theme as Mr. Todhunter. To all mathematicians these volumes will be detply interesting, and to all succeeding investigators, of the highest practical utility." - A thenæum.

AN ELEMENTARY TREATISE ON LAPLACE'S, LAME'S, AND BESSEL'S FUNCTIONS. Crown 8vo. Ios. $6 d$.

Wilson (W. P.) - A TREATISE ON DYNAMICS. By W. . Wilson, M.A., Fellow of St. John's College, Canibridge, and Professor of Mathematics in Queen's College, Belfast. 8vo. 9s. $6 d$.

Wolstenholme.-MATHEMATICAL PROBLEMS, on Subjects included in the First and Second Divisions of the Schedule of Subjects for the Cambridge Mathematical Tripos Examination. Devised and arranged by JOSEPH WOLSTENHOLME, late Fellow of Christ's College, sometime Fellow of St. John's College, and Professor of Mathematics in the Royal Indian Engineering Colleze. New Edition, greatly enlarged. 8vo. I8s.

Young.-SIMPLE PRACTICAL METHODS OF CALCU. LATING STRAINS ON GIRDERS, ARCHES, AND TRUSSES. With a Supplementary Essay on Economy in suspension Bridges. By E. W. Young, Associate of King's College, London, and Member of the Institution of Civil Engineers. 8vo. 7s. $6 d$. 


\section{PHYSICAL SCIENCE.}

Airy (G. B.) -POPULAR ASTRONOMY. With Illustrations. By Sir G. B. ArRy, K.C.B., Astronomer Royal. New Edition I8mo. cloth. 4s. $6 d$.

Bastian.-Works by H. Charlton Bastian, M.D., F.R.S., Professor of Pathological Anatomy in University College, London, \&c. :-

THE BEGINNINGS OF LIFE: Reing some Account of the Nature, Modes of Origin, and Transformations of Lower Organisms. In Two Volumes. With upwards of 100 Illustrations. Crown 8vo. 28.s. "It is a book that cannot be ignored, and must inevitably lead to renewed discussions and repeated observations. and through these to the establishment of truth." - A. R. Wallace in Nature.

EVOLUTION AND THE ORIGIN OF LIFE. Crown 8vo. 6s. $6 \dot{d}$.

"Abounds in information of interest to the student of biological science."- -Daily News.

Blake.-ASTRONOMICAL MYTHS. Based on Flammarion's "The Heavens." By John F. BLAKE. With numerous Illustrations. Crown 8vo. 9s.

Blanford (H. F.)-RUDIMENTS OF PHYSICAL GEO. GRAPHY FOR THE USE OF INDIAN SCHOOLS. By H. F. BlanforD, F.G.S. With numerous Illustrations and Glossary of Technical Terms employed. New Edition. Globe 8vo. 2s, $6 d$.

Blanford (W. T.)-GEOLOGY AND ZهOLOGY OF ABYSSINIA. By W. T. Blanford. 8vo. $2 \mathrm{I} s$.

Bosanquet.-AN ELEMENTARY TREATISE ON MUSICAL INTERVALS AND TEMPERAMEN $r$. With an Account of an Enharmonic Harmonium exhibited in the Loan Collection of Scientific Instruments, South Kensington, 1876 ; also of an Enharmonic Organ exhibited to the Musical Association of London, May, 1875. By R. H. Bosanquet, Fellow of St. John's College, Oxford. 8vo. $6 s$.

Coal : ITS HISTORY AND ITS USES. By Professors Green, Miall, ThORPE, RÜCKER, and MARShall, of the Yorkshire College, Leeds. With Illustrations. 8vo. I2s. $6 d$.

"It furnishes a very comprehensive treatise on the zwhole subject of Coal from the geological, chemical, mechanical, and industrial points of view, concluding with a chapter on the important topic known as the 'Coal Question." - Daily New's. 
Cooke (Josiah P., Jun.)-FIRST PRINCIPLES OF CHEMICAL PHILOSOPHY. By JOSIAH P. COOKE, Jun., Ervine Professor of Chemistry and Mineralogy in Harvard College. Third Edition, revised and corrected. Crown 8vo. $12 s$.

Cooke (M. C.)-HANDBOOK OF BRITISH FUNGI, with full descriptions of all the Species, and Illustrations of the Genera. By M. C. Cooke, M.A. Two vols. crown 8vo. 24s.

"Will maintain its place as the standard English book, on the subject of which it treats, for many years to come." - Standard.

Dawkins,-CAVE-HUNTING : Researches on the Evidence of Caves respecting the Early Inhabitants of Europe. By W. BOYD Dawkins, F.R.S., \&c., Professor of Geology at Owens College, Manchester. With Coloured Plate and Woodcuts. 8vo. 21s.

"The mass of information he has brought together, with the judicious use he has made of his materials, will be found to invest his book with much of new and singular value." -Saturday Review.

Dawson (J. W.)-ACADIAN GEOLOGY. The Geologic Structure, Organic Remains, and Mineral Resources of Nova Scotia, New Brunswick, and Prince Edward Island. By JонN Wrlliam Dawson, M.A., LL.D., F.R.S., F.G.S., Principal and Vice-Chancellor of M'Gill College and University, Montreal, \&c. With a Geological Map and numerous Illustrations. Third Edition, with Supplement. 8vo. 2Is. Supplement, separately, 2s. $6 d$.

"The book will doubtless find a place in the library, not only of the scientific geologist, but also of all who are desirous of the industrial progress and commercial prosperity of the Acadian provinces."-Mining Journal.

Fleischer.-A SYSTEM OF VOLUMETRIC ANALISIS. By Dr. E. Fleischer. Translated from the Second German Edition by M. M. Pattison Muir, with Notes and Additions. Illustrated. Crown 8vo. 7 s. $6 d$.

Forbes.-THE TRANSIT OF VENUS. By George Forbes, B.A., Professor of Natural Philosophy in the Andersonian University of Glasgow. With numerous Illustrations. Crown 8vo. 3 s. $6 d$.

Foster and Balfour.-ELEMENTS OF EMBRYOLOGY By Michael Foster, M.D., F.R.S., and F. M. Balfour, M.A., Fellow of Trinity College, Cambridge. With numerous Illustrations. Part I. Crown 8vo. 7s. $6 d$.

Galton.-Works by Francis Galton, F.R.S. :-

METEOROGRAPHICA, or Methods of Mapping the Weather. IIlustrated by upwards of 600 Printed Lithographic Diagrams. 4to. $9 \mathrm{~s}$. 
Galton-continued.

HEREDITARY GENIUS : An Inquiry into its Laws and Consequences. Demy 8vo. I2s.

The Times calls it " a most able and most interesting book."

ENGLISH MEN OF SCIENCE; THEIR NATURE AND NURTURE. 8vo. 8s. $6 d$.

"The book is certainly one of very great interest."-Nature.

Geikie.-Works by Arcinibald Geikie, LL.D., F.R S., Murchison Professor of Geology and Mineralogy at Edinburgh :ELEMENTARY LESSONS IN PHYSICAL GEOGRAYHY. With numerous Illustrations. 'Fcap. 8vo. 4s. 6d. Questions, Is. $6 d$. FIELD GEOLOGY. With Illustrations. Crown ชvo. [Shortly. PRIMER UF GEOLOGY. Illustrated. I8mo. I $s$.

PRIMER OF PHYSICAL GEOGRAPHY. Illustrated. I8mo. Is.

Gurdon.-AN ELEMENTARY BOOK ON heat. By J. E. H. Gurdon, B.A., Gonville and Caius College; Cambridge. Crown 8vo. $2 s$.

Guillemin.-THE FORCES OF NATURE : A Popular Introduction to the Study of Physical Phenomena. By Amédée Guillemin. Translated from the French by Mrs. NOKMAN LOCKYER; and Edited, with Additions and Notes, by J. NormaN LOCKYER, F.R.S. Illustrated by Coloured Plates, and 455 Woodcuts. Third and cheaper Edition. Royal 8vo. 2 Is.

"Translator and Editor have done justice to their trust. The text has all the force and. flow of original writing, combining faithfulness to the author's meaning with purity and independence in regard to idiom; while the historical precision and accuracy pervading the work throughout, speak of the watchful editorial supervision which has been given to every scientific detail. Nothing can well exceed the clearness and delicacy of the illustrative woodcuts. Altogether, the work may be said to have no parallel, either in point of fulness or attraction, as a popular manual of physical science." - Saturday Review.

THE APPLICATIONS OF PHYSICAL FORCES. By A. Guillemin. Translated from the French by Mrs. Lockyer, and Edited with Notes and Additions by J. N. LockYER, F.R.S. With Coloured Plates and numerous Illustrations. Cheaper Edition. Imperial 8vo. cloth, extra gilt. $36 s$.

Also in Eighteen Monthly Parts, price Is. each. Part I. in November, I 878 .

"A book which we can heartily recommend, both on account of the width and soundness of its contents, and also because of the excellence of its print, its illustrations, and external appearance."Westminster Review. 
Hanbury.-SCIENCE PAPERS : chiefly Pharmacological and Botanical. By Daniel Hanbury, F.R.S. Edited, with Memoir, by J. INCE, F.L.S., and Portrait engraved by C. H. JEENS. 8Vo. I4s.

Henslow.-THE THEORY OF EVOLUTION OF LIVING THIINGS, and Application of the Principles of Evolution to Religion considered as Illustrative of the Wisdom and Beneficence of the Almighty. By the Rev. George Henslow, M.A., F.L.S. Crown 8vo. $6 s$.

Hooker.-Works by Sir J. D. Hooker, K.C.S.I., C.B., F.R.S., M.D., D.C.L. :-

THE STUDENT'S FLORA OF THE BRITISH ISLANDS. Second Edition, revised and improved. Globe 8vo. Ios. $6 d$.

The object of this work is to supply students and field-botanists with a fuller account of the Plants of the British Islands than the manuals hitherto in use aim at giving. "Certainly the fullest and most accurate manual of the kind that has yet appeared. Dr. Hooker has shown his characteristic industry and ability in the care and skill which he has thrown into the characters of the plants. These are to a great extent original, and are really admirable for their combination of clearness, brevity, and completeness."-Pall Mall Gazette.

PRIMER OF BOTANY. With Illustrations. I8mo. Is. New Edition, revised and corrected.

Hooker and Ball.-JOURNAL OF A TOUR IN MAROCCO AND THE GREAT ATLAS. By Sir J. D. Honker, K.C.S.I., C.B., F.R.S., \&c., and JoHN BALL, F.R.S. With Appendices, including a Sketch of the Geology of Marocco. By G. MAw, F.L.S., F.G.S. With Map and Illustrations. 8vo. $21 s$.

Huxley and Martin.-A COURSE OF PRACTICAL INSTRUCTION IN ELEMENTARY BIOLOGY. By T. H. HuXLEY, LL.D., Sec. R.S., assisted by H. N. MaR'TIN, B.A., M.B., D.Sc., Fellow of Christ's College, Cambridge. Crown 8vo. $6 s$.

"This is the most thoroughly valuable book to teachers and students of biology which has ever appeared in the English tongue."London Quarterly Review.

Huxley (Professor).-LAY SERMONS, ADDRESSES, ANI REVIEWS. By T. H. HuxLey, LL.D., F.R.S. New and Cheaper Edition. Crown 8vo. 7s. $6 d$.

Foun teen Discourses on the following subjects:-(I) On the, Advisableness of Improving Natural Knowiledge:-(2) EmancipationBlack and White:-(3) A Liberal Education, and where to find it:-(4) ScientificEducation:-(5) On the Eiducational Value of 


\section{Huxley (Professor)-continued.}

the Natural History Sciences:-(6) On the Study of Zoology:(7) On the Physical Basis of Life:-(8) The Scientific Aspects of Positivism:-(9) On a Piece of Chalk:-(10) Geological Contemporaneity and Persistent Types of Life:-(II) Geological Reform:(12) The Origin of Species:-(13) Criticisms on the "Origin of Species:"-(I4) On Descartes' "Discourse touching the Method of using One's Reason rightly and of seeking Scientific Truth."

ESSAYS SELECTED FROM "LAY SERMONS, AD. DRESSES, AND REVIEWS." Second Edition. Crown 8vo. Is. CRITIQUES AND ADDRESSES. 8vo. Ios. 6 6 .

Contents:-1. Administrative Nihilism. 2. The School Boards: what they can do, and what they may do. 3. On Medical Education. 4. Yeast. 5. On the Formation of Coal. 6. On Coral and Coral Reefs. 7. On the Methods and Results of Ethnology. 8. On some Fixed Points in British Ethnology. 9. Palcontology and the Doctrine of Evolution. 10. Biogenesis and Abiogenesis. II. Mr. Darvin's Critics. 12. The Genealogy of Animals. 13. Bishop Berkeley on the Metaphysics of Sensation.

LESSONS IN ELEMENTARY PHYSIOLOGY. With numerous Illustrations. New Edition. Fcap. 8vo. 4s. $6 d$.

"Pure gold throughout."-Guardian. " Unquestionably the clearest and most complete elementary treatise on this subject that we possess in any language." -Westminster Review.

AMERICAN ADDRESSES : with a Lecture on the Study of Biology. 8vo. 6s. $6 d$.

PHYSIOGRAPHY : An Introduction to the Study of Nature. With Coloured Plates and numerous Woodcuts. New Edition. Crown 8vo. $7 s .6 d$.

Jellet (John H., B.D.) - A TREATISE ON THE THEORY OF FRICTION. BY JUHN H. JELLET, B.D., Senior Fellow of Trinity College, Dublin; President of the Royal Irish Academy. 8vo. 8s. 6d.

Jones.-THE OWENS COLLEGE JUNIOR COURSE OF PRACTICAL CHEMISTRY. By FRANCIS JONES, Chemical Master in the Grammar School, Manchester. With Preface by Professor Roscoe. New Edition. 18mo. with Illustrations. 2s. $6 d$.

Kingsley.-GLAUCUS: OR, THE WONDERS OF THE SHORE. By Charles Kingsley, Canon of Westminster. New Edition, with numerous Coloured Plates. Crown 8vo. 6s.

Langdon.-THE APPLICATION OF ELECTRICITY TO RAILWAY WORKING. By W. E. LANGDON, Member of the Society of Telegraph Engineers. With numerous Illustrations. Extra fcap. $8 \mathrm{vn}$. 4s. 6 d. 
Lockyer (J. N.) -Works by J. NORMAN LOCKyer, F.R.S.ELEMENTARY LESSONS IN ASTRONOMY. With numerous Illustrations. New Edition. 18 mo. 5s. $6 c$.

"The book is full, clear, sound, and worthy of attention, not only as a popular exposition, but as a scientific 'Index." "- Athenæum.

"The most fascinating of elementary books on the Sciences."Nonconformist.

THE SPECTROSCOPE AND ITS APPLICATIONS. By J. NORMAN LOCKYER, F.R.S. With Coloured Plate and numerous Illustrations. Second Edition. Crown 8vo. 3s. $6 d$.

CONTRIBUTIONS TO SOLAR PHYSICS. By J. NORMAN LOCKYER, F.R.S. I. A Popular Account of Inquiries into the Physical Constitution of the Sun, with especial reference to Recent Spectroscopic Researches. II. Comrnunications to the Royal Society of London and the French Academy of Sciences, with Notes. Illustrated by 7 Coloured Lithographic Plates and 175 Woodcuts. Royal 8vo. cloth, extra gilt, price $31 s .6 \%$.

"The book may be taken as an aulhentic exposition of the present state of science in connection with the important subject of spectro. scopic analysis. . . Even the unscientific public may derive much information from it."'-Daily News.

PRIMER OF ASTRONOMY. With Illustrations. I8mo. $1 s$.

Lockyer and Seabroke.-STAR-GAZING : PAST AND PRESENT. An Introduction to Instrumental Astronomy. By J. N. Lockyer, F.R.S. Expanded from Shorthand Notes of a Course of Royal Institution Lectures with the assistance of G. M. SEABROKE, F. R.A.S. With numerous Illustrations. Royal 8vo. 2 I $s$. "A book of great interest and utility to the astronomical student." - Athenæum.

Lubbock.-Works by SiR Jонм Luввоск, M.P., F.R.S., D.C.L. : THE ORIGIN AND METAMORPHOSES OF INSECTS. With Numerous Illustrations. Second Edition. Crown 8vo. 3s. $6 d$. "As a summary of the phenomena of insect metamorphoses his little book is of great value, and will be read with interest and profit by all students of natural history. The whole chapter on the origin of insects is most interesting and valuable. The illustrations are numerous and good." - Westminster Review.

ON BRITISH WILD FLOWERS CONSIDERED IN RELATION TO INSECTS. With Numerous Illustrations. Second Edition. Crown 8 vo. 4 s. $6 d$.

Macmillan (Rev. Hugh).-For other Works by the same Author, see Theological Catalogiv.

HIOLIDAYS ON HIGH LANDS; or, Rambles and Incidents in search of Alpine Plants. Globe 8vo. cloth. $6 s$.

"One of the most charming books of its kind ever written." Literary Churchman. "Mr. Macmillan's glowing pictures of Scandinavian scenery."-Saturday Review. 
Macmillan (Rev. Hugh)-continued.

FIRST FORMS OF VEGETATION. Second Edition, corrected and enlarged, with Coloured Frontispiece and numerous Illustrations. Glube 8vo. $6 s$.

The first edition of this book was published under the name of "Footnoles from the Pase of Nature; or, First Forms of Vegetation. Probably tine best popular guide to the study of mosses, lichens, and jungi ever written. Iis practical value as a help to the student and collector cannot be exaggesated."-Manchester Examiner.

Mansfield (C. B.) - Works by the late C. B. Mansfield :-

A THEORY OF SALTS. A Treatise on the Constitution of Bipolar (two-membered) Chemical Compounds. Crown 8vo. I4s.

AËRIAL NAVIGATION. The Problem, with Hints for its Solution. Edited by R. B. MANSFiEli). With a Preface by J. M. Ludlow. With Illustrations. Crown 8vo. IOs. $6 d$.

Mayer-SOUND : a Series of Simple, Entertaining, and Inexpensive Experiments in the Phenomena of Sound, for the Use of Students of every age. By A. M. MAYER, Professor of Physics in the Stevens Institute of Technology, \&c. With numerous Illustrations. Crown 8vo. $3 s .6 d$.

Mayer and Barnard.-LIGHT. A Series of Simple, Entertaining, and Useful Experiments in the Phenomena of Light, for the use of Students of every age. By A. M. Mayer and C. BARNARD. With Illustrations. Crown 8vo. $2 s .6 d$.

Miall.-STUdiES IN COMPARATIVE ANATOMY. No. I, The Skull of the Crocodile. A Manual for Students. By L. C. Miall, Professor of Biology in Yorkshire College. 8vo. 2s. $6 d$. No. 2, The Anatomy of the Indian Elephant. By L. C. Miall and F. Greenwood. With Plates. $5 s$.

Miller.-THE ROMANCE OF ASTRONOMY. By R. Kalley Mrller, M.A., Fellow and Assistant Tutor of St. Peter's College, Cambridge. Second Edition, revised and enlarged. Crown 8vo. $4 s .6 d$.

Mivart (St. George).-Works by St. George Mivart, F.R.S. \&c., Lecturer in Comparative Anatomy at St. Mary's Hospital:ON THE GENESIS OF SPECIES. Crown 8vo. Second Edition, to which notes have been added in reference and reply to Darwin's "Descent of Man." With numerous Illustrations. pp. xv. 296. 9 s.

"In no work in the English language has this great controversy been treated at once with the same broad and vigorous grasp of facts, and the same liberal and candid temper." - Saturday Review. 
Mivart (St. George)-continued.

THE COMMON FROG. With Numerous Illustrations. Crown 8 vo. 3s. 6d. (Nature Series.)

"It is an able monogram of the Frog, and something more. It throzes valuable crosslights over zoide portions of animated nature. Would that such works were more plentiful."-Quarterly Journal of Science.

Moseley.-NOTES BY A NATURALIST ON THE "CHALLENGER," being an account of various observations made during the voyage of H.M.S. "Challenger" round the world in the years 1872-76. By H. N. Moseley, M.A.. F.R.S., Member of the Scientific Staff of the "Challenger." Withi. Map, Coloured Plates, and Woodcuts. 8vo. 2Is.

Muir.-PRACTICAL CHEMISTRY FOR MEDICAL STUDENTS. Specially arranged for the first M. B. Course. By M. M. Pattison Muir, F.R.S.E. Fcap. 8vo. is. $6 d$.

Murphy.-HABIT AND INTELLIGENCE: a Series of Essays on the Laws of Life and Mind. By JOSEPH JoHN MURPHY. Second Edition, thoroughly revised and mostly rewritten. With Illustrations. 8vo. I6s.

Nature.-A WEEKLY ILLUSTRATED JOURNAL OF SCIENCE. Published every Thursday. Price $6 d$. . Monthly Parts, 2s. and 2s. $6 d$. ; Half-yearly Volumes, $15 s$. Cases for binding Vols. Is. $6 d$.

"This able and well-edited fournal, which posts up the science of the day promptly, and promises to be of signal service to students and savants. . . . . Scarcely any expressions that we can employ would exaggerate our sense of the moral and theological value of the work." - British Quarterly Review.

Newcomb.-POPUlAR ASTRONOMY. By Simon Newсомв, LL.D., Professor U.S. Naval Observatory. With II2 Engravings and Five Maps of the Stars. 8vo. $18 s$.

"As affording a thoroughly reliable foundation for more advanced reading, Professor Newcomb's 'Popular Astronomy' is deserving of strong recommendation." -Nature.

Oliver.-Works by Daniel OLIVER, F.R.S., F.L.S., Professor of Botany in University College, London, and Keeper of the Herbarium and Library of the Royal Gardens, Kew :-

LESSONS IN ELEMENTARY BOTANY. With nearly Two Hundred Illustrations: New Edition. Fcap. 8vo. 4s, $6 d$.

This book is designed to teach the elements of Botany on Professor Henslow's plan of selected Types and by the use of Schedules. The earlier chapters, embracing the elements of Structural and Physiological Rotany, introduce us to the methodical study of the Ordinal Types. The concluding chapters are entitled," "How to Dry 
Oliver-continued.

Plants" and "How to Describe Plants." A valuable Glossary is appended to the volume. In the preparation of this work free use has been made of the manuscript materials of the late Professor Henslow.

FIRST BOOK OF INDIAN BOTANY. With numerous Illustrations. Extra fcap. 8vo. 6s. $6 d$.

"It contains a well-digested summary of all essential knowuledge pertaining to Indian Botany, wrought out in accordance with the best principles of scientific arrangement."-Allen's Indian Mail.

Pennington.-NOTES ON THE BARROWS AND BONE CAVES OF DERBYSHIRE. With an account of a Descent into Elden Hole. By Rooke Pennington, B.A., LL.B., F.G.S. 8 vo. $6 s$.

Penrose (F. C.) - ON A METHOD OF PREDICTING BY GRAPHICAL CONSTRUCTION, OCCULTATIONS OF STARS BY THE MOON, AND SOLAR ECLIPSES FOR ANY GIVEN PLACE. Together with more rigorous methods for the Accurate Calculation of Longitude. By F. C. Penrose, F.R.A.S. With Charts, Tables, \&c. 4to. I2s.

Perry.-AN ELEMENTARY TREATISE ON STEAM. By John PERry, B.E., Professor of Engineering, Imperial College of Engineering, Yedo. With numerous Woodcuts, Numerical Examples, and Exercises. 18mo. 4s. $6 d$.

"Mr. Perry has in this compact little volume brought together an immense amount of information, new told, regarding steam and its application, not the least of its merits being that it is suited to the capacities alike of the tyro in engineering science or the better grade of artisan."-Iron.

Pickering.-ELEMENTS OF PHYSICAL MANIPULATION. By E. C. Pickering, Thayer Professor of Physics in the Massachusetts Institute of Technology. Part I., medium 8vo. Ios. $6 d$. Part II., IOs. $6 d$.

"When finished 'Physical Manipulation' will no doubt be considered the best and most complete text-book on the subject of which it treats."-Nature.

Prestwich.-THE PAST AND FUTURE OF GEOLOGY. An Inaugural Lecture, by J. PresTwiCH, M.A., F.R.S., \&c., Professor of Geology, Oxford. 8vo. 2s.

Radcliffe.-PROTEUS : OR UNITY IN NATURE. . By. C. B. RADCLIFFE, M.D., Author of "Vital Motion as a mode of Physical Motion. Second Edition. 8vo. $7 s .6 d$. 
Rendu.-THE THEORY OF THE GLACIERS OF SAVOY. By M. le Chanoine Rendu. Translated by A. Wells, Q.C., late President of the Alpine Club. To which are added, the Criginal Memoir and Supplementary Articles by Professors TAIT and RUSKIN. Edited with Introductory remarks by GEORGE FORBES, B.A., Professor of Natural Philosophy in the Andersonian University; Glasgow. 8vo. 7 s. $6 d$.

Roscoe.-Works by Henky E. Roscoe, F.R.S., Professor of Chemistry in Owens College, Manchester :-

LESSONS IN ELEMENTARY CHEMISTRY, INORGANIC AND ORGANIC. With numerous Illustrations and Chromolitho of the Solar Spectrun, and of the Alkalis and Alkaline Earths. New Edition. Fcap. 8vo. 4s. $6 d$.

CHEMICAL PROBLEMS, adapted to the above by Professor THORPE. Fifth Edition, with Key. 2s.

"We unhesitatingly pronounce it the best of all our elementary treatises on Chemistry.".-Medical Times.

PRIMER OF CHEMISTRY. Illustrated. $18 \mathrm{mo}$. Is.

Roscoe and Schorlemmer.-A TREATISE ON CHEMISTRY. By Professors RosCoe and SCHORLEMMER.

Vol. I., The Non-metallic Elements. With numerous Illustrations and Portrait of Dalton. Medium 8vo. 2Is.

Vol. II., Metals. Part I. With Illustrations. 8vo. $18 s$.

"Regarded as a treatise on the Non-metallic Elements, there can be no doubt that this volume is incomparably the most satisfactory one of which we are in possession."-Spectator.

"It would be difficult to praise the work too highly. All the merits which we noticed in the first volume are conspicuous in the second. The arrangement is clear and scientific; the facts gained by modern research are fairly represented and judiciously selected; and the style throughout is singularly lucid." -Lancet.

[Metals, Part II. in the Press.

Rumford (Count).--THE LIFE AND COMPLETE WORKS OF BENJAMIN THOMPSON, COUNT RUMFORD. With Notices of his Daughter. By GEORGE Ellis. With Portrait. Five Vols. 8vo. 4l. I 4 s. $6 d$.

Schorlemmer.-A MANUAL OF THE CHEMISTRY OF THECARBON COMPOUNDS OR-ORGANICCHEMISTRY. By C. Schortemmer, F.R.S., Lecturer in Organic Chemistry in Owens College, Manchester. 8vo. I 4 s.

"It appears to us io be as complete a manual of the metamorphoses of carbon as could be at present produced, and it must prove eminently useful to the chemical student."-A thenæum. 
Shann.-AN ELEMENTARY TREATISE ON HEAT, IN RELATION TO STEAM AND THE STEAM ENGINE. By G. Shann, M.A. With Illustrations. Crown 8vo. 4s. $6 d$.

Smith.-HISTORIA FILICUM : An Exposition of the Nature, Number, and Organography of Ferns, and Review of the Principles upon which Genera are founded, and the Systems of Classification of the principal Authors, with a new General Arrangement, \&c. By J. Smith. A.L.S., ex-Curator of the Royal Botanic Garden, Kew. With Thirty Lithographic Plates by W. H. Fitch, F.L.S. Crown 8vo. $12 s .6 d$.

"No one anxious to work up a thorough knowledge of ferns can afford to do without it." -Gardener's Chronicle.

South Kensington Science Lectures.-Vol. I.-Containing Lectures by Captain ABNey, F.RS., Professor Stokes, Professor Kennedy, F. J. Bramwell, F.R.S., Professor G. Forbes, H. C. SORBY, F.R.S., J. T. BOTTOMLEY, F.R.S.E., S. H. Vines, B.Sc., and Professor Carey Foster. Crown 8vo. $6 s$.

[Vol. II. nearly ready.

Spottiswoode.-POLARIZATION OF LIGHT. By W. SPOTTISWOODE, President of the Royal Society. With numerous Illustrations. Second Edition. Cr. 8vo. 3s. 6d. (Nature Series.)

"The illustrations are exceedingly well adapted to assist in making the text comprehensible."-Athenæum. "A clear, trustworthy manual." - Standard.

Stewart (B.) - Works by Balfour Stewart, F.R.S., Professor of Natural Philosophy in Owens College, Manchester:-

LESSONS IN ELEMENTARY PHYSICS. With numerous Illustrations and Chromolithos of the Spectra of the Sun, Stars, and Nebulæ. New Edition. Fcap. 8vo. 4s. $6 d$.

The Educational Times calls thrs the beau-ideal of a scicntific textbook, clear, accurate, and thorough."

PRIMER OF PHYSICS. With Illustrations. New Edition, with Questions. $18 \mathrm{mo}$. Is.

Stewart and Tait.-THE UNSEEN UNIVERSE: or, Physical Speculations on a Future State. By Balfouk STEwarT, F.R.S., and P. G. TAIT, M.A. Sixth Edition. Crown 8vo. $6 s$. "The book is one which well deserves the attention of thought/ul ana religious readers. . . . It is a perfectly sober inquiry, on scientific grounds, into the possibilities of a future existence."-Guardian.

Tait.-LECTURES ON SOME RECENT ADVANCES IN PHYSICAL SCIENCE. By P. G. TAIT, M.A., Professor of Philosophy in the University of Edinburgh. Second edition, revised and enlarged, with the Lecture on Force delivered before the British Association. Crown 8vo. 9s. 
Tanner.-FIRST PRINCIPLES OF AGRICULTURE. By Henry TAnner, F.C.S., Professor of Agricultural Science, University College, Aberystwith, Examiner in the Principles of Agriculture under the Government Department of Science. $18 \mathrm{mo}$. Is.

Taylor.-SOUND AND MUSIC: A Non-Mathematical Treatise on the Physical Constitution of Musical Sounds and Harmony including the Cliief Acoustical Discoveries of Professor Helm holtz. By Sedley TAYlor, M.A., late Fellow of Trinity Col ledge, Cambridge. Large crown 8vo. $8 s .6 d$.

"In no previous scientific treatise do we remember so exhaustive and so richiy illustrated a description of forms of vibration and of wave-motion in fluids." - Musical Standard.

Thomson.-Works by Sir Wyville Thomson, K.C.B., F.R.S. THE DEPTHS OF THE SEA : An Account of the General Results of the Dredging Cruises of H.M.SS. "Porcupine" and "Lightning" during the Summers of 1868.69 and 70 , under the scientific direction of Dr. Carpenter, F.R.S., J. Gwyn Jeffreys, F.R.S., and Sir Wyville Thomson, F.R.S. With nearly roo Illustrations and 8 coloured Maps and Plans. Second Edition. Royal 8vo. cloth, gilt. $3 \mathrm{I} s .6 d$.

The Athenæum says: "The book is full of interesting matter, and is zuritten by a master of the art of popular exposition. It is excellently illustrated, both coloured maps and woodcuts possessing high merit. Those who have already become interested in dredging operations will of course make a point of reading this work; those who wish to be pleasantly introduced to the subject, and rightly to appreciate the newes which arives from time to time from the 'Challenger,' should not fail to seek instruction from it."

THE VOYAGE OF THE "CHALLENGER."-THE ATLANTIC. A Preliminary account of the Exploring Voyages of H.M.S. "Challenger," during the year 1873 and the early part of 1876 . With numerous Illustrations, Coloured Maps \& Charts, \& Portrait of the Author, engraved by C. H. JeEns. 2 Vols. Medium 8vo. $42 s$. The Times says:- "It is right that the public should have some authoritative account of the general results of the expedition, and that as many of the ascertained data as may be accepted with confidence should speedily find their place in the general body of scientific knowledge. No one can be more competent than the accomplished' scientr fic chief of the expedition to satisfy the public in this respect. . . . The paper, printing, and especialiy the numerous illustrations, are of the highest quality. ... We have rarely, if ever, seen more beautiful specimens of wood engraving than abound in this work. . . . Sir Wyville Thomson's style is particularly attractive; he is easy and graceful, but vigorous and exceedingly 
Thomson-continued.

happy in the choice of language, and throughout the work there are touches which show that science has not banished sentiment from his bosom."

\section{Thudichum and Dupré.-A TREATTSE ON THE} ORIGIN, NATURE, AND VARIETIES OF WINE. Being a Complete Manual of Viticulture and Enology. By J. L. W. Thudichum, M.D., and August Dupré, Ph.D., Lecturer on Chemistry at Westminster Hospital. Medium 8vo. cloth gilt. $25 s$.

"A treatise almost unique for its usefulness either to the wine-grower, the vendor, or the consumer of wine. The analyses of wine are the most complete we have yet seen, exhibiting at a glance the constituent principles of nearly all the wines known in this country." -Wine Trade Review.

Wallace (A. R.) - Works by Alfred Russel Wallace.

CONTRIBUTIONS TO THE THEORY OF NATURAL SELECTION. A Series of Essays. New Edition, with Corrections and Additions. Crown 8vo. 8s. $6 d$.

Dr. Hooker, in his address to the British Association, spoke thus of the author: "Of Mr. Wallace and his many contributions to philosophical biology it is not easy to speak without enthusiasm; for, putting aside their great merits, he, throushout his writings, with a modesty as rare as I believe it to be unconscious, forgets his own unquestioned claim to the honour of having originated independently of $M r$. Darwin, the theories which he so ably defends." The Saturday Review say's: "He has combined an abundance of fresh and original facts with a liveliness and sagacity of reasoning which are not often displayed so effectively on so small a scale."

THE GEOGRAPHICAL DISTRIBUTION OF ANIMALS, with a study of the Relations of Living and Extinct Faunas as Elucidating the Past Changes of the Earth's Surface. 2 vols. 8vo. with Maps, and numerous Illustrations by Zwecker, $42 s$.

The Times says: "Altogether it is a wonderful and fascinating story, whatever objections may be taken to theories founded upon it. Mr. Wallace has not attempted to add to its interest by any adornments of style; he has given a simple and clear statement of intrinsically interesting facts, and what he considers to be legitimate inductions from them. Naturalists ought to be grateful to him for having undertaken so toilsome a task. The work, indeed, is a credit to all concerned - the author, the publishers, the artistunfortunately now no more - of the attractive illustrations-last but by no means least, $M r$. Stanford's map-designer." 
Wallace (A. R.)-continued.

TROPICAI, NATURE: with other Essays. 8vo. I2s.

"Nowhere amid the many descriptions of the tropics that have been given is to be found a summary of the past history and actual phenomena of the tropics which gives that which is distinctive of the phases of nature in them more clearlv, shortly, and impres. sively."-Saturday Review.

Warington.-THE WEEK OF CREATION; OR, THE COSMOGONY OF GENESIS CONSIDERED IN ITS RELATION TO MODERN SCIENCE. By GEORGE WARINGTON, Author of "The Historic Character of the Pentateuch Vindicated." Crown 8vo. 4s. $6 d$.

Wilson.-RELIGIO CHEMICI. By the late GEORGE Wilson, M.D., F.R.S.E., Regius Professor of Technology in the University of Edinburgh. With a Vignette beautifully engraved after a design by Sir Noel Paton. Crown 8vo. 8s. $6 d$.

"A more fascinating volume," the Spectator says, "has seldom fallen into our hands."

Wilson (Daniel.)_CALIBAN : a Critique on Shakespeare's "Tempest" and "Midsummer Night's Dream." By DANieL, Wilson, LL.D., Professor of History and English Literature in University College, Toronto. 8 vo. IOs. $6 d$.

"The whole volume is most rich in the eloquence of thought and imasination as well as of words. It is a choire contribution at once to science, theology, religion, and literature."-British Quarterly Review.

Wright.-METALS AND THEIR CHIEF INDUSTRIAL APPLICATIONS. By C. AI.DER WRIGHT, D.Sc., \&c., Lecturer on Chemistry in St. Mary's Hospital School. Extra fcap. 8vo. 3s. $6 d$.

Wurtz.-A HISTORY OF CHEMICAL THEORY, from the Age of Lavoisier down the present time. By AD. WURTz. Translated by Henry WaTts, F.R.S. Crown 8vo. $6 s$.

"The discourse, as a résumé of chemical theory and research, unites singular luminousness and grasp. A ferv judicious notes are added by the translator."-Pall Mall Gazette. "The treatment of the subject is admirable, and the translator has evidently done his duty" most efficiently." -Westminster Review: 


\section{WORKS ON MENTAL AND MORAL PHILOSOPHY, AND ALLIED SUBJECTS.}

Aristotle. - AN INTRODUCTION TO ARISTOTLE'S RHETORIC. With Analysis, Notes, and Appendices. By E. M. Cope, Trinity College, Cambridge. 8vo. I4s.

ARISTOTLE ON FALLACIES; OR, THE SOPHISTICI ELENCHI. With a Translation and Notes by EDWARD PosTe, M.A., Fellow of Oriel College, Oxford. 8vo. 8s. $6 d$.

Birks.-Works bý the Rev. T. R. Birks, Professor of Moral Philosophy, Cambridge :-

FIRST PRINCIPLES OF MORAL SCIENCE; or, a Firs Course of Lectures delivered in the University of Cambridge. Crown 8vo. 8s. $6 d$.

This work treats of three topics all preliminary to the direct exposition of Moral Philosophy. These are the Certainty and Dignily of Moral Science, its Spiritual Geography, or relation to other main subjects of human thought, and its Formative Principles, or some elementary truths on whuch its whole development must depend.

MODERN UTILITARIANISM ; or, The Systems of Paley, Bentham, and Mill, Examined and Compared. Crown 8vo. 6s.6d. MODERN PHYSICAL FATALISM, AND THE DOCTRINE OF EVOLUTION ; including an Examination of Herbert Spencer's First Principles. Crown 8vo. 6s.

Boole. - AN INVESTIGATION OF THE LAWS OF THOUGHT, ON WHICH ARE FOUNDED THE MATHEMATICAL THEORIES OF LOGIC AND PROBABILITIES. By GEORGE BOOLE, LL.D., Professor of Mathematics in the Queen's University, Ireland, \&c. 8vo. I 45.

Butler.-LECTURES ON THE HISTORY OF ANCIENT PHILOSOPHY. By W. ARCHER Butler, late Professor of Moral Philosophy in the University of Dublin. Edited from the Author's MSS., with Notes, by WILliam HepworTh THOMPson, M.A., Master of Trinity College, and Regius Professor of Greek in the University of Cambridge. New and Cheaper Edition, revised by the Editor. 8vo. I2s.

Caird.-A CRITICAL ACCOUNT OF THE PHILOSOPHY OF KANT. With an Historical Introduction. By E. CAIRD, M.A., Professor of Moral Philosophy in the University of Glasgow. 8 vo. I8s. 
Calderwood.-Works by the Rev. Henry CALDERwood, M.A., LL.D., Professor of Moral Philosophy in the University of Edinburgh :-

PHILOSOPHY OF THE INFINITE: A Treatise on Man's Knowledge of the Infinite Being, in answer to Sir W. Hamilton and Dr. Mansel. Cheaper Edition. 8vo. 7s. $6 d$.

"A book of great ability . . . . written in a clear style, and may be easily understood by even those who are not versed in such discussions."-British Quarterly Review.

A HANDBOOK OF MORAL PHILOSOPHY. New Edition. Crown 8vo. 6s.

"It is, we feel convinced, the best handbook on the subject, intellectually and morally, and does infinite credit to its author."-Standard. "A compact and useful work, going over a great deal of ground in a manner adapted to suggest and facilitate further study. . . . His book will be an assistance to many students outside his own University of Edinburgh. - Guardian.

THE RELATIONS OF MIND AND BRAIN. [Nearly ready.

Fiske.-OUTLINES OF COSMIC PHILOSOPHY, BASED ON THE DOCTRINE OF EVOLUTION, WITH CRITICISMS ON THE POSITIVE PHILOSOPHY. By JoHN FISKE, M.A., LL.B., formerly Lecturer on Philosophy at Harvard University. 2 vols. 8vo. 25 s.

"The work constitutes a very effective encyclopodia of the evolutionary philosophy, and is well worth the study of all who wish to see at once the entire scope and purport of the scientific dogmatism of the dav."-Saturday Review.

Herbert.-THE REALISTIC ASSUMPTIONS OF MODERN SCIENCE EXAMINED. By T. M. Herbert, M.A., late Professor of Philosophy, \&c., in the Lancashire Independent College, Manchester. 8vo. I $4 s$.

Jardine.-THE ELEMENTS OF THE PSYCHOLOGY OF COGNITION. By Robert Jardine, B.D., D.Sc., Principal of the General Assembly's College, Calcutta, and Fellow of the University of Calcutta. Crown 8vo. $6 s .6 d$.

Jevons.-Works by W. Stanley Jevons, LL.D., M.A., F.R.S., Professor of Political Economy, University College, London.

THE PRINCIPLES OF SCIENCE. A Treatise on Logic and Scientific Method. New and Cheaper Edition, revised. Crown 8vo. I2s. $6 d$.

"No one in future can be said to have any true knoreledge of what has been done in the way of logical and scientific method in Enpland without having carefully studied Professor Fevons' book."-Spectator. 
Jevons-continued.

THE SUBSTITUTION OF SIMILARS, the True Principle of Keasoning. Derived from a Modification of Aristotle's Dictum. Fcap. 8vo. 2s. 6d.

ELEMENTARY LESSONS IN LOGIC, DEDUCTIVE AND INDUCTIVE. With Questions, Examples, and Vocabulary of Logical Terms. New Edition. Fcap. 8vo. 3s. $6 d$.

PRIMER OF LOGIC. New Edition. I8mo. Is.

Maccoll.-THE GREEK SCEPTICS, from Pyrrho to Sextus. An Essay which obtained the Hare Prize in the year I868. By Norman Maccoll, B.A., Scholar of Downing College, Cambridge. Crown 8vo. 3s. $6 d$.

M'Cosh.-Works by James M'Cosh, LL.D., President of Princeton College, New Jersey, U.S.

"He certainly showes himself skilful in that application of logic to psychology, in that inductive science of the human mind which is the fine side of English philosophy. His philosophy as a whole is worthy of attention."-Revue de Deux Mondes.

THE METHOD OF THE DIVINE GOVERNMENT, Physical and Moral. Tenth Edition. 8vo. IOs. $6 d$.

"This work is distinguished from other similar ones by" its being based upon a thorough study of physical science, and an accurate knozoledge of its present condition, and by its entering in a deeper and more unfettered manner than its predecessors upon the discussion of the appropriate psychological, ethical, and theological questions. The author keeps aloof at once from the à priori idealism and dreaminess of German speculation since Schelling, and from the onesidedness and narrowness of the empiricism and positivism which have so prevailed in England."-Dr. Ulrici, in "Zeitschrift. für Philosophie."

THE INTUITIONS OF THE MIND. A New Edition. 8vo. cloth. IOs. $6 d$.

"The undertaking to adjust the claims of the sensational and intuitional philosophies, and of the à posteriori and à priori method's, is accomplished in this work with a great amount of success." Westminster Review. "I value it for its large acquaintance with English Philosophy, which has not led him to neglect the great German works. I admire the moderation and clearness, as well as comprehensiveness, of the author's views."-Dr. Dörner, of Berlin.

AN EXAMINATION OF MR. J. S. MILL'S PHILOSOPHY: Being a Defence of Fundamental Truth. Second edition, with additions. IOs. $6 d$.

"Such a work greatly needed to be done, and the author was the man to do it. This voiume is important, not merely in reference to the 
$\mathrm{M} \cdot \mathrm{Cosh}$ - continued.

views of Mr. Mill, but of the whole school of writers, past and present, British and Continental, he so ably represents."-Princeton Review.

THE LAWS OF DISCURSIVE THOUGHT: Being a Textbook of Formal Logic. Crown 8ro. 5 s.

"The amount of summarized information which it contains is zery great; and it is the only work on the very important subject with which it deals. Never was such a work so much needed as in the present day."-London Quarterly Review.

CHRISTIANITY AND POSITIVISM : A Series of Lectures to the Times on Natural Theology and Apologetics. Crown 8vo. 7s. $6 d$.

THE SCOTTISII PHILOSOPHY FROM HUTCHESON TO HAMILTON, Biographical, Critical, Expository. Koyal 8vo. I6s.

Masson.-RECENT BRITISH PHILOSOPHY : A Review with Criticisms ; including some Comments on Mr. Mill's Answer to Sir William Hamilton. By David Masson, M.A., Professor of Rhetoric and English Literature in the University of Edinburgh. Third Edition, with an Additional Chapter. Crown 8vo. 6s.

"We can nowhere point to a work which gives so clear an exposition of the course of philosophical speculation in Britain during the past century", or which indicates so instructively the mutual influences of philosophic and scientific thought." - Fortnightly Review.

Maudsley.-Works by H. Maudsley, M.D., Professor of Medical Jurisprudence in University College, London.

THE PHYSIOLOGY OF MIND; being the First Part of a Third Edition, Revised, Enlarged, and in great part Rewritten, of "The Physiology and Pathology of Mind." Crown 8vo. Ios. $6 d$.

THE PATHOLOGY OF MIND.

[In the Press.

BODY AND MIND : an Inquiry into their Connexion and Mutual Influence, specially with reference to Mental Disorders. An Enlarged and Revised edition. To which are added, Psychological Essays. Crown 8vo. 6s. $6 d$.

Maurice.-Works by the Rev. Frederick Denison Maurice, M.A., Professor of Moral Philosophy in the University of Cambridge. (For other Works by the same Author, see THEOLOGICAL Catalogue.)

SOCIAL MORALITY. Twenty-one Lectures delivered in the University of Cambridge. New and Cheaper Edition. Crown 8vo. IOs. $6 d$. 
MENTAL AND MORAL PHILOSOPHY, ETC.

Maurice-continued.

"Whilst reading it ree are charmed by the freedom from exclusiveness and prejudice, the large charity, the loftiness of thought, the eagerness to recognize and appreciate whatever there is of real worth extant in the world, which animates it from one end to the other. We gain new thoughts and new ways of viewing things, even more, perhaps, from being brought for a time under the influence of so noble and spiritual a mind." -Athenæum.

THE CONSCIENCE : Lectures on Casuistry, delivered in the University of Cambridge. New and Cheaper Edition. Crown 8vo. 5 s.

The Saturday Review says: "We rise from them with detestation of all that is selfish and mean, and with a living impression that there is such a thing as goodness after all."

MORAL AND METAPHYSICAL PHILOSOPHY. Vol. I. Ancient Philosophy from the First to the Thirteenth Centuries; Vol. II. the Fourteenth Century and the French Revolution, with a glimpse into the Nineteenth Century. New Edition and Preface. 2 Vols. Svo. 25 s.

Morgan.-ANCIENT SOCIETY : or Researches in the Lines of Human Progress, from Savagery, through Barbarism to Civilisation. By Lewis H. Morgan, Member of the National Academy of Sciences. 8vo. I6s.

Murphy,-THE SCIENTIFIC BASES OF FAITH, By, JOSEPH JOHN MURPHY, Author of "Habit and Intelligence." 8vo. I4s.

"The book is not vithout substantial value; the ruriter continues the work of the best apologists of the last century, it may be with less force and clearness, but still with commendable persuasiveness and tact; and with ah intelligent feeling for the changed conditions of the problem."-Academy.

Paradoxical Philosophy.-A Sequel to "The Unseen Universe." Crown 8vo. 7s. $6 d$.

Picton.-THE MYSTERY OF MATTER AND OTHER ESSAYS. By J. Allanson Picton, Author of "New Theories and the Old Faith." Cheaper issue with New Preface. Crown 8 vo. $6 s$.

Contents :- The Mystery of Matter-The Philosophy of Ignorance-The Antithesis of Faith and Sight-The Essential Nature of Religion-Christian Pantheism. 
Sidgwick.-THE METHODS OF ETHICS. By HENRY SIDGwick, M.A., Prælector in Moral and Political Philosophy in Trinity College, Cambridge. Second Edition, revised throughout with important additions. 8vo. I4s.

A SUPPLEMENT to the First Edition, containing all the important additions and alterations in the Second. 8vo. $2 s$.

"This excellent and very velcome volume. . . . Leaving to metaphysicians any further discussion that may be needed respecting the already over-discussed problem of the origin of the moral faculty, he takes it for granted as readily as the geometrician takes space for granted, or the physicist the existence of matter. But he takes little else for granted, and defining ethics as 'the science of conduct,' be carefully examines, not the various ethical systems that have been propounded by Aristotle and Aristotle's followers downwwards, but the principles upon which, so far as they confine themselves to the strict province of ethics, they are based."-A thenæum.

Thornton.-OLD-FASHIONED ETHICS, AND COMMONSENSE METAPHYSICS, with some of their Applications. By WILliam THOMAS THORNTON, Author of "A Treatise on Labour." 8 vo. Ios. $6 d$.

The present volume aeals with problems which are agitating the minds of all thoughtjul men. The following are the Contents:I. Ante-Utilitarianism. II. History's Scientific Pretensions. III. David Hume as a Metaphysician. IV. Huxleyism. V. Recent Phase of Scientific Atheism. VI. Limits of Demonstrable Theism.

Thring (E., M.A.)-THOUGHTS ON LIFE-SCIENCE. By Edward Thring, M.A. (Benjamin Place), Head Master of Uppingham School. New Edition, enlarged and revised. Crown 8vo. $7 s .6 d$.

Venn.-THE LOGIC OF CHANCE : An Essay on the Foundations and Province of the Theory of Probability, with especial reterence to its logical bearings, and its application to Moral and Social Science. By JoHN VENN, M.A., Fellow and Lecturer of Gonville and Caius College, Cambridge. Second Edition, rewritten and greatly enlarged. Crown 8vo. IOs. $6 d$.

"One of the most thoughtful and philosophical treatises on any subject connected with logic and evidence which has been produced in this or any other country for many years."-Mill's Logic, vol. ii. p. 77. Seventh Edition. 


\section{SCIENCE PRIMERS FOR ELEMENTARY SCHOOLS.}

Under the joint Editorship of Professors HuxLEy, RosCOE, and Balfour Stewart.

Chemistry.-By H. E. Roscoe, F.R.S., Professor of Chemistry in Owens College, Manchester. With numerous Illustrations. 18mo. Is. New Edition. With Questions.

Physics.-By Balfour STEwart, F.R.S., Professor of Natural Philosophy in Owens College, Manchester. With numerous Illustrations. I8mo. Is. New Edition. With Questions.

Physical Geography. - By Archibald Geikie, F.R.S., Murchison Professor of Geology and Mineralogy at Edinburgh. With numerous Illustrations. New Edition with Questions. I8mo. Is.

Geology.-By Professor GeIkiE, F.R.S. With numerous Illustrations. New Edition. 18mo. cloth. Is.

Physiology.-By Michael Foster, M.D., F.R.S. With numerous Illustrations. New Edition. I8mo. Is.

Astronomy.-By J. Norman Lockyer, F.R.S. With numerous Illustrations. New Edition. I8mo. Is.

Botany.-By Sir J. D. Hooker, K.C.S.I., C.B., F.R.S. With numerous Illustrations. New Edition. I8mo. Is.

Logic.-By Professor Stanley Jevons, F.R.S. New Edition. I $8 \mathrm{mo}$. Is.

Political Economy.-By Professor Stanley Jevons, F.R.S. I8mo. Is.

In preparation:-

INTRODUCTORY. By Professor Huxley. \&c. \&c.

\section{ELEMENTARY SCIENCE CLASS-BOOKS.}

Astronomy.-By the Astronomer Royal. POPULAR ASTRONOMY. With Illustrations. By Sir G. B. AIRY, K.C.B., Astronomer Royal. New Edition. 18mo. 4s. $6 d$.

Astronomy.-ELEMENTARY LESSONS IN ASTRONOMY. With Coloured Diagram of the Spectra of the Sun, Stars, and Nebulæ, and numerous Illustrations. By J. NORMAN LockYer, F.R.S. New Edition. Fcap. 8vo. 5s. $6 d$. 
Elementary Science Class-books-continued.

QUESTIONS ON LOCKYER'S ELEMENTARY LESSONS IN ASTRONOMY. For the Use of Schools. By JoHN FORBES ROBERTSON. I8mo, cloth limp. is. $6 d$.

Physiology.-LESSONS IN ELEMENTARY PHYSIOLOGY. With numerous Illustrations. By T. H. HuxLeY, F.R.S., Professor of Natural History in the Royal School of Mines. New Edition. Fcap. 8vo. 4s. $6 d$.

QUESTIONS ON HUXLEY'S PHYSIOLOGY FOR SCHOOLS. By T. ALCOCK, M.D. I8mo. Is. $6 d$.

Botany.-LESSONS IN ELEMENTARY BOTANY. By D. OLIVER, F.R.S., F.L.S., Professor of Botany in University College, London. With nearly Two Hundred Illustrations. New Edition. Fcap. 8vo. 4s. 6d.

Chemistry.-LESSONS IN ELEMENTARY CHEMISTRY, INORGANIC AND ORGANIC. By HENRY E. ROSCOE, F.R.S., Professor of Chemistry in Owens College, Manchester. With numerous Illustrations and Chromo-Litho of the Solar Spectrum, and of the Alkalies and Alkaline Earths. New Edition. Fcap. 8vo. 4s. $6 d$.

A SERIES OF CHEMICAL PROBLEMS, prepared with Special Reference to the above, by T. E. THORPE, Ph.D., Prufessor of Chemistry in the Yorkshire College of Science, Leeds. Adapted for the preparation of Students for the Government, Science, and Society of Arts Examinations. With a Preface by Professor Roscoe. Fifth Edition, with Key. $18 \mathrm{mo}$. $2 s$.

Political Economy.-POLITICAL ECONOMY FOR BEGINNERS. By MIllicent G. Fawcett. New Edition. $18 \mathrm{mo} .2 s .6 d$.

Logic.-ELEMENTARY LESSONS IN LOGIC; Deductive and Inductive, with copious Questions and Examples, and a Vocabulary of Logical Terms. By W. Stanley Jevons, M.A., Professor of Political Economy in University College, London. New Edition. Fcap. 8vo. 3s. $6 d$.

Physics.-LESSONS IN ELEMENTARY PHYSICS. By Balfour Stewart, F.R.S., Professor of Natural Philosophy in Owens College, Manchester. With numerous Illustrations and Chromo-Litho of the Spectra of the Sun, Stars, and Nebulæ. New Edition. Fcap. 8vo. 4s. $6 d$.

Practical Chemistry.-THE OWENS COLLEGE JUNIOR COURSE OF PRACTICAL CHEMISTRY. By FRANCIS Jones, Chemical Master in the Grammar School, Manchester. With Preface by Professor Roscoe, and Illustrations. New Edition. I8mo. 2s. $6 d$. 


\section{Elementary Science Class-books-continued.}

Anatomy.-LESSONS IN ELEMENTARY ANATOMY. By St. Georgu MivarT, F.R.S., Lecturer in Comparative Anatomy at St. Mary's Hospital. With upwards of 400 Illustrations. Fcap. 8 vo. $6 s .6 d$.

Mechanics.-AN ELEMENTARY TREATISE. By A. B. W. KENNEDy, C.E , Professor of Applied Mechanics in University College, London. With Illustrations.

[In preparation.

Steam.-AN Elementary TREATISE. By John Perry, Professor of Engineering, Imperial College of Engineering, Yedo. With numerous Woodcuts and Numerical Examples and Exercises. I8mo. 4s. $6 d$.

Physical Geography.-ELEMENTARY LESSONS IN PHYSICAL GEOGRAPHY. By A. GEIKIE, F.R.S., Murchison Professor of Geology, \&c., Edinburgh. With numerous Illustrations. Fcap. 8vo. 4s. $6 d$.

QUESTIONS ON THE SAME. Is. $6 d$.

Geography.-CLASS-BOOK OF GEOGRAPHY. By C. B. Clarke, M.A.. F.R.G.S. Fcap. 8vo. 2s. $6 d$.

Natural Philosophy.-NATURAL PHILOSOPHY FOR BEGINNERS. By I. TODHUNTER, M.A., F.R.S. Part I. The Properties of Solid and Fluid Bodies. I8mo. 3s. $6 d$. Part II. Sound, Light, and Heat. $18 \mathrm{mo} .3$ s. $6 d$.

Sound.-AN ELEMENTARY TREATISE. By W. H. STONE, M.D., F.R.S. With Illustrations. $18 \mathrm{mo.}$ [In the Press.

Others in Preparation.

\section{MANUALS FOR STUDENTS.}

\section{Crown 8vo.}

Dyer and Vines.-THE STRUCTURE OF PLANTS. By Professor THiselton Dyer, F.R.S., assisted by SydNeY Vines, B.Sc., Fellow and Lecturer of Christ's College, Cambridge. With numerous Illustrations,

[In preparation.

Fawcett.-A MANUAL OF POLITICAL ECONOMY. By Professor FAwCETT, M.P. New Edition, revised and enlarged. Crown 8vo. I $2 s .6 d$.

Fleischer.-A SYSTEM OF VOLUMETRIC ANALYSIS. Translated, with Notes and Additions, from the second German Edition, by M. M. PATTISON MUIR, F.R.S.E. With Illustrations, Crown 8vo. 7s. $6 d$. 
Manuals for Students-continued.

Flower (W. H.) -AN INTRODUCTION TO THE OSTEOLOGY OF THE MAMMALIA. Being the Substance of the Course of Lectures delivered at the Royal College of Surgeons of England in 1870. By Professor W. H. Flower, F.R.S., F.R.C.S. With numerous Illustrations. New Edition, enlarged. Crown 8vo. Ios. $6 d$.

Foster and Balfour.-THE ELEMENTS OF EMBRY. OLOGY. By Michael Foster, M.D., F.R.S., and F. M. BAlfour, M.A. Part. I. crown 8vo. $7 s .6 \%$.

Foster and Langley.-A COURSE OF ELEMENTARY PRACTICAL PHYSIOLOGY. By MiChaEL Foster, M.D., F.R.S., and J. N. Langley, B.A. New Edition. Crown 8vo. $6 s$. Hooker (Dr.) - THE STUDENT'S FLORA OF THE BRITISH ISLANDS. By Sir J. D. Hooker, K.C.S.I., C.B., F.R.S., M.D., D.C.L. New Edition, revised. Globe 8vo. Ios. $6 d$.

Huxley.-PHYSIOGRAPHY. An Introduction to the Study of Nature. By Professor HUXLEY, F.R.S. With numerous Illustrations, and Coloured Plates. New Edition. Crown 8vo. $7 s .6 d$.

Huxley and Martin.-A COURSE OF PRACTICAL INSTRUCTION IN ELEMENTARY BIOLOGY. By Professor Huxley, F.R.S., assisted by H. N. MarTin, M.B., D.Sc. New Edition, revised. Crown 8vo. $6 s$.

Huxley and Parker.-ELEMENTARY BIOLOGY. PART II. By Professor HuxLEY, F.R.S., assisted by - PARKER. With Illustrations.

[In preparation.

Jevons.-THE PRINCIPLES OF SCIENCE. A Treatise on Logic and Scientific Method. By l'rofessor W. Stanley Jevons, LL.D., F.R.S., New and Revised Edition. Crown 8vo. $12 s .6 d$.

Oliver (Professor).-FIRST BOOK OF INDIAN BOTANY. By Professor Daniel Oliver, F.R.S., F.L.S., Keeper of the Herbarium and Library of the Royal Gardens, Kew. With numerous Illustrations. Extra fcap. 8vo. $6 s .6 d$.

Parker and Bettany.-THE MORPHOLOGY OF THE SKULL. By Professor PARKer and G. T. BetTany. Illustrated. Crown 8vo. Ios. $6 d$.

Tait-AN ELEMENTARY TREATISE ON HEAT.- By Professor TÁT, F.R.S.E. Illustrated.

Thomson.-ZOOLOGY. By Sir C. Wrville Thomson, F.R.S. Illustrated. [In preparation.

Tylor and Lankester.-ANTHROPOLOGY. By E. B. Tylor, M.A., F.R.S., and Professor E. Ray Lankester, M.A., F.R.S. Illustrated.

[In preparation.

Other volumes of these Manuals will follow. 


\section{NATURE SERIES.}

THE SPECTROSCOPE AND ITS APPLICATIONS. By J. N. LOCKYER, F.R.S. With Illustrations. Second Edition. Crown 8 vo. 3 s. $6 d$.

THE ORIGIN AND METAMORPHOSES OF INSECTS. By Sir JOHN LUBBOCK, M.P., F.R.S. With Illustrations. Crown 8 vo. $3 s, 6 d$. Second Edition.

THE TRANSIT OF VENUS. By G. Forbes, B.A., Professor of Natural Philosophy in the Andersonian University, Glasgow. With numerous Illustrations. Crown 8 vo. $3 s, 6 d$.

'THE COMMON FROG. By St. George Mivart, F.R.S. Illustrated. Crown 8vo. 3s. $6 d$.

POLARISATION OF LIGHT. By W. SPOTTISwOode, LL.D., President of the Royal Society. Illustrated. Second Edition. Crown 8vo. 3 s. $6 d$.

ON BRITISH WILD FLOWERS CONSIDERED IN RELATION TO INSECTS. By SiR JOHN LUBBOCK, M.P., F.R.S. Illustrated. Second Edition. Crown 8vo. 4s. $6 d$.

THE SCIENCE OF WEIGHING AND MEASURING. By H. W. CHISHOLM, Warden of the Standard's. Illustrated. Crown 8vo. 4 s. 6 d.

HOW TO DRAW A STRAIGHT LINE : A Lecture on Linkages. By A. B. KEMPE, B.A. Illustrated. Crown 8vo. is. $6 d$.

LIGHT: A Series of Simple, Entertaining and Useful Experiments in the Phenomena of Light for the Use of Students of every Age. By ALFRED M. MAYER and CHARLES BARNARD. With Illustrations. Crown 8 vo. $2 s .6 d$.

SOUND: A Series of Simple, Entertaining and Inexpensive Experiments in the Phenomena of Sound, for the Use of Students of every Age. By A. M. MAYER, Professor of Physics in the Stevens Institute of Technology, \&c. With numerous Illustrations. Crown 8 vo. 3 s. $6 d$.

(Others to follow.)

MACMILLAN AND CO,, LONDON. 
Published every Thursday, price 6d.; Monthly Parts 2s. and 2s. 6d., Half-Yearly Volumes, 15 s.

\section{NATURE:}

AN ILLUSTRATED TOURNAL OF SCIENCE.

NATURE expounds in a popular and yet authentic manner, the Grand Results of Scientific Research, discussing the most recent scientific discoveries, and pointing out the bearing of Science upon civilisation and progress, and its claims to a more general recognition, as well as to a higher place in the educational system of the country.

It contains original articles on all subjects within the domain of Science; Reviews setting forth the nature and value of recent Scientific Works ; Correspondence Columns, forming a medium of Scientific discussion and of intercommunication among the most distinguished men of Science; Serial Columns, giving the gist of the most important papers appearing in Scientific Journals, both Home and Foreign; Transactions of the principal Scientific Societies and Academies of the World, Notes, \&c.

In Schools where Science is included in the regular course of studies, this paper will be most acceptable, as it tells what is doing in Science all over the world, is popular without lowering the standard of Science, and by it a vast amount of information is brought within a small compass, and students are directed to the best sources for what they need. The various questions connected with Science teaching in schools are also fully discussed, and the best methods of teaching are indicated. 


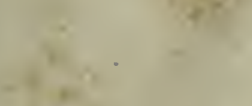

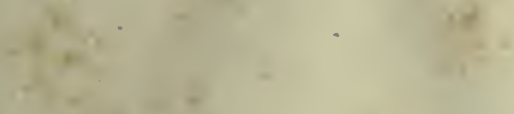

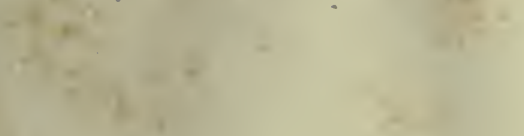

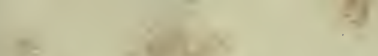

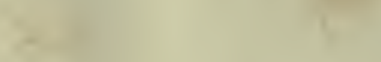

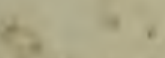

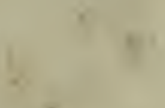

$\sqrt{2}$

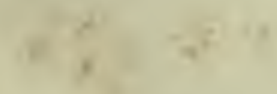

$+3$

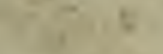

$\operatorname{tr} 4+4$

$+\frac{1}{2}$

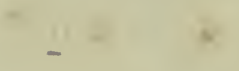

$+7 x^{2}=-1$

$x^{2}+2$

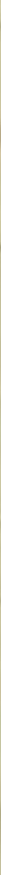

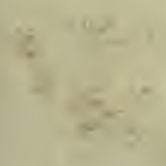


THIS BOOK IS DUE ON THE LAST DATE STAMPED BELOW

RENEWED BOOKS ARE SUBJECT TO IMMEDIATE RECALL

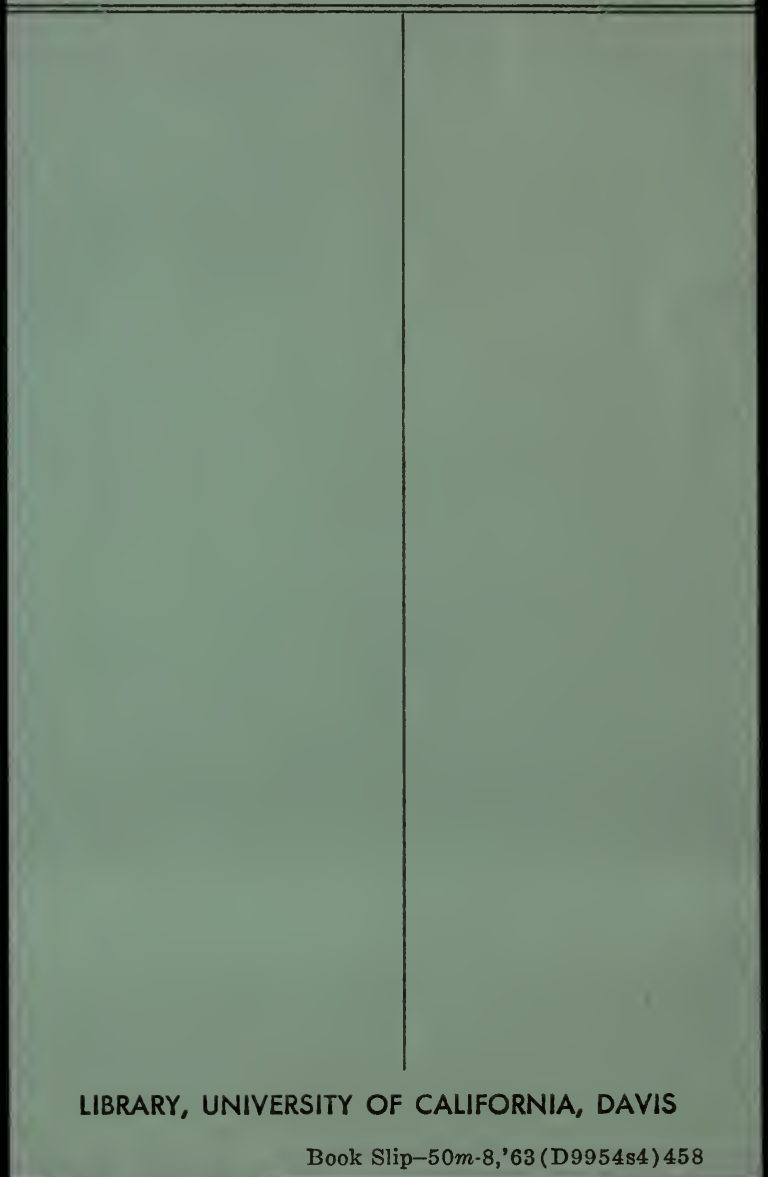

Book Slip-50m-8,'63(D9954s4)458 


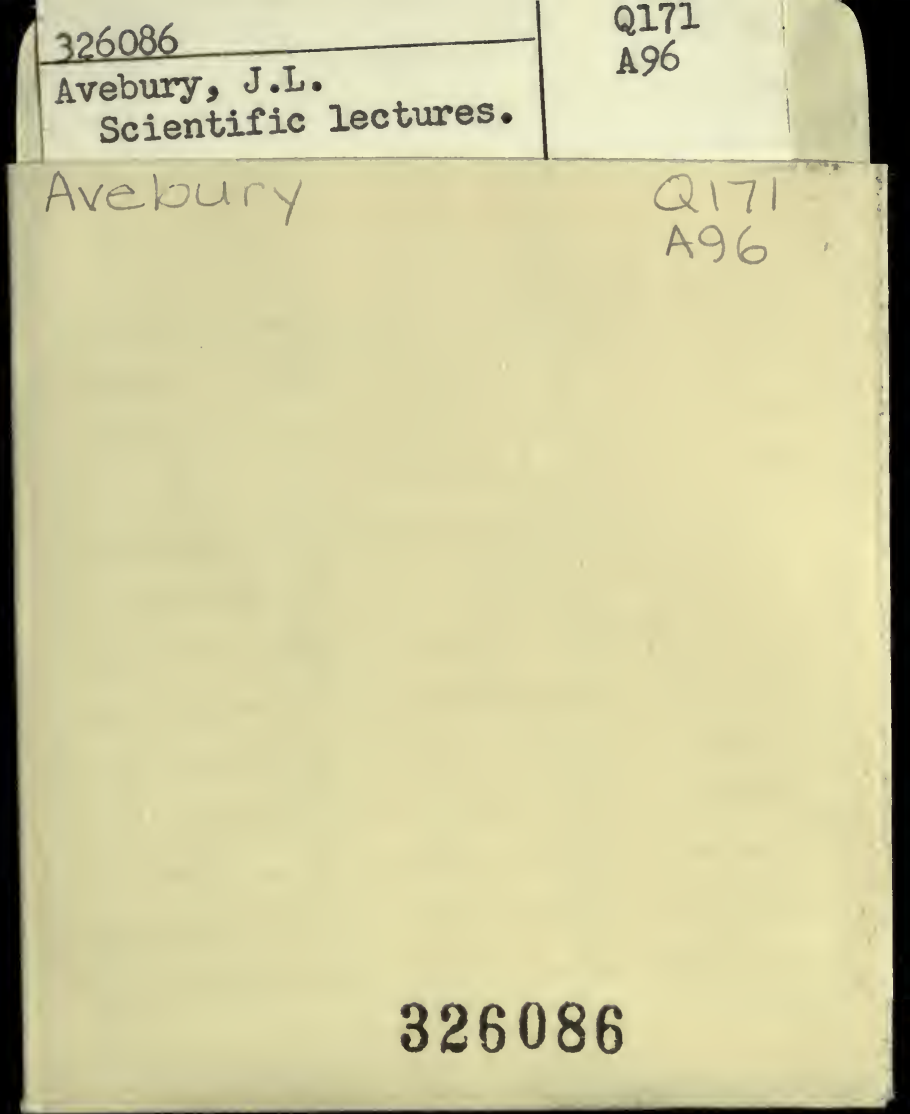


